\title{
The Role of Mindfulness, Self-Compassion, and Emotion Regulation as Protective Factors Against Disordered Eating in a Sample of University Students
}

Lisa Paylo Meyer

Follow this and additional works at: https://researchrepository.wvu.edu/etd

\author{
Recommended Citation \\ Meyer, Lisa Paylo, "The Role of Mindfulness, Self-Compassion, and Emotion Regulation as Protective \\ Factors Against Disordered Eating in a Sample of University Students" (2016). Graduate Theses, \\ Dissertations, and Problem Reports. 6225. \\ https://researchrepository.wvu.edu/etd/6225
}

This Dissertation is protected by copyright and/or related rights. It has been brought to you by the The Research Repository @ WVU with permission from the rights-holder(s). You are free to use this Dissertation in any way that is permitted by the copyright and related rights legislation that applies to your use. For other uses you must obtain permission from the rights-holder(s) directly, unless additional rights are indicated by a Creative Commons license in the record and/ or on the work itself. This Dissertation has been accepted for inclusion in WVU Graduate Theses, Dissertations, and Problem Reports collection by an authorized administrator of The Research Repository @ WVU.

For more information, please contact researchrepository@mail.wvu.edu. 
The Role of Mindfulness, Self-Compassion, and Emotion Regulation as Protective Factors Against Disordered Eating in a Sample of University Students

Lisa Paylo Meyer, M.A.

\begin{abstract}
Dissertation submitted to the College of Education and Human Services at West Virginia University in Partial Fulfillment of the Requirements

for the Degree of Doctor of Philosophy in Counseling Psychology
\end{abstract}

Monica Leppma, Ph.D., Committee Chairperson James Bartee, Ph.D. Jeffrey Daniels, Ph.D. Christa Lilly, Ph.D. Christine Schimmel, Ed.D.

Department of Counseling, Rehabilitation Counseling, and Counseling Psychology

$$
\text { Morgantown, WV }
$$

2016

Keywords: eating disorders, mindfulness, self-compassion, emotion regulation, university Copyright 2016 Lisa Paylo Meyer 


\title{
ABSTRACT \\ The Role of Mindfulness, Self-Compassion, and Emotion Regulation as Protective Factors Against Disordered Eating in a Sample of University Students
}

\author{
Lisa Paylo Meyer, M.A.
}

Although eating disorders and related interventions have been heavily researched, less is known about potentially protective variables, including self-compassion, mindfulness, and emotion regulation. It is important to understand these constructs and their relationship to eating disorder symptoms because such factors may prevent these disorders in at-risk individuals and aid in more successful psychotherapeutic outcomes. Independent theories related to these variables and their relationship to disordered eating have been postulated, but not yet combined into a single model. In this study, 100 university students completed self-report surveys that were analyzed using a Path Analysis (PA) method. This method tested an integrated model of the influence of mindfulness, self-compassion, and emotion regulation on eating disorder symptoms. The results indicate that higher levels of self-compassion are related to higher levels of mindfulness, both of which are predictive of lower levels of emotion regulation difficulties and lower levels of disordered eating. Emotion regulation partially mediated the relationships between selfcompassion and eating disorder symptoms and between mindfulness and eating disorder symptoms through self-compassion. Self-compassion was also directly related to eating disorder symptoms. Clinical implications and recommendations for future research are provided in the context of the study's limitations. 


\section{TABLE OF CONTENTS}

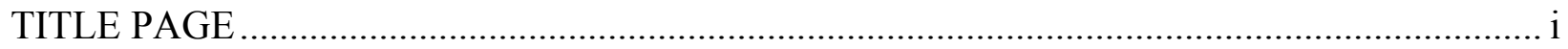

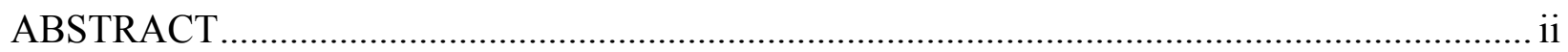

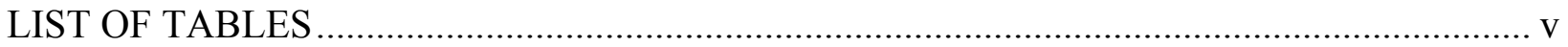

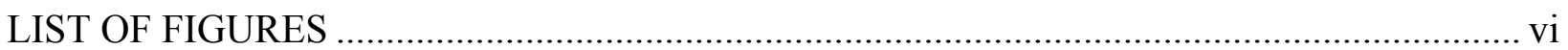

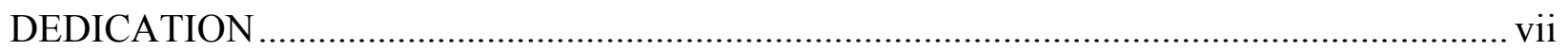

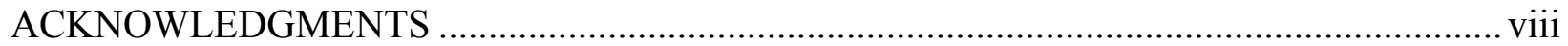

1. INTRODUCTION AND REVIEW OF THE LITERATURE......................................... 1

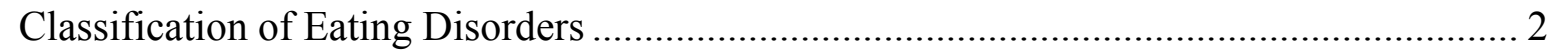

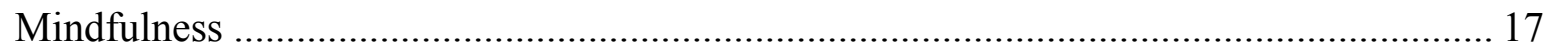

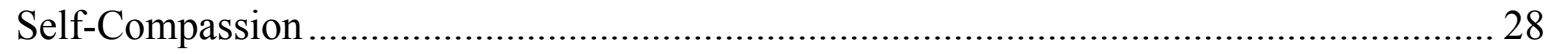

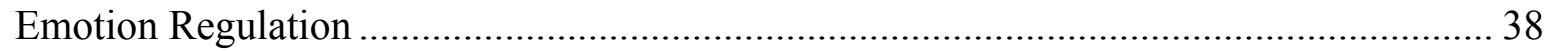

2. RESEARCH DESIGN AND METHODOLOGY …................................................... 51

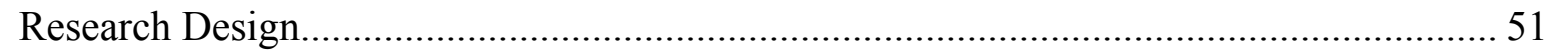

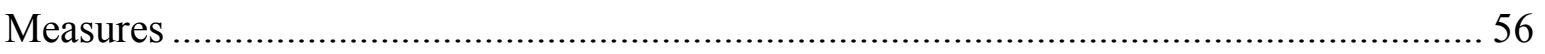

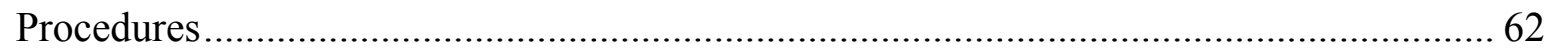

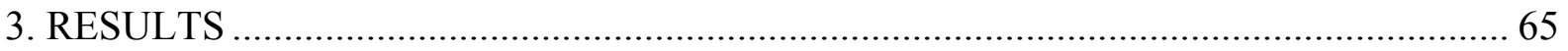

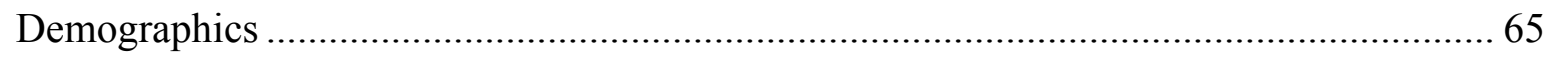

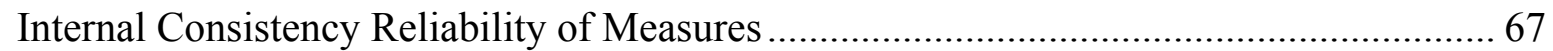

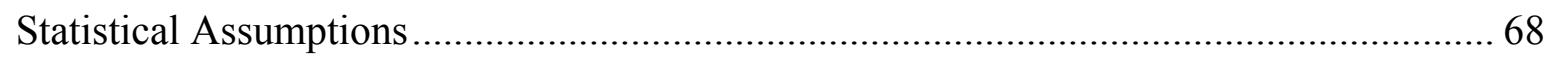

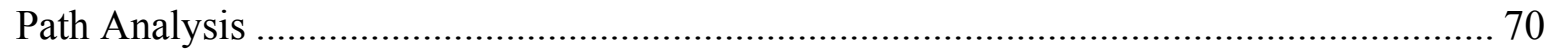




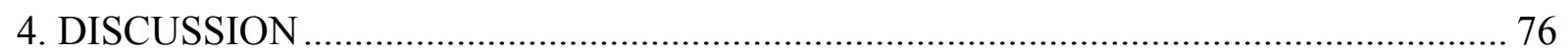

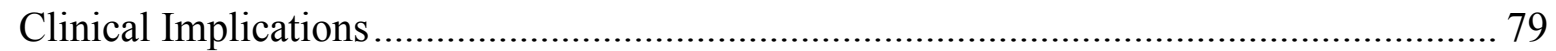

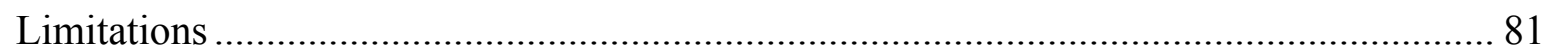

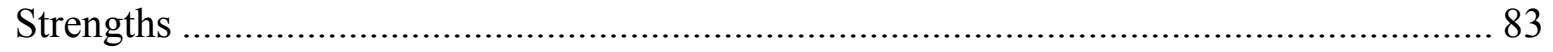

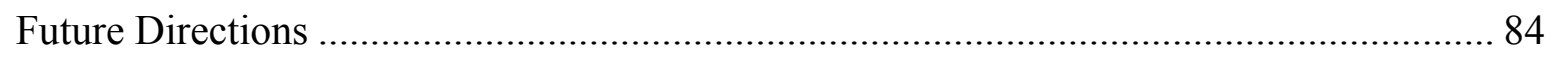

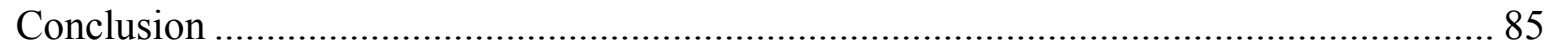

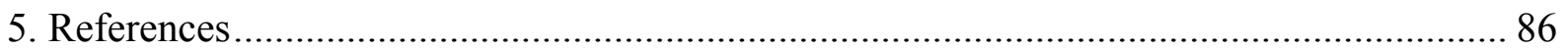

Appendix A (Integrated Model of Eating Disorder Symptomatology) …………….......... 119

Appendix B (Survey Advertisement)............................................................................. 120

Appendix C (Alternative Survey Advertisement)............................................................. 121

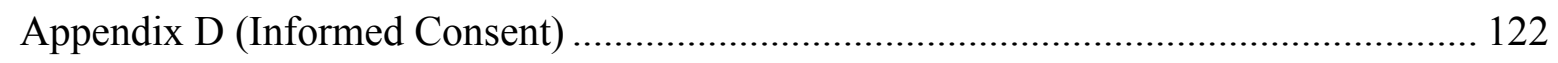

Appendix E (Demographic Questionnaire) …………................................................ 124

Appendix F (Five Facet Mindfulness Questionnaire)..................................................... 126

Appendix G (Self-Compassion Scale) …………….................................................... 128

Appendix H (Difficulties in Emotion Regulation Scale).................................................. 130

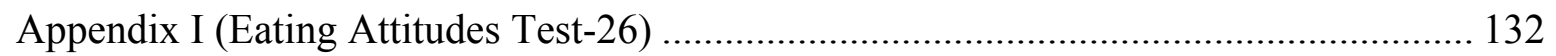

Appendix J (Counseling Referral List) ............................................................................. 134 


\section{LIST OF TABLES}

Tables

Page

1. Demographic Information of Participants ........................ 67

2. Cronbach's Alpha Scores for Measures .......................... 68

3. Skewness and Kurtosis Statistics............................... 69

4. Correlation Matrix for Variables Included in Tested Models ........ 71

5. Fit Indices of the Revised Model .............................. 72

6. Direct, Indirect, and Total Effects of the Model ..................

7. Goodness of Fit Indices for Demographic Variables Included in 75 the Model ....................................................... 


\section{LIST OF FIGURES}

Figure $\quad$ Page

1. The proposed model of eating disorders for this study ............ 55

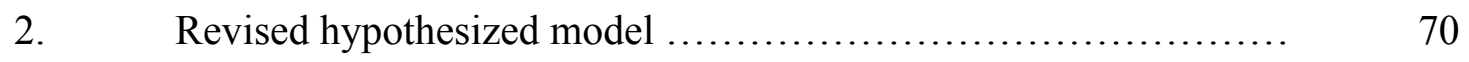

3. Revised hypothesized model with standardized beta coefficients ... 73 


\section{DEDICATION}

There are many individuals who contributed to this work. First and foremost, I would like to dedicate this dissertation to my mother, who cultivated a love for learning and sacrificed endlessly to make my passions a reality. She and my siblings are dedicated to working hard for the betterment of others and have inspired me to do the same.

I would also like to dedicate this work to my husband. His unwavering love and support throughout this process have been unmatched. I am beyond grateful for his selfless and encouraging spirit, which made every step along the way a little less challenging.

Lastly, I would like to dedicate this dissertation to those who have been touched by an eating disorder. It takes tremendous strength to overcome these illnesses and it is my hope that this work will contribute to more effective treatments that make the journey more promising. 


\section{ACKNOWLEDGMENTS}

Graduate school and the dissertation process require a great deal of perseverance and I am fortunate that I did not have to go it alone. I would like to acknowledge my dissertation chair, Dr. Monica Leppma, for her ongoing guidance and support. You have found an amazing way to balance offering direction and fostering independence, which has helped me to build greater confidence in my work. Thank you for your encouragement amidst challenges and your celebration in times of success. Most of all, I would like to thank you for sharing your love for research with me.

I would also like to thank Dr. Christa Lilly for being generous with her statistics expertise. You are the best statistics professor I have had and your genuine care for students is apparent. I cannot thank you enough for your positivity and patience throughout this process; I would have been lost without it.

I have also had the privilege of being supported and challenged by Dr. James Bartee, Dr. Jeffrey Daniels, and Dr. Christine Schimmel. Each of you added something uniquely wonderful to my experience at West Virginia University and I am grateful for your ongoing dedication to your students. Thank you for the time and energy you invested in me; it continues to inspire me to be a better clinician and researcher. 


\section{CHAPTER 1: INTRODUCTION AND REVIEW OF THE LITERATURE}

\section{Background}

Although referenced as far back as the late 1600s, eating disorders began receiving increased attention in the 1970s (Bruch, 1978). Medical providers were seeing the devastating effects of this new disease in startling proportions. In her seminal work, Bruch (1978) considered the growing rate of eating disorders, namely anorexia nervosa, and indicated that most physicians learned about these disorders in medical school, but never saw them in real life. She deemed them a growing problem in high schools and colleges and noted that, "One might speak of an epidemic illness, only there is no contagious agent" (Bruch, 1978, xx).

The following decades were marked by a growth in eating disorder research (Agras, 2010). Attention was directed to more detailed case histories, more complex etiological models, and to the diverse populations these disorders impacted. This broadened focus included consideration of presentations beyond anorexia nervosa, the development of a multidimensional model of eating disorders, and the creation of journals devoted to eating disorder research (e.g., International Journal of Eating Disorders; Agras, 2010; Garfinkel \& Garner, 1982).

Although views about the taxonomy and treatment of eating disorders have expanded, there is still consensus that they are illnesses most prominent in Western societies (Fairburn \& Brownell, 2013). While these disorders are one of the most prevalent mental health concerns women experience (APA, 2007), there is growing evidence that body dissatisfaction and disordered eating behaviors have also risen among males in the past several decades (Mellor, Fuller-Tyszkiewicz, McCabe, \& Ricciardelli, 2010). It is traditionally believed that $10 \%$ of eating disorder cases occur in males; however, some estimates consider lifetime prevalence rates to be comparable to those seen in women (Swanson, Crow, Le Grange, Swendsen, \& 
Merikangas, 2011; Wade, Bergin, Tiggemann, Bulik, \& Fairburn, 2006). Regardless of the impacted population, eating disorders are of the most deadly of psychiatric disorders and take the lives of more than 5\% of individuals for every decade they continue to be ill (Harvard Women's Health Watch, 2012).

\section{Statement of the Purpose}

The period of 'emerging adulthood' experienced by university students is marked by stressful educational, home life, relationship, and identity changes (Arnett, 2001). The emotional stress related to this transition can negatively impact health-related practices (Bell \& Lee, 2006) and increase the risk of psychological disorders (DeBate, Blunt, \& Becker, 2010; Hudson, Hiripi, Pope, \& Kessler 2007; Sacker \& Cable, 2010). The rates of anxiety, depression, and other disorders among young adults in the United States have steadily risen over the past seven decades (Twenge et al., 2010). Poor psychological well-being is common among those with poor eating habits (Crow, Zander, Crosby, \& Mitchell, 1996). As mental health concerns increase, so does the occurrence of disturbed eating practices, such as dietary restraint and disinhibited eating, which can precipitate eating disorders (Bulik, 2002).

The influence of mindfulness, self-compassion, and emotion regulation on eating disorders is gaining attention in the literature. Until recently, the combined impact of these constructs has been neglected. However, given the relevant research, it is hypothesized that it is possible to understand the relationships between these constructs and their impact on eating disorder symptoms. The factor that is believed to influence eating disorder symptoms is emotion regulation, which is impacted by both mindfulness and self-compassion.

The model set forth in this study (see Appendix A) is based on theories outlined by Germer (2009), McBeth and Camley (2012), and Lavender, Gratz, and Tull (2011) and makes 
several suppositions. First, it posits that mindfulness and self-compassion maintain a reciprocal relationship. Mindfulness is believed to be a precursor to self-compassion, in that there must initially be mindful awareness of personal suffering. Likewise, self-compassion requires attention to internal experiences, rather than to oneself as the experiencer, along with a posture of acceptance and non-judgment toward those experiences. The model also suggests that mindfulness and self-compassion are adaptive emotion regulation strategies that subsequently impact eating disorder symptoms, both distinctly and as forms of emotion regulation.

Therefore, the primary purpose of this study was to highlight factors that are potentially protective against eating disorders by integrating and empirically examining theoretical frameworks for mindfulness, self-compassion, emotion-regulation, and eating disorder symptomatology. The theoretical model includes factors related to the variability in eating disorder symptoms and was tested using path analysis. This quantitative methodological approach examines relationships between observed variables and determines if the proposed model successfully explains the actual relationships observed in the sample data. Since it is an extension of multiple linear regression and focuses on correlational associations of data, causality cannot be inferred. However, this analysis attempted to create a structural model to explain the relationship amongst the variables in the study and tested the direct, indirect, and mediating effects on eating disorder symptoms.

\section{Classification of Eating Disorders}

The Diagnostic and Statistical of Mental Disorders (DSM-5; American Psychiatric Association, 2013) organizes eating disorders into three primary types: Anorexia Nervosa (AN), Bulimia Nervosa (BN), and Binge Eating Disorder (BED). In addition, Other Specified Eating or Feeding Disorder (OSFED) and Unspecified Eating or Feeding Disorder (USFED) are 
included for those clinical presentations that include characteristics of a feeding or eating disorder that do not meet the full criteria for any of the disorders in the diagnostic class, but cause clinically significant distress, impairment in social, occupational, or other important areas of functioning

Anorexia Nervosa (AN). The distinguishing characteristic of AN is an intense fear of gaining weight or becoming fat, or engaging in behaviors that interfere with weight gain. To meet criteria for AN, the individual must also restrict energy intake, leading to significantly low body weight, considering age, sex, developmental trajectory, and physical health. Additionally, there is a disturbance in the experience of one's body weight or shape, an unwarranted influence of body weight on self-evaluation, or a denial of the seriousness of being underweight. AN is divided into two subtypes. The Restricting Type involves restriction of food intake and accomplishment of weight loss by means of dieting, fasting, and/or excessive exercise. To meet criteria for this subtype, the individual cannot have engaged in episodes of binging or purging behavior over the last three months. The Binge-Eating/Purging Type involves episodes of binging and subsequent purging, which have occurred over the last three months. Specifiers for this category are defined in terms of Body Mass Index (BMI), which is the measure of individuals' body fat based on their weight in relation to their height. These include mild (BMI $\geq 17 \mathrm{~kg} / \mathrm{m}^{2}$ ), moderate (BMI 16-16.99 kg/m²), severe (BMI $15-15.99 \mathrm{~kg} / \mathrm{m}^{2}$ ), and extreme (BMI $<15 \mathrm{~kg} / \mathrm{m}^{2}$ ). The 12 -month prevalence of AN among young females is approximately $0.4 \%$. Less is known about the prevalence in males; however, AN is far more common in females than in males.

Bulimia Nervosa (BN). Key characteristics of BN are recurrent episodes of binge eating and recurrent inappropriate compensatory behaviors. Binge eating involves eating, within a two- 
hour time period, an amount of food that is substantially larger than most people would eat under comparable conditions. The binge episodes are characterized by a sense of lack of control over eating during the episode. The individual must also engage in recurrent compensatory behaviors, such as self-induced vomiting, excessive exercise, use of laxatives, or fasting, in order to prevent weight gain. In addition, self-evaluation is excessively influenced by body shape and weight. To meet criteria for $\mathrm{BN}$, the binge eating and compensatory behaviors must both occur at least once per week for three or more months, and the episode cannot occur exclusively during the occurrence of anorexia nervosa. Specifiers for this category include mild (an average of one to three episodes of inappropriate compensatory behaviors per week), moderate (an average of four to seven episodes of inappropriate compensatory behaviors per week), severe (an average of eight to 13 episodes of inappropriate compensatory behaviors per week), and extreme (an average of 14 or more episodes of inappropriate compensatory behavior per week). The 12month prevalence of $\mathrm{BN}$ among young females is between $1 \%$ and $1.5 \%$. Less is known about the prevalence in males; however, $\mathrm{BN}$ is far more common in females than in males.

Binge Eating Disorder (BED). Binge Eating Disorder (BED) involves regular episodes of binge eating without the regular use of unhealthy compensatory strategies utilized in the BN subtypes. The binge episodes are correlated with three or more of the following: eating more quickly than normal, eating large portions of food when not hungry, eating until feeling uncomfortably full, eating alone due to embarrassment from amount of food consumed, and feeling guilty after overeating. The episodes cause distress and occur at least once per week for at least three months. To meet criteria for BED, the binge episodes are not associated with recurrent use of compensatory behaviors as in $\mathrm{BN}$, and the episodes do not occur exclusively during the course of AN or BN. Specifiers for this category include mild (one to three binge 
episodes per week), moderate (four to seven binge episodes per week), severe (eight to 13 binge episodes per week), and extreme (14 or more binge episodes per week). The 12-month prevalence of BED is approximately $1.6 \%$ among adult females and $0.8 \%$ among adult males. $\mathrm{BED}$ is more common among individuals seeking weight-loss interventions than among those in the general population.

Other Specified Feeding or Eating Disorder (OSFED). This category applies to presentations that include characteristics of a feeding or eating disorder that do not meet the full criteria for any of the disorders in the diagnostic class, but cause clinically significant distress or impairment in social, occupational, or other important areas of functioning. This diagnosis is used when the clinician chooses to communicate the reason that the presentation does not meet full criteria for any of the related disorders.

Unspecified Feeding or Eating Disorder (USFED). This category applies to presentations that include characteristics of a feeding or eating disorder that do not meet the full criteria for any of the disorders in the diagnostic class, but cause clinically significant distress or impairment in social, occupational, or other important areas of functioning. This diagnosis is used when the clinician chooses not to communicate the reason that the presentation does not meet full criteria for any of the related disorders.

\section{Medical Complications of Eating Disorders}

Eating disorders have destructive effects on an individual's health and well-being. Both AN and BN share severe medical complications. DeBate et al. (2010) outline several categories of health concerns. Individuals with $\mathrm{AN}$ or $\mathrm{BN}$ can face cardiovascular complications, such as low blood pressure, dizziness, and heart failure. They also can endure gastrointestinal issues, including esophageal and gastric rupture, ulcers, enlarged parotid gland, chronic irregular bowel 
movements and constipation. Women with AN or BN may also face reproductive and pregnancy difficulties, such as infertility, miscarriage, delivery complications, postpartum depression, and babies with low-birth weight. In addition, individuals can endure skin complications, growth of lanugo, loss of hair, brittle nails, finger calluses, dry skin, and dental complications. Beyond these conditions, an enduring pattern of disordered eating can result in death. Mortality rates are estimated to be $4 \%$ for those with $\mathrm{AN}, 3.9 \%$ for those with BN, and 5.2\% for those with BED and Other Specified Eating Disorders (Crow et al., 2009)

\section{Comorbidity with other Psychological Disorders}

Eating disorders are highly comorbid with other psychological disorders. AN is linked to mood disorders (i.e., major depressive disorder and dysthymic disorder; DeBate et al., 2010; Hudson et al., 2007) and various anxiety disorders (i.e., generalized anxiety disorder, obsessivecompulsive disorder, social phobia, and separation anxiety disorder; DeBate et al., 2010). BN is also linked to mood disorders (i.e., major depressive disorder, dysthymic disorder, and bipolar disorder; Hudson et al., 2007) and has a high comorbidity with all anxiety disorders, except for generalized anxiety disorder (Hudson et al., 2007). Although it is a fairly new diagnosis, BED has been notably associated with all types of mood and anxiety disorders (Hudson et al., 2007). Both $\mathrm{BN}$ and $\mathrm{BED}$ are also significantly correlated to impulse disorders, with the exception of intermittent explosive disorder (Hudson et al., 2007). In addition, AN, BN, and BED are all significantly correlated to substance abuse (Hudson et al., 2007; Luce, Engler, \& Crowther, 2007).

\section{Definition of Terms}

Body Image. Body image is a multidimensional construct involving feelings and selfperceptions about physical appearance (Cash \& Pruzinsky, 2004). A key element is body image 
satisfaction or dissatisfaction, which results from a person's subjective assessment of his or her overall physical appeal (Slade, 1994). Body dissatisfaction denotes an unfavorable evaluation of one's appearance, along with a desire to be more physically attractive (Cash \& Pruzinsky, 2004). Dissatisfaction with one's body is so rampant that is has been deemed a 'normative discontent' (Rodin, Silberstain, \& Striegel-Moore, 1985).

Disordered Eating Attitudes. Eating disordered attitudes include thoughts and affective states related to concerns about weight, self-control, and acceptance from self and others (Fairburn, 2008). Such attitudes have demonstrated associations between eating cognitions, eating behaviors (Cooper, 2006), and psychological distress (Masuda, Price, Anderson, \& Wendell, 2010). Body image and disordered eating cognitions and behaviors are impacted by various factors, including neurobiological factors (Kaye, 2008) and psychosocial factors, such as race and ethnicity (Baugh, Mullis, Mullis, Hicks, \& Peterson, 2010), media (Ferguson, Munoz, Contreras, \& Velasquez, 2011), peer comparison (McCabe \& Ricciardelli, 2005), family-oforigin (Sira \& White, 2010), and involvement in athletics (Anderson \& Petrie, 2012; Petrie and Greenleaf, 2013). There is also evidence to suggest that these attitudes and behaviors are affected by cognitive factors, including mindfulness (Lavendar et al., 2011), self-compassion (Gilbert, 2010), and emotion regulation (Aldao \& Nolen-Hoeksema, 2010).

\section{Factors Contributing to Eating Disorders}

Neurobiological factors. There is growing recognition of the role of neurobiological vulnerabilities as contributing to the pathogenesis of eating disorders. Considerable research has focused on neuropeptides and neurotransmitters related to the development and maintenance of these disorders. One potential contributor is central nervous system (CNS) neuropeptide dysregulation (Stoving, Hangard, Hansen-Nord, \& Hagen, 1999). The complex interaction 
between peripheral systems and CNS neuropeptides are thought to influence the mechanisms of food intake (Morton, Cummings, Baskin, Barsh, \& Schwartz, 2006). Neuropeptides have shown a role in feeding behaviors and energy metabolism in various animal studies (Schwartz, Woods, Porte, Seeley, \& Baskin, 2000) and are present in distorted levels in humans who are malnourished and underweight (Kaye, 2008).

Studies have also found a reduction in those neurochemicals that inhibit food intake, including serotonin (5-HT), in those with AN and BN (Grilo \& Mitchell, 2010). While there is some evidence that the level of this neurotransmitter increases after recovery (Favaro, Monteleone, Santonastaso, \& Maj, 2008), some research suggests that there are persistent alterations in serotonin after recovery (Kaye, 2008). It has been posited that those who are vulnerable to eating disorders may begin with increased serotonin receptor activity, which contributes to higher levels of anxiety and harm avoidance (Grilo \& Mitchell, 2010). These individuals may restrict intake to better regulate related anxiety (Kaye, Frank, Bailer, \& Henry, 2005).

Diet can also interfere with 5-HT neurotransmission (Kaye, 2008). Tryptophan (TRP) is an essential amino acid made available through one's diet and precedes 5-HT release and, in turn, impacts appetite regulation; however, in the case of a restricted diet, there is a decreased availability of TRP to the brain (Kaye, 2008). Dopamine dysfunction can also result from restricted intake and impacts reward and affect, executive function, and decreased food ingestion (Haber, Kim, Mailly, \& Calzavara, 2006; Halford, Cooper, \& Dovey, 2004; Yin \& Knowlton, 2006).

Brain imaging has shown promise of better understanding the pathophysiology of AN and BN. These have involved the use of technology such as computerized tomograph (CT), 
magnetic resonance imaging (MRI), positron emission tomography (PET), single photon emission computed tomography (SPECT), and functional magnetic resonance imaging (fMRI) (Kaye, 2008). Even though these studies have not identified pathways or behavioral correlates, they have demonstrated differences in frontal, cingulate, temporal, and parietal regions of the brain between individuals with eating disorders and healthy controls (Kaye, 2008). These studies have found increased activity in the anterior cingulate cortex (ACC) region, which serves to regulate emotions and detect errors or shortcomings from a certain standard (Nieuwenhuis, Ridderinkhof, Blom, Band, \& Kok, 2001), as well as reduced activity in other cortical regions (Grilo \& Mitchell, 2010), brain matter reduction in AN (Keel, 2005), as well as enlarged ventricles in those with $\mathrm{AN}$ and $\mathrm{BN}$ and decreased cortical mass in individuals with $\mathrm{BN}$ (Keel, 2005).

Race and ethnicity. Irrespective of a particular ethnicity, men and women who identify with and relate to the majority culture maintain a greater likelihood of embracing beliefs about being exceptionally muscular or thin, respectively (Chatterton \& Petrie, 2013; Soh, Tonyz, \& Surgenor, 2006). Baugh, Mullis, Mullis, Hicks, \& Peterson (2010) studied the effects of race on body satisfaction and eating behaviors, and found that there were significant differences in eating disordered behavior between a group of ethnically diverse women. In their study, African American women maintained similar levels of body image dissatisfaction to those of the Caucasian women. However, African American women were less likely to engage in destructive eating habits. Likewise, DeLeel, Hughes, Miller, Hipwell, and Theodore (2009) found similarities in body image when comparing majority and minority cultures. But, again, there were racial differences when comparing eating disturbances (DeLeel et al., 2009). Researchers 
have posited that African American women exist in a culture that is tolerant of weight, so the pressure of meeting thin-ideals is less prevailing (Abrams \& Stormer, 2002).

Kelly, Cotter, Tanofsky-Kraff, and Mazzeo (2015) examined racial variations in disordered eating beliefs and practices in a sample of undergraduate males. The authors found that Asian American men endorsed greater internalization of the male ideal and a higher drive for muscularity than their Caucasian and African American male counterparts. Both Caucasian and Asian American men reported significantly more shape concerns than African American men; however, levels of body satisfaction were similar between Caucasian and African American men. Asian American men endorsed the highest levels of body dissatisfaction and it was found that compulsive exercise was highest among this group, particularly for those with a history of binge eating.

Such findings do not suggest that certain ethnicities are free from eating disturbances (DeLeel et al., 2009). In fact, there is some evidence that the prevalence of bulimia nervosa is more common among Latinos and African Americans, while anorexia nervosa and binge eating disorder is similar across cultures (Marques et al., 2011), Regrettably, some issues involving body image and eating disorders in racially diverse persons may be ignored because of existing stereotypes created by research (Walcott, Pratt, \& Patel 2003). Nonetheless, high levels of ethnic identity, which counter majority culture, may be protective of the development of eating disordered behavior.

Media. Media can be considered through the lens of sociocultural theory, which considers ideals for physical attractiveness to be the basis for body image dissatisfaction (Groesz, Levine, \& Murnen, 2002). In a media-driven culture, individuals are confronted with unrealistic body archetypes, through the means of television, magazines, and the Internet. Media creates the 
misperception that audiences are in competition with the most physically attractive people, while not recognizing that these are also the most surgically and technologically enhanced (Smith, Li, Joiner, 2011). It is easy for individuals to neglect the fact that only a minute percentage of the population can meet such an unrealistic ideal.

While findings about the impact of media are conflicting, the majority of studies conducted have shown at least some influence on body image (Grabe, Ward, \& Hyde, 2008). Clark and Tiggemann (2008) demonstrated that females with elevated body mass indexes were at an increased risk of internalizing the thin-ideal message, and therefore, maintained a greater desire to be thin. Such internalization can come from exposure to media and conversations surrounding physical appearance (Sides-Moore \& Tochkov, 2011)

Peer comparison and competition. While media may greatly influence body image, peer pressure to fit body ideals may be even more predictive of body image dissatisfaction (McCabe \& Ricciardelli, 2005). The realm of peers becomes particularly prominent in adolescence and young adulthood, when friends begin to surpass parents as support systems (Brittain, 1963; Furman \& Buhrmester, 1992). Because peer influence may also be more impressive than media images, social comparison processes may more powerfully perpetuate cultural ideals from average-size friends than from persons in the media (Shomaker \& Furman, 2007).

In a systematic review by Marcus et al. (2013), the authors found positive and significant relationships between peer interactions and body image and eating behaviors in adolescents. The authors only found significant gender differences related to peer interactions, such that females endorsed greater influence from their peer groups for disordered eating practices than males did. Beyond comparisons of physical beauty, those who are faced with an intimidating comparison in 
a particular realm, may try to compete in another domain that is socially appropriate, in order to protect their self-concept (Pliner, Rizvi, \& Remick, 2009). Attention to physical fitness and beauty comprise a domain that is viewed as socially appropriate. However, competition in such an area can lead to adverse effects on one's body image, and likewise, eating behaviors.

Family-of-origin. A small portion of studies has investigated the impact of family-oforigin processes on an individual's body image (Sira \& White, 2010). Because the roles of media, society, and peer influence have been heavily researched, family is a factor that has frequently been disregarded (Peterson, Paulson, \& Williams, 2007). However, members of one's family may be prominent communicators of body-ideal messages (Shomaker \& Furman, 2007), therefore, it is a significant factor to consider.

Schwartz, Phares, Tantleff-Dunn, and Thompson (1999) found that parents' remarks to their children concerning appearance were associated with negative body image and poor psychological functioning in their daughters, as well as poor psychological functioning in their sons. Even though females' body images were more likely to be affected by parents' explicit comments, males were still at risk for internalizing such messages. Sira and White (2010) also explored the influence of parents on a child's body satisfaction. They discovered that in females, healthy body image was inversely related to parental control. Parental care, however, was directly related to self-esteem, which positively impacted body satisfaction. Likewise, in males, parental care positively influenced self-esteem and body image, whereas parental control was also negatively related to healthy body image (Sira \& White, 2010).

Since mothers can unintentionally exemplify healthy and destructive body images to their daughters (Elfhag \& Linne, 2004), these specific relationships are also critical to consider. In a study with mother-daughter dyads, Mchiza, Goedecke, and Lambert (2011) found intra-familial 
similarities in perceived and ideal body sizes, as well as in body dissatisfaction. For young girls, who have yet to develop influential peer supports, this finding gives credibility to the notion that parents can serve as transmitters of particular body beliefs. A positive role model in the home can aid in the development of a child's healthy body image; conversely, family members may model preoccupation with body size and shape, dietary restraint, and/or compensatory weight control strategies that may encourage unfavorable body image and disordered eating (Marcus et al., 2013).

Athletics. Involvement in athletics may also be related to disordered eating behaviors. Within male athletes, Petrie and Greenleaf (2013) identified two types of pressures that may negatively influence males eating and weight control behaviors, including societal messages and sport-specific pressures. Males are exposed to general messages from society, by means of the media, family, and friends that emphasize cultural standards for appearance, body shape and size, and what it means to be a man. In addition, these males are also prone to pressures and messages related to the functionality of their bodies, muscularity and leanness, and to being a high level performer. These compounding pressures from coaches, sport judges, teammates, peers, family, and society can influence body dissatisfaction and increase the use of unhealthy eating and weight control practices.

Even though most research has focused on female athletes and eating disorders (Chatterton \& Petrie, 2013), existing studies indicate that male athletes also experience eating disorders and subclinical disordered eating patterns (Petrie, Greenleaf, Reel, \& Careter, 2008). Male athletes are more likely to draw on exercising, eating, and gaining muscle mass more often that using diet pills, diuretics, and purging behaviors. In a study of male collegiate athletes by Petrie et al. (2008), it was found that $4.5 \%$ used diuretics, $7.9 \%$ used laxatives, and $16.7 \%$ binge- 
ate at least one time per week, while 6.5\% engaged in purging (i.e., vomiting) several times per month, $14.2 \%$ went on strict diets at least twice in the prior year, and $37 \%$ exercised two or more hours on a daily basis. Chatterton and Petrie (2013) examined eating and weight control behaviors in a large and diverse national sample of male collegiate athletes. They found that, while only about one-percent met criteria for an eating disorder, $16 \%$ endorsed sub-threshold levels of an eating disorder. Therefore, although eating disorders in male college athletes are rare, they may be at-risk for developing subclinical disorders, which may result in psychological and physical complications.

In contrast to male athletes, eating disorders and subthresold symptoms are more prevalent in female collegiate athletes by approximately $14 \%$ to $19 \%$ (Anderson \& Petrie, 2012). These women are thought to be just as susceptible to the same weight concerns as their nonathlete counterparts (Smolak, Murnen, \& Ruble, 2000) and may use disordered eating practices to offset their body dissatisfaction if encouraged by their social environment to do so (Forney \& Ward, 2013). These unhealthy eating and weight control patterns may be viewed as dedication, rather than as an indication of psychological problems (Wells, Chin, Tacke, \& Bunn, 2015). Wells et al. (2015) examined internal and external factors that may increase risk of disordered eating practices in female college athletes. They found that involvement in lean sports, or those focused on body composition, was related to increased risk of disordered eating symptoms. External views about body satisfaction and internal factors related to team trust were positively associated with such unhealthy practices.

Dance. Female dancers, who are particularly vulnerable to eating disorders, may be at an even greater risk than other female athletes (Ringham et al., 2006). These athletes are exposed to complicated health risks related to strength, endurance, appearance, and optimal health 
(Krasnow, 2005). Most research about ballet dancers has found an endorsement of perfectionism, body dissatisfaction, preoccupation with eating and weight, and eating disordered practices, (Anshel, 2004; Ringham et al., 2006). Distinct from the continual pressure to maintain low body weight, modern dancers appear to have more physical and artistic freedoms (Clabaugh \& Morling, 2004). However, a drive for perfectionism and external pressure to maintain acceptable body weight may increase the risk of developing an eating disorder (Thomas, Keel, \& Heatherton, 2005). Schluger (2010) examined the relationship between types of dance and disordered eating attitudes and patterns in female college students. The author found that those women who were involved in ballet dance endorsed significantly higher levels of pressure to achieve and maintain low body weight than those who participated in modern dance. However, no differences were found between the groups in terms of dieting practices and levels of perfectionism. This finding suggests that collegiate dancers may maintain high self-expectations regardless of the type of dance in which they participate. Overall, Ringham et al. (2006) found higher reported levels of perfectionism in dancers than in non-dancers.

Cognitive factors. Cognitive factors, such as mindfulness, self-compassion, and emotion regulation are also believed to impact the development and course of eating disorders. Mindfulness refers to an awareness of moment-by-moment experiences that arises from purposeful and non-judgmental present-moment attention (Kabat-Zinn, 2003). Self-compassion refers to the demonstration of kindness to oneself, the observation of one's own imperfection as an inevitable aspect of the human condition, and a mindful awareness of one's distressing thoughts and emotions (Neff, 2003a). Emotion regulation consists of those extrinsic and intrinsic processes individuals use to influence their psychological experiences and the ways in which they experience and express emotions (Masuda, Price, \& Latzman, 2012). Adaptive 
emotion regulation typically indicates the use of strategies that aid in managing unfavorable emotions in such a way that prevents emotions from interfering with the attainment of goals (Bridges, Denham, \& Ganiban, 2004).

Although researchers have heavily studied eating disorder symptoms and interventions, much of the research focuses on variables that negatively impact body image and eating attitudes and behaviors. Less is known about protective variables, which may be unique and not merely opposites of those that are related to negative body image and eating disorders (Striegel-Moore \& Cachelin, 1999). For example, the role of self-compassion, mindfulness, and emotion regulation in eating disorder symptomatology is gaining increasing attention in the literature (Aldao \& Nolen-Hoeksema, 2010; Kelly, Carter, \& Zuroff, 2013; Lavender, Gratz, \& Tull, 2011). Therefore, it is important to better understand these constructs and their relationship with eating disorder symptoms because such factors may prevent disordered eating behaviors in atrisk individuals and may aid in more successful psychotherapeutic outcomes (Carter, Kelly, \& Norwood, 2012; Tylka, 2011). Therefore, the primary variables of interest in this study are mindfulness, self-compassion, and emotion regulation.

\section{Mindfulness}

Mindfulness practices originated in Eastern spiritual traditions, and it was believed that regular engagement in meditation would develop mindfulness and result in increased levels of calmness, awareness, insight, wisdom, and compassion (Goldstein, 2002; Kabat-Zinn, 2000). In the last several decades, mindfulness practices have been modified and incorporated into medical and mental health interventions (Baer, Smith, Hopkins, Krietemeyer, \& Toney, 2006). However, there is still limited understanding of the construct of mindfulness, and there are many definitions of it within the literature (Holas \& Jankowski, 2013). A commonly cited definition 
describes mindfulness as "awareness that emerges through paying attention on purpose, in the present moment, and non-judgmentally to the unfolding of experience moment by moment" (Kabat-Zinn, 2003, p. 145).

Shapiro, Carlson, Astin, and Freedman (2006) described the various elements contained in the definition of mindfulness. First, mindfulness is an intentional process, such that attention is being directed and focused in a deliberate way. Second, the object of attention in mindfulness occurs consciously in the present moment. Lastly, mindfulness promotes a position of openness and acceptance toward present moment experiences. Overall, the goal of mindfulness is less concerned with achieving a certain type of experience, and more concerned with preserving a unique relationship between the actual experience and the process of becoming aware of it (Holas \& Jankowski, 2013).

Baer et al. (2006) validated the internal consistency of available mindfulness instruments in a sample of undergraduate students, including the Mindfulness Attention Awareness Scale (MAAS; Brown \& Ryan, 2003), the Freiburg Mindfulness Inventory (FMI; Walach, Buchheld, Buttenmuller, Kleinknect, \& Schmidt, 2006), the Cognitive Affective Mindfulness Scale (CAMS; Hayes \& Feldman, 2004), the Mindfulness Questionnaire (MQ; Chadwick, Taylor, \& Abba, 2005), and the Kentucky Inventory of Mindfulness Skills (KIMS; Baer, Smith, \& Allen, 2004). Then, they examined the various facets of mindfulness being addressed by the measures. Upon conducting exploratory and confirmatory factor analyses, they identified five key factors related to the construct of mindfulness, including (1) observing experiences; (2) describing experiences; (3) acting with awareness; (4) non-judgment of experiences; and (5) non-reactivity to experiences. 
Holas and Jankowski (2013) proposed a model of the cognitive aspects involved in mindfulness. They explained mindfulness as a two-part process, including (1) a deliberate state of meta-awareness, and (2) openness to the content of the experience. The authors conceptualized mindfulness as a construct in which a state of meta-awareness is elicited and maintained by collaboration between processes of attention and executive function. Individual differences in level and quality of mindfulness can be seen as the result of a complex interaction between mindfulness training, genetic predispositions, and environmental factors that influence one's personality (Brown, Ryan, \& Creswell, 2007).

There is strong evidence in support of mindfulness as an effective means to increasing behavioral regulation skills and subjective well-being and decreasing negative mood states and emotional reactivity (Keng, Smoski, \& Robins, 2011). Mindful awareness is associated with increases in clarity of awareness, decreases in frequency of dissociations, as well as decreases in the influence of implicit evaluative processes (Holas \& Jankowski, 2013). Mindfulness has also been linked to interruptions and reductions in self-regulation processes. If experiences are accepted, standards for comparison are deferred and an accurate representation of the presentmoment experience can be developed (Carver \& Scheier, 1998). Therefore, there is decreased need to approach, avoid, or control the experience.

Holas and Jankowski (2013) posited that several processes, including decentering, decreases in self-focused attention, and the development of self-compassion, mediate the positive effects of mindfulness. Individuals who develop mindfulness skills begin to understand that they do not need to identify with the content of their experiences, but rather focus on being a conscious observer to internal and external events. Individuals also begin to decrease selfconsciousness, which allows for more spontaneous and naturally-occurring behavior (Leary, 
Adams, \& Tate, 2006) and decreases self-identification (Brown et al., 2007). Lastly, Holas and Jankowski (2006) suggested that self-compassion might also mediate the positive impact of mindfulness. Self-compassion helps individuals begin to develop self-kindness and an attitude of active acceptance toward the tone and nature of events.

Mindfulness and eating disorders. Mindfulness in this context does not focus on reaching a particular goal or appearance ideal, but promotes willingness to accept the present state of one's appearance (Kabat-Zinn, 1990). It fosters the ability to contact and remain in a present-moment experience, which is contrary to body avoidance. It also encourages compassionate rather than judgmental attention, which is opposite of the self-critical process involved in eating disorders. Therefore, increased mindfulness is expected to decrease disordered eating cognitions and behaviors. However, there is a deficit in the literature examining the relationship between mindfulness and eating pathology (Alberts, Thewissen, \& Raes, 2012). In addition, most of these studies use a unidimensional definition of mindfulness, even though theoretical and empirical conceptualizations of mindfulness suggest that it is a multifaceted construct (Baer et al., 2006; Bishop et al., 2004).

Lavendar et al. (2011) studied the relationship between disordered eating and multiple facets of trait mindfulness in young adult women. They used the Five Facet Mindfulness Questionnaire (FFMQ; Baer et al., 2006), which accounts for (1) acting with awareness; (2) observing experiences; (3) nonreactivity to inner experiences; (4) nonjudgment of inner experiences; and (5) describing inner experiences. They found that the facets of acting with awareness, observing experiences, nonreactivity to inner experiences, and nonjudgment of inner experiences were all significantly and negatively related to disordered eating, while describing inner experiences was not related to eating pathology. The findings suggest that the ability to 
observe, attend to, and accept internal experiences, coupled with the ability to remain unattached to inner experiences during distress and maintain behavioral control, are indicative of lower levels of disordered eating. Therefore, trait mindfulness is related to disordered eating in young adult women.

Butryn et al. (2013) also examined the relationship between mindfulness and disordered eating symptoms and examined how changes in levels of mindfulness over the course of treatment impacted changes in symptoms in a sample of women in a residential eating disorder program. The authors found that more severe symptoms at time of admission were related to higher levels of emotional avoidance and lower levels of awareness, acceptance, and cognitive defusion, even when accounting for symptoms of anxiety and depression. In addition, they found that those participants who showed the greatest improvements in awareness, acceptance, and emotional avoidance also demonstrated the greatest improvements in disordered eating symptoms. Because the residential facility's treatment was not directly focused on mindfulnessbased therapies, such modalities may further promote improvements in such symptoms.

Body image and social comparison. There is consensus that body dissatisfaction is a product of unrealistic and unattainable ideals of what is attractive (Dijkstra \& Barelds, 2011). Negative body image, or harmful views about one's physical appearance (Fisher, 1990), is a major contributing factor to the development and maintenance of eating disorders (Cooley \& Toray, 2001). Poor body image can result from comparison to appearance ideals (Thompson, Heinberg, Altabel, \& Tantleff Dunn, 1999) and social comparison is one means that media messages are linked to body dissatisfaction (Hargreaves \& Tiggemann, 2004). Contrast-effects impact individuals' sense of perceived attractiveness, such that viewing an attractive same-sex 
individual elicits decreases in body satisfaction, while viewing an unattractive person results in increases in body satisfaction (Krones, Stice, Batres, \& Orjada, 2005).

Mindfulness can be seen as being conscientious and intentional in action, being open to possibilities, and approaching the present-moment without judgment (Siegel, 2010). The notion of non-judgment is pertinent to body image (Reindl, 2002), as taking a position of non-judgment protects against body dissatisafaction. Langer, Pirson, and Delizonna (2010) posited that most individuals are unaware of their implicit choices related to their comparison subject, that they accept the comparison as meaningful, and that they mindlessly accept the evaluation criteria.

Dijkstra and Barelds (2011) assessed the relationship between dispositional mindfulness and body satisfaction. The authors found a positive relationship between these two constructs, such that as mindfulness increased, satisfaction with one's body increased. They also found that those individuals who were engaged in mindfulness to a greater extent were less likely to make body comparisons. Additionally, Dijkstra and Barelds found a partial mediation effect of body comparison in the association between mindfulness and body satisfaction and small mediation effect of mindfulness in the relationship between body comparison and body satisfaction. These results suggest that both body comparison and mindfulness have a direct and indirect effect on levels of body satisfaction.

Disordered eating cognitions. Disordered eating cognitions related to attaining an ideal shape and weight to be accepted by others, fear of gaining weight, and demonstration of selfcontrol and restraint over diet and weight are prevalent in Western culture (Fairburn 2008; Fairburn, Cooper, \& Shafran, 2003; Mizes et al. 2000). Such cognitions are associated with eating disorders (Cooper, 2006) and overall psychological distress (Masuda et al., 2010). 
In addition, dichotomous thinking has been linked to the maintenance of eating disorders (Fairburn et al., 2003). It is a form of cognitive rigidity that categorizes reality into polarities (i.e., food is either "good" or "bad"). This cognitive style increases the appeal of "forbidden" food (Mann \& Ward, 2011), enhances obsessiveness about food, and produces feelings of guilt if such food is consumed (Dewberry \& Ussher, 2001). However, mindfulness is characterized by non-judgmental observation of experiences; therefore, it may encourage awareness of critical thoughts without over-identifying with them (Alberts et al., 2012). Disengagement from such evaluative thoughts can decrease the occurrence of dichotomous thinking.

Rumination is a cognitive avoidance strategy associated with various psychological disorders (Aldao, Nolen-Hoeksema, \& Schweizer, 2010; Harvey, Watkins, Mansell, \& Shafran, 2004). It may be considered a transdiagnostic process that intensifies psychopathology, rather than a strategy exhibited in a particular disorder (Harvey et al., 2004). Diagnostic frameworks for eating disorders emphasize the role of preoccupation of weight and shape concerns and eating (Park, Dunn \& Barnard, 2012). For example, neuroimaging studies have shown that individuals with past or current AN demonstrated attentional biases and increased vigilance related to the body and eating (Brooks, Prince, Stahl, Campbell, \& Treasure, 2011).

Rumination avoids the emotional and physical experience of starvation (Park et al., 2011) and may reinforce disordered eating behaviors (Schmidt \& Treasure, 2006). In fact, previous work has demonstrated that individuals with AN had significantly higher levels of rumination on weight, shape, and eating than control participants and rumination related to these domains was predictive of eating disorder symptoms (Cowdrey \& Park, 2012). Specifically, those with AN may struggle with connecting to and tolerating emotions (Hambrook et al., 2011) and may avoid averse affective experiences, which perpetuates disordered eating symptoms (Lavender \& 
Anderson, 2010; Lavender et al., 2011; Rawal, Park, \& Williams, 2010). Rawal, Williams, and Park (2011) found that induction of a ruminative mode of thinking before an imaginary meal produced a greater stress response and greater attempts to neutralize the negative affect when compared with induction of a mindful mode of processing before the meal. Therefore, rumination and experiential avoidance can exacerbate disordered eating symptoms.

The productive equivalent to rumination and experiential avoidance is mindfulness (Cowdrey \& Park, 2012) and it may be essential in the recovery from eating disorders (Park et al., 2011). Prior research demonstrates that there is an inverse relationship between mindfulness and disordered eating cognitions (Lavender, Jardin, \& Anderson, 2009; Lavender et al., 2011). It has been proposed that mindfulness mediates the link between these cognitions and psychological distress (Masuda \& Wendell, 2010).

Cowdrey and Park (2012) investigated the hypotheses of Park et al. $(2011,2012)$ that rumination about eating and weight and shape concerns, experiential avoidance, and low levels of mindfulness are related to disordered eating behaviors in a healthy adult sample. The authors found that all independent variables were associated with disordered eating symptoms in the sample. Specifically, ruminating about eating, weight, and shape were associated with the symptoms. Experiential avoidance was related to ruminative brooding on eating, weight, and shape, but not to disordered eating symptoms in those with a history of AN. Reflection on eating, weight, and shape were associated with the symptoms in those with AN. Therefore, only ruminative brooding in the healthy sample and reflection in those with AN predicted disordered eating symptoms. This finding may be explained by the notion that the relationship between experiential avoidance, mindfulness, and disordered eating symptoms may be impacted by depression and anxiety, which are frequently comorbid with eating disorders (Kaye, Bulik, 
Thornton, Barbarich, \& Masters, 2004) and are thought to contribute to most psychological disorders (Bishop et al., 2004; Hayes \& Feldman, 2004).

Mindfulness is also related to, but distinct from, psychological flexibility (Masuda, Anderson, \& Sheehan, 2009), which is the ability to consciously and non-judgmentally connect with the present moment, while also engaging in value-driven behaviors (Lavender et al., 2011). Masuda et al. (2012) examined the relationship between mindfulness, psychological flexibility, psychological distress, and eating disorder cognitions. The authors found that disordered eating cognitions were related to increased levels of psychological distress and that higher levels of mindfulness and psychological flexibility were related to decreased levels of psychological distress. However, they found that neither mindfulness nor psychological flexibility moderated the relationship between disordered eating cognitions and psychological distress. This finding suggests that aspects of disordered eating cognitions explain psychological distress that is distinct from mindfulness or psychological flexibility. The positive relationship between disordered eating cognitions and behaviors appear to be dependent upon mindfulness, such that higher levels of mindfulness weaken the association of disordered eating cognitions and behaviors.

Disordered eating behaviors. There are three primary types of eating patterns characteristic of eating disorders, including restrained, emotional, and external eating (Van Strien, Frijters, Bergers, \& Defares, 1986). Restrained eating is characterized by evaluative cognitions about appearance that drive restrictive eating behaviors (Spangler, 2002). External eating is defined as eating in response to external cues, rather than internal cues, such as satiety and hunger (Conner, Fitter, \& Fletcher, 1999). Emotional eating refers to a pattern of eating in response to distressing or negative emotions (Van Strien et al., 1986). 
Mindfulness can counteract the damaging effects of restrained, emotional, and external eating. For restrained eating, mindfulness promotes acceptance and decreases judgment by reducing identification with them. For emotional eating, mindfulness encourages the experiencing of emotions and reduces the use of avoidance coping strategies. Regarding external eating, mindfulness directs attention internally to thoughts, emotions, and bodily sensations and strengthens attention for these cues (Kristeller \& Hallett, 1999).

In addition, food cravings have been linked to the development of obesity (Schlundt, Virts, Sbrocco, \& Pope-Cordle, 1993) and eating disorders (Mitchell, Hatsukami, Eckert, \& Pyle, 1985). They consist of an intense desire to eat certain foods (Weingarten \& Elston, 1991). Alberts et al. (2012) examined the impact of a mindfulness program on food cravings in a nonclinical sample of overweight and obese adult women. They found that individuals experienced a significant reduction in food cravings after taking part in a seven-week mindfulness-based treatment intervention.

Mindfulness interventions for eating disorders. Traditional mindfulness practices have been modified and incorporated into medical and mental health interventions (Baer et al., 2006), including mindfulness-based stress reduction (MBSR; Kabat-Zinn, 1982, 1990), mindfulness-based cognitive therapy (MBCT; Segal, Williams, \& Teasdale, 2002), dialectical behavior therapy (DBT; Linehan, 1993a, 1993b), acceptance and commitment therapy (ACT; Hayes, Strosahl, \& Wilson, 1999), and substance abuse relapse prevention (Marlatt \& Gordon, 1985; Parks, Anderson, \& Marlatt, 2001). All of these treatment approaches consider mindfulness to be a set of skills that can be attained and used to reduce psychological symptoms and promote health and well-being (Baer et al., 2006). 
Mindfulness-based stress reduction (MBSR) is the most commonly used mindfulnesstraining program (Neff \& Germer, 2013). It is an experiential program that involves a curriculum of formal and informal group mindfulness and meditation exercises over eight weekly sessions and a half-day retreat (Kabat-Zinn, 1982). Mindfulness-based cognitive therapy (MBCT), a variant of MBSR, is also widespread and includes psychoeducational and experiential domains, such as meditation, the body scan, mindful eating, self-acceptance, and the paradox of control (Segal et al., 2002). In meta-analytic reviews, both of these modalities have demonstrated positive physical and psychological outcomes in diverse populations (Chiesa \& Seretti, 2009; Hoffman, Sawyer, Witt, \& Oh, 2010), as well as increases in self-compassion (Birnie, Speca, \& Carlson, 2010; Shapiro, Brown, \& Biegel, 2007).

Alberts et al. (2012) studied the effect of an eight-week MBCT intervention on body mass index (BMI), body image concern, dichotomous thinking, food cravings, and eating behavior. They delivered a mindfulness-based eating program based off of Mindfulness-Based Cognitive Therapy (MBCT) by Segal et al. (2002) to a non-clinical sample of adult women. Those individuals who participated in the program reported significantly lower levels of body dissatisfaction, dichotomous thinking, food cravings, emotional eating, and external eating, compared to the waitlist control group. The intervention group also demonstrated a greater increase in trait mindfulness after completion of the program. There was a decrease in BMI at post-test; there was a significant reduction of BMI for those in the control group and a marginally significant reduction for those in the experimental group. Restrained eating increased for both the experimental and control groups. However, these results suggest that increasing mindful awareness and acceptance of internal experiences related to eating, self-acceptance, and emotion regulation may be helpful in decreasing disordered eating behaviors. 
Mindfulness is a fairly new treatment approach for BED and may be beneficial, particularly when provided in addition to cognitive-behavioral modalities. Woolhouse, Knowles, and Crafti (2012) examined the effectiveness of a 10-week mindfulness-CBT group therapy treatment in a sample of women with binge eating problems. They found significant reductions in binge eating and dieting, as well as significant increases in body satisfaction. The authors also conducted interviews with some of the participants after completion of the treatment, specifically assessing what changes the women attributed to the mindfulness aspect of the intervention. Women identified the practice of mindful eating as the most helpful aspect of the program, noting that they believed it helped to decrease the frequency and severity of binge episodes. Participants also shared that the practice of mindfulness positively influenced their overall quality of life and ability to regulate emotions. Woolhouse et al. (2012) examined those specific aspects of mindfulness that were particularly useful in promoting change. Participants reported that being in the present moment, moving from avoidance to awareness, gaining control and choice, and movement from self-punishment to self-kindness all contributed to a positive impact on their well-being. Overall, participants reported that the mindfulness components of the treatment were more helpful than the cognitive-behavioral aspects, which suggests that mindfulness-based approaches may be useful in the treatment of BED and related disorders.

\section{Self-Compassion}

Western research has focused heavily on empirical work related to compassion for others; however, more recent efforts have begun to explore self-compassion (Neff, 2003a). Compassion involves seeking to relieve others' and one's own distress (Neff, 2003a; Neff, 2003b). Relatedly, Neff (2003a) proposed that self-compassion entails three interconnected components: (a) demonstrating understanding and kindness to oneself, rather than being self-critical; (b) viewing 
one's own imperfection as an inevitable aspect of the human condition, rather than seeing it as an isolating experience; and (c) being mindfully aware of one's distressing thoughts and emotions, rather than avoiding or overidentifying with them.

Demonstrating self-kindness entails providing empathy, warmth, sensitivity, and forgiveness to all parts of the self, including one's thoughts, emotions, behaviors, and impulses (Gilbert \& Irons, 2005; Neff, 2003a). A position of self-kindness views worth as unconditional and, despite failures, extends affirmation that one's self is deserving of happiness, affection, and love (Barnard \& Curry, 2011). Conversely, a stance of self-judgment depreciates aspects of self (Neff, 2003a) or rejects one's thoughts, emotions, behaviors, and impulses (Brown, 1998). The nature of self-judgment is unremitting (Whelton \& Greenburg, 2005) and can evoke distress equivalent to or beyond that elicited by the particular circumstance (Germer, 2009).

Viewing one's imperfection as a part of common humanity involves acknowledging one's connection to others, namely in times of tragedy, confusion, and weakness, while extending forgiveness to one's self for being human and flawed (Neff, 2003a). In times of frustration and pain, many individuals feel isolated from others and those who ascribe shame to their shortcomings or to themselves often try to hide their true self (Barnard \& Curry, 2011).

The last component, being mindfully aware of one's distressing thoughts and emotions, entails observing and labeling one's cognitive and emotional experiences instead of responding to them (Kabat-Zinn, 2003). Mindfulness is expected to aid one in experiencing and learning from the present moment without becoming distracted by concerns about the past or future or any type of self-evaluation (Neff, 2003a). However, avoidance of, or overidentification with, cognitive and emotional content can prevent mindfulness (Barnard \& Curry, 2011). Avoidance of distressing thoughts, feelings, and experiences can exacerbate negative emotional states and 
hinder understanding (Germer, 2009). Overidentification, which involves rumination about one's imperfection, can magnify the meaning of failures (Neff, Hsieh, \& Dejitterat, 2005; Shapiro et al., 2007) and detract from experiencing the present moment (Gilbert \& Procter, 2006; Neff \& Vonk, 2009).

Initial research regarding self-compassion demonstrates that those individuals who exhibit greater self-compassion report higher levels of happiness, relational connectedness, and overall satisfaction with life, as well as lower levels of shame, fear of failure, depression, and anxiety (Mills, Gilbert, Bellew, McEwan, \& Gale, 2007; Neff et al., 2005; Neff, Rude, et al., 2007; Williams, Stark, \& Foster, 2008). Likewise, positive relationships have been found between self-compassion and optimism, agreeableness, extroversion, social connectedness, emotional intelligence, and personal initiative and negative relationships to neuroticism, rumination, self-criticism, and thought suppression (Neff, 2003a; Neff, Kirkpatrick, et al., 2007; Neff, Rude, et al., 2007).

Interrelatedness of self-compassion facets. There is some lack of clarity about whether Neff's (2003a) definitions suggest that the three components of self-compassion are innately connected or that they are simply positively related and stimulate one another. Nonetheless, Barnard and Curry (2011) posited that these three aspects engender one another. Self-kindness stimulates a sense of shared experience and mindfulness, a sense of shared experience inspires self-kindness and mindfulness, and mindfulness encourages self-kindness and connection to humanity.

As mentioned, self-kindness may promote both common humanity and mindfulness. If individuals are empathic, sensitive, and forgiving of themselves, they may refrain from ascribing shame to their imperfections and may connect with other individuals, recognizing that others 
share similar faults and struggles (Brown, 1998). Self-kindness also has the potential to encourage mindfulness, in that kindness towards the self allows one to remain in a distressing present and assume a realistic, balanced view (Barnard \& Curry, 2011). In contrast to selfjudgment, which promotes a focus on past failures or related future fears and undermines the present moment, self-kindness fosters patience and understanding toward the perceived lacking aspects of self. In addition, a posture of self-kindness permits nonjudgmental observation of internal dialogue, devoid of critical and judgmental mental processes (Greenburg \& Watson, 1998).

Likewise, common humanity may encourage self-kindness and mindfulness (Barnard \& Curry, 2011). Those individuals who feel a sense of connection with others may be less harsh in their judgments about their own shortcomings and may accept these imperfections as an innate condition of the human experience. Similarly, common humanity can also encourage mindfulness, such that those who are connected to others may view failures as less threatening and, therefore, are less likely to be overidentified with or avoided (Barnard \& Curry, 2011).

Lastly, mindfulness also has the potential to promote self-kindness and common humanity. Mindful observation and nonjudgmental labeling of weaknesses or failures may help individuals to identify with the humanity of others and may prevent self-degradation. On the contrary, overidentification with distressing thoughts, emotions, behaviors, or failures may evoke shame and prevent individuals from being connected to others (Neff, 2003a).

Self-compassion and well-being. Recent research by Neff (2009a, 2009b, 2009c) has shown a relationship between self-compassion and psychological well-being, including such constructs as optimism, happiness, and conscientiousness, as well as decreases in anxiety, depression, and rumination. Hall, Row, Wuensch, and Godley (2013) examined the link between 
self-compassion and physical and psychological well-being. Self-compassion, in this study, adhered to Neff's (2003a, 2003b) definition, which includes the facets of self-kindness versus self-judgment, common humanity versus isolation, and mindfulness versus over-identification. Hall et al. (2013) found that self-compassion was associated with both psychological and physical well-being; however, each facets' relationship to both types of well-being varied. Selfkindness and mindfulness were significantly and positively related to physical well-being. Regression analyses showed that both self-kindness and common humanity were predictive of physical well-being; however, mindfulness was not. In addition, common humanity suppressed extraneous variance, which served to enhance the predictive power of self-kindness. Therefore, self-kindness was the key predictor in physical well-being. This suggests that when individuals exhibit greater self-compassion, they are more likely to engage in healthy behaviors and are more inclined to attend to physical needs.

These findings align with Gilbert and Irons' (2005) postulation that self-compassionate behavior activates the oxytocin-opiate system, which reduces the body's threat system and promotes physical well-being. In line with previous research, these individuals may be more apt to ruminate about their weaknesses and, in doing so, isolate from others (Martell, Dimidjian, \& Herman-Dunn, 2010; Nolen-Hoeksema, Wisco, \& Lyubomirsky, 2008). Additionally, the three facets of self-compassion were significantly related to perceived stress (Hall et al., 2013), suggesting that self-judgment may detract from individuals' ability to implement helpful coping strategies in the presence of stress. As the isolation component increased, effective management of stress decreased. In line with previous research (Fredrickson, 2001; Tugade \& Fredrickson, 2004), social support promoted the use of helpful coping strategies in response to stress. Furthermore, the mindfulness facet significantly predicted adaptive management of stress, 
implying that mindfulness can serve as a productive means to managing stress, which supports previous research (Kabat-Zinn, 1990; Shapiro, Astin, Bishop, \& Cardova, 2005).

Likewise, self-compassion also has shown inverse relationships to negative affect and symptoms of anxiety and depression (Neff, Rude, et al., 2007; Neff \& Vonk, 2009). In a study with undergraduate students, Neff and Vonk (2009) found that, even when self-esteem was controlled for, self-compassion positively related to positive emotion. Additionally, Neff, Kirkpatrick, et al. (2007) conducted a study that utilized a two-chair gestalt technique, designed to increase participants' self-compassion. They found that such increases were negatively related to symptoms of anxiety and depression. In an earlier study by Neff et al. (2005), the relationship between self-compassion and symptoms of anxiety and depression were partially mediated by increased competence and a decreased fear of failure. In an examination of selfcompassion and anxiety by Raes (2010), levels of self-compassion were partially mediated by the extent of participants' worry and rumination. The relationship between self-compassion and depression was partially mediated by lower levels of coherence, or the sense the life is unmanageable and deficient of meaning (Ying, 2009), as well as by worry and brooding (Raes, 2010).

Self-compassion and eating disorders. There is a dearth of literature related to selfcompassion and body image disturbance and disordered eating patterns (Webb \& Forman, 2013). However, some research suggests that greater self-compassion is correlated with healthy body image (Ferreira, Pinto-Gouveia, \& Duarte, 2011; Wasylkiw, MacKinnon, \& MacLellan, 2012) and decreased guilt about consuming restricting foods (Adams \& Leary, 2007). Self-compassion offers kindness to oneself, namely during distressing emotional experiences (Baer, 2010; Germer, 2009; Neff, 2003a). 
Disordered eating behaviors can function as a means of managing internal and external threats and attempting to create a safe social environment, by avoiding criticism or rejection due to body shape and weight, in those women who are sensitive to such bodily scrutiny, view themselves as socially inferior, or who endorse high levels of shame (Goss \& Gilbert, 2002). Because self-compassion entails meeting one's thoughts, emotions, and experiences with a sense of empathy, kindness, and shared humanity (Neff, 2003a, 2003b), it can be seen as an adaptive way to regulate negative affect and potential threat (Gilbert, 2005, 2009a). Self-compassion promotes safety and encouragement to strive towards greater well-being (Neff, 2004). When such a posture is taken with views about the body, women can experience greater connectedness, in that there is recognition of shared, negative body-related experiences that do not require suppression or change, but rather validation and acceptance (Berry, Kowalski, Ferguson, \& McHugh, 2010).

Ferreira et al. (2013) conducted a study examining whether self-compassion emerges as a mediator between body image dissatisfaction, drive for thinness, and external shame in a sample of women both with and without an eating disorder. Those women with eating disorders reported significantly higher levels of self-critical judgment, external shame, depressive and anxiety symptoms, body dissatisfaction, and drive for thinness, as well as lower levels of selfcompassion when compared to the nonclinical sample. Conversely, in the nonclinical sample, external shame, drive for thinness, body dissatisfaction, and psychopathological symptoms were all negatively associated with self-compassion. However, correlations between variables were stronger in the group with eating disorders. In both groups, self-critical judgment was significantly and positively related to all variables. External shame predicted drive for thinness and self-compassion in both groups. In the nonclinical group, body dissatisfaction predicted 
greater drive for thinness and lower levels of self-compassion. In the eating disorder sample, body dissatisfaction predicted higher levels of drive for thinness and this was partially mediated by levels of self-compassion. Therefore, higher levels of self-compassion were associated with lower levels of body dissatisfaction and less involvement in disordered eating behaviors, with relationships stronger in the clinical sample.

Rumination. Just as self-compassion is positively related to mindfulness, it is also negatively related to avoidance, thought suppression, and rumination (Neff et al., 2005; Neff, Kirkpatrick, et al., 2007; Neff \& Vonk, 2009; Raes, 2010; Thompson \& Waltz, 2008). Neff, Kirkpatrick, et al. (2007) examined self-compassion and rumination in undergraduate students over a one-month time period. They found that increases in self-compassion over the interval were associated with decreases in rumination, thought suppression, and avoidance. Likewise, Raes (2010) found that self-compassion was negatively correlated with rumination.

Shame. Shame is defined as painful emotion elicited from viewing the self as damaged, weak, and repulsive, and believing that others also view the self in this way (Tangney \& Dearing, 2002). Eating disorders have been conceptualized as 'disorders of shame' (Kaufman, 1989), as individuals with these disorders tend to be highly critical of their weight, shape, and eating behavior, frequently adhering to inflexible eating rules and engaging in compensatory behaviors (Kelly et al., 2013). Compared to other psychiatric groups (Cook, 1994) and healthy samples (Swan \& Andrews, 2003), those with eating disorders typically endorse higher levels of shame.

In modern cultures, there is a high value placed on self-control. However, a loss of selfcontrol, which is associated with eating disorders, ultimately promotes feelings of shame (Skarderud, 2003). Those with AN may feel ashamed of their bodies' need for food and 
generally endorse feelings of disgust after losing control through even minimal food consumption (Goss \& Gilbert, 2002). The secretive behaviors associated with BN and BED may reflect an attempt to avoid repulsing others with abnormal eating practices, but the binging and/or compensatory strategies subsequently intensify feelings of self-disgust (Keith, Gillanders, $\&$ Simpson, 2009). Therefore, even though disordered eating symptoms can temporarily relieve distressing emotions, they ultimately preserve feelings of shame (Kelly et al., 2013).

Gilbert (2005) suggested that shame could be counteracted by self-compassion. Selfcompassion is an unconditional type of self-regard that permeates instances of disappointment and failure (Gilbert, 2005, 2009b; Neff \& Vonk, 2009). It is a healthy modality to regulate shame because it mirrors compassion imparted to others (Gilbert, 2005, 2009b).

Magnus, Kowalski, and McHugh (2010) examined levels of trait self-compassion and motivation for exercising in undergraduate women. They found that those females who endorsed higher levels of self-compassion were more prone to engaging in exercise for intrinsic reasons, such as fun, joy, and fulfillment. Conversely, those who reported lower levels of selfcompassion were more likely to exercise for extrinsic reasons, such as to gain esteem from others and to avoid judgment, as well as for introjected reasons, such as to avoid feeling shame or guilt. In addition, Adams and Leary (2007) found that after self-compassionate priming, disinhibited eating after breaking a dietary rule was reduced. The results from these two studies indicate that self-compassion in non-clinical samples might promote more adaptive eating and exercise patterns. However, individuals with eating disorders are typically less inclined to provide themselves with self-compassion (Kelly et al., 2013).

Fear of self-compassion. Extending self-compassion can be a challenging experience for some individuals. There is evidence that people vary in the degree to which they fear self- 
compassion, and such fear is elevated in those individuals susceptible to psychopathology (Kelly et al., 2013). Those who are more fearful of self-compassion are less likely to demonstrate selfcompassion and more likely to be self-critical, anxious, and depressed (Gilbert, McEwan, Matos, \& Rivis, 2011; Gilbert, 2012).

Kelly et al. (2013) sought to test Gilbert's (2005) theoretical model of self-compassion, shame, and fear of self-compassion in a population with eating disorders. They found that those taking part in day hospital and inpatient treatment programs who reported higher selfcompassion endorsed lower levels of shame and less eating disordered pathology, while those who reported higher fear of self-compassion endorsed greater shame and more severe eating pathology. Kelly et al. (2013) also found that baseline trait self-compassion and fear of selfcompassion interacted to predict shame over the course of the 12 weeks of treatment. Individuals lower in self-compassion and higher in fear of self-compassion did not significantly change in terms of eating disorder behavior, which was different from the improvements seen in other participants. Furthermore, those higher in self-compassion experienced a reduction in disordered eating symptoms over the course of treatment, independently of their fear of selfcompassion; however, those with lower self-compassion experienced a decrease in symptoms only if fear of self-compassion was reasonably low. These findings indicate that the combination of fear of self-compassion and low trait self-compassion might interact to hinder treatment of eating disorders.

Self-compassion interventions for eating disorders. Gilbert (2010) developed compassion-focused therapy (CFT), a general therapeutic approach to enhancing selfcompassion. The primary goal of CFT is to help individuals develop and provide themselves with a sense of warmth and emotional responsiveness. A variety of exercises are used to 
accomplish this goal, including visualization, developing self-kindness through language, and engaging in self-compassionate behaviors. A pilot study of the treatment included individuals in a hospital day treatment program who struggled with self-criticism and shame. The results showed significant decreases in self-attacking, shame, feelings of inferiority, and depression (Gilbert \& Procter, 2006). CFT is currently being used in the treatment of eating disorders, depression, bipolar disorder, and other psychological disorders (Gilbert, 2010; Goss \& Allan, 2010; Kelly, Zuroff, \& Shapira, 2009; Lowens, 2010).

Neff and Germer (2013) developed the Mindful Self-Compassion (MSC) program, which is modeled off of the MBSR program and is intended for clinical and non-clinical populations. The main goal of this approach is to help individuals increase self-compassion and mindfulness, with mindfulness skill development being a secondary aim. The MSC program consists of eight weekly sessions and a half-day meditation retreat. A variety of formal and informal experiential self-compassion activities are used to enhance self-kindness. A pilot study of the intervention included a non-clinical sample of individuals who were interested in taking part in the training program. Neff and Germer (2013) found that the MSC program was associated with significant increases in self-compassion, mindfulness, happiness, and life satisfaction, as well as significant decreases in anxiety, stress, and depression, all of which were maintained at six-month followup.

\section{Emotion Regulation}

Emotion regulation consists of those extrinsic and intrinsic processes individuals use to influence their psychological experiences and the ways in which they experience and express emotions (Masuda et al., 2012). These processes involve the experiencing, differentiating, offsetting, and controlling emotional states (Gratz \& Roemer, 2004; Gratz \& Tull, 2010). 
Adaptive emotion regulation typically indicates the use of strategies that aid in managing unfavorable emotions in such a way that prevents emotions from interfering with the attainment of goals (Bridge et al., 2004). Such regulation helps individuals respond to emotional distress, rather than trying to control or inhibit it (Gratz \& Roemer, 2004). However, deficits in adaptive emotion regulation strategies may cause negative affective states to persist with greater intensity and duration and may also lead to feelings of loss of control over emotions, causing the individual to feel as though their emotions will continue to impair their well-being (Berking \& Whitley, 2014). Such a conceptualization is consistent with theories of anxiety disorders (Roemer et al., 2009), substance use disorders (Fox, Hong, \& Sinha, 2008), and personality disorders (Bornovalova et al., 2008).

Gross (1998) developed a process model of emotion regulation. He posited that regulation of affect begins with an appraisal of emotional cues, which can activate corresponding behavioral and physiological response tendencies. When these responses are initiated, they can be regulated in numerous ways. Situation selection refers to avoidance of particular people, places, or events that may elicit negative emotions. After a situation is selected, situation modification is a means by which an individual can alter a situation, in order to decrease its emotional impact. Because situations may consist of various aspects, attentional deployment is a way of focusing on those aspects that are less negative. When a particular aspect becomes the focus, cognitive change can be employed to create a more positive meaning about the situation. Lastly, response modulation is a general way of influencing emotional responses once they are stimulated.

Gratz and Roemer (2004) proposed a multidimensional model of emotion regulation that consists of four aspects, including (a) flexible use of helpful strategies to regulate the intensity 
and duration of emotions; (b) maintaining behavior control over aversive affective states; (c) acceptance, clarity, and acceptance of emotions; and (d) willingness to experience painful emotions in order to pursue goals (Gratz, 2007; Gratz \& Tull, 2010). According to this model, deficits in at least one of these dimensions are considered to constitute emotion dysregulation.

Emotion dysregulation is a psychological factor that is gaining attention in the eating disorder literature (e.g., Hayaki, 2009; Lavender \& Anderson, 2010; Safer, Telch, \& Chen, 2009). The emotion regulation model of eating disorders theorizes that eating disordered behaviors, such as binge eating and purging, serve the function of reducing or avoiding negative affective or cognitive experiences (Heatherton \& Baumeister, 1991; Wiser \& Telch, 1999) and has been empirically validated (Deaver, Miltenberger, Smyth, Meidinger, \& Crosby, 2003; Engelberg, Steiger, Gauvin, \& Wonderlich, 2007; Hilbert \& Tuschen-Caffier, 2007; Smyth et al., 2007).

Emotion regulation and eating disorders. Researchers have recently begun exploring the relationship between emotion regulation and eating disorders (e.g., Aldao \& NolenHoeksema, 2010). Current etiological models of eating disorders highlight the impact of emotion regulation difficulties as a transdiagnostic factor (Fairburn et al., 2003; Treasure, Corfield, \& Cardi, 2012). Emotion regulation difficulties and the experiencing of negative emotions are thought to be significant contributors to the maintenance of these disorders (Harrison, Sullivan, Tchanturia, \& Treasure, 2010).

Prior research has shown difficulties in experiencing and differentiating emotions in AN (Brockmeyer et al., 2012a), BN (Harrison et al., 2010), and BED (Zeeck, Stelzer, Linster, Joos, \& Hartmann, 2011), as well as impaired abilities to offset and regulate emotions in these disorders (Brockmeyer et al., 2012b; Svaldi, Caffier, \& Tuschen-Caffier, 2010). Lavender and 
Anderson (2010) found that emotion dysregulation, indicated by non-acceptance of negative affect and an inability to access and employ adaptive emotion regulation strategies, explained the unique variance in general eating disorder symptoms in a sample of undergraduate students, after accounting for negative affect and BMI. Likewise, Harrison et al. (2010) found that, in general, individuals with eating disorders reported greater deficits in emotional arousal, awareness, understanding, acceptance of emotions, and the ability to act in desired ways regardless of an emotional state, as demonstrated by the Difficulties in Emotion Regulation Scale (DERS; Gratz \& Roemer, 2004), compared to a healthy sample.

More specifically, Wildes, Ringham, and Marcus (2010) studied emotion regulation in individuals with AN. They found that those with AN engaged in emotional avoidance at levels similar to individuals with social phobia and avoidant personality disorder. Such avoidance strategies have also been found in individuals endorsing bulimic symptoms (Lavender et al., 2009). Lavender et al. (2009) studied the impact of thought suppression on binge-purge episodes in a sample of undergraduate males and females. They found that this maladaptive emotion regulation strategy accounted for a significant amount of variance in bulimic symptoms, even after controlling for BMI.

There is an established relationship between negative emotion and binge episodes in BN and BED (Haedt-Matt \& Keel, 2011; Hilbert \& Tuschen-Caffier, 2007). Binge eating may be seen as an attempt to escape from awareness of aversive states, which increases the desire to eat (Alpers \& Tuschen-Caffier, 2001; Heatherton \& Baumeister, 1991). However, individuals may engage in binge episodes to try to decrease the intensity of aversive affective states (Deaver et al., 2003), which often leads to binging and purging behaviors (Evers, Stok, \& de Ridder, 2010). Likewise, Schmidt and Treasure (2006) hypothesized that individuals with AN may engage in a 
mental focus on food and eating to aid in decreasing the prominence of emotions. However, most of the previous research related to emotion regulation and eating disorders has neglected to distinguish between subtypes of eating disorders (Brockmeyer et al., 2014).

A common explanation for disordered eating behaviors is that individuals with these disorders have difficulty regulating emotions productively and employ maladaptive strategies to offset aversive emotions (Heatherton \& Baumeister, 1991). They may either lack access to emotion regulation strategies (Aldao et al., 2010; Harrison et al., 2010; Svaldi et al., 2012) or may employ maladaptive ones (Danner, Evers, Stok, Elburg, \& Ridder, 2012; Racine \& Wildes, 2013; Smyth et al., 2007). Aldao et al. (2010) suggested that those with AN restricting type tend to limit caloric intake, while those with $\mathrm{AN}$ binge-purge type, $\mathrm{BN}$, and BED engage in emotional eating as a means to regulate emotions because they lack other helpful means of doing so. As these individuals attempt to regulate their emotions and use more unproductive strategies, symptom severity typically increases (Aldao et al., 2010; Forbush and Watson, 2006; Harrison et al., 2010).

Specific dimensions of emotion regulation. Prior research related to emotion regulation in eating disorders has highlighted the role of impulse control, cognitive reappraisal, emotional suppression, and the experiencing of specific emotions (Anestis, Selby, Fink, \& Joiner, 2007; Lavender \& Anderson, 2010; Whiteside et al., 2007).

Impulse control. Impulse control may be one factor of emotion regulation in which differences between subtypes exist (APA, 2014). Those disorders that exhibit bulimic-type symptoms (i.e., AN binge-purge type, BN, and BED) were found to demonstrate higher levels of impulsive eating behavior than disorders without these symptoms (i.e., AN restrictive type), which may reflect an attempt to obtain comfort from aversive affective states (Smyth et al., 
2007). However, there may be further distinctions between impulse control and eating disorder subtypes that include binge episodes. Studies using neuropsychological tests have found increased impulsive decision-making and weakened inhibitory control in AN binge-purge type (Cavedini et al., 2006) and BN (Kemps \& Wilsdon, 2010), but not in BED (Danner et al., 2012). Likewise, Latner and Clyne (2008) found that, compared to a sample of individuals with BN, binge episodes in those with BED were longer in duration and occurred less frequently. Because impulsivity appears to be a multifaceted construct (Friederich, Wu, Simon, \& Herzog, 2013), findings may vary depending on the subcomponent being examined. Nonetheless, inhibitory control may be a major factor in the regulation of emotional arousal and impulses.

Brockmeyer et al. (2014) examined differences in emotion regulation difficulties across the spectrum of eating disorders. They found that people across all of the eating disorder subtypes reported significantly more emotion regulation difficulties than healthy controls, as evidenced by greater difficulties in experiencing and differentiating emotions, as well as impaired abilities to offset and regulate emotions. They also found that people with AN bingepurge type, but not BN nor BED, endorsed greater difficulties in impulse control than the AN restricting type. This suggests that there are differences between AN subtypes, which is consistent with prior findings. However, the finding that BN and BED did not significantly differ from AN restricting type is contrary to prior research that demonstrated an association between impulsivity and bulimic symptoms (Fisher, Smith, \& Cyders, 2008), which may suggest that impulse control in the context of eating disorders may extend beyond impulsive eating. Although this study only included females and did not account for differences in previous or current treatment these participants were receiving, it provided support for the notion that there may be differences in emotion regulation abilities within AN, namely related to impulse control. 
Cognitive reappraisal and emotional suppression. One particularly common emotion regulation strategy is cognitive reappraisal (Gross \& John, 2003; Richards \& Gross, 2000), which refers to re-interpreting a situation in a way that reduces the negative emotional impact of it. It often takes place prior to an emotionally-laden situation and, therefore, reduces a situation's emotional impact when it occurs. Cognitive reappraisal may correct negatively biased information processing and, therefore, reduce negative affect (Aldao et al., 2010). However, the maladaptive alternative to cognitive reappraisal is emotional suppression (Gross \& John, 2003; Richards \& Gross, 2000). Suppression of emotions reduces emotional expression (Gross, 2002) and involves more physiological arousal than the actual experiencing of emotions.

Aldao et al. (2010) conducted a meta-analysis that examined emotion regulation strategies in various psychopathological disorders, including eating disorders. Although they did not differentiate between eating disorder subtypes, they found a small effect size for impaired cognitive reappraisal abilities and a lack of productive emotion regulation strategies in those individuals with eating disorders. Danner et al. (2012) studied the relationship between emotional eating, cognitive reappraisal, and eating pathology in a sample of adult women with and without an eating disorder. They found that women who exhibited binge-purge symptoms endorsed limited use of cognitive reappraisal and engaged in emotional eating more frequently than those individuals who exhibited food restriction behaviors. In addition, the combination of limited cognitive reappraisal and emotional eating was associated with increased symptom severity, an interaction effect that was not found in the non-clinical or restricting-type groups.

Danner, Sternheim, and Evers (2014) compared the use of emotional suppression and cognitive reappraisal in a sample of adult women with $\mathrm{AN}, \mathrm{BN}$, and $\mathrm{BED}$, in order to replicate the findings of Svaldi et al. (2012). In addition, the authors sought to distinguish between 
emotion regulation strategies of restricting type and binge-purge type in those with AN. They found that participants of all eating disorder subtypes suppressed their emotions to a greater degree than those in the control group. Likewise, they found that participants in the healthy control group were more likely to employ cognitive reappraisal than those women with an eating disorder. There was also a positive association between emotional suppression and level of depression. Although no participants who used antidepressant medications were included, which could bias results, women with BED endorsed more symptoms of depression and anxiety than the control group but reported lower levels than those with $\mathrm{AN}$ and BN. These participants were also less likely to engage in emotional suppression than $\mathrm{AN}$ and $\mathrm{BN}$, which may be due to decreased mood disturbances.

Specific emotional experience. Fox and Power (2009) developed a theoretical model of eating disorders that focuses on the influence of emotions on symptomatology. Their model (SPAARS-ED) is based on the Schematic Propositional Analogical Associative Representation System (SPAARS; Power \& Dalgleish, 2008) and posits that all basic emotions, including happiness, sadness, fear, anger, and disgust, connect to an appraisal of an event and trigger a response from the individual experiencing the emotion. From this model, if a particular emotion is deemed unacceptable, it may become ego-dystonic and the individual may dissociate from it. In addition, various emotions can intersect and become helpful or hindering. For example, Fox and Power (2009) theorized that the experience of disgust is an automatic and over-learned emotion in those with eating disorders and may be used to prevent the experiencing of more painful emotions.

Espeset, Gulliksen, Nordbø, Skårderud, and Holte (2012) examined the ways in which individuals with AN manage negative behaviors and connect their emotion regulation efforts to 
their disordered eating behaviors. Through the use of interviews, the authors obtained information about how 14 women obtaining treatment for AN managed negative emotions and how they connect those experiences to their symptoms. The sample was heterogeneous, with variability in ages, subtypes, duration of the disorder, treatment history, and current stages of recovery. Overall, participants described their focus on body and food as a way to avoid aversive emotions. Likewise, they endorsed avoiding circumstances that could elicit emotions, such as social interactions and situations that brought attention to the body or food. Participants also reported using food intake or exercising as a means to reduce or release negative emotion.

Additionally, the authors found that the women described different relationships to each of the emotions. Participants tended to suppress emotions of sadness and anger in social situations, but tended to exhibit high levels of these emotions towards themselves and their bodies. Individuals in the study also tended to connect emotions in particular ways. It was found that sadness and fear were translated into body dissatisfaction and disgust, which is consistent with prior research findings that self-disgust is a key factor in the maintenance of eating disorders (Fox \& Power, 2009). More specifically, sadness was related to symptoms of depression, hopelessness, and body dissatisfaction. Anger was described as an emotion that was difficult to control and inhibit, with it typically being directed inwards and manifested as excessive self-control and self-harm. Participants also reported a link between fear and eating disordered behaviors, such as restrictive eating, purging, and body checking.

Subtype distinctions. There are conflicting findings regarding emotion regulation differences between AN, BN, and BED. Svaldi et al. (2012) assessed emotion regulation strategies in a sample of women with eating disorders and compared findings against a group with other clinical disorders, as well as a healthy control group. They found that participants 
with all eating disorder subtypes endorsed using less adaptive and more unproductive strategies when compared to the healthy group; however, no significant differences between $\mathrm{AN}$, BN, and BED were found.

While there is some evidence for lower levels of emotional awareness in AN than BN (Gilboa-Schechtman, Avnon, Zubery, \& Jeczmien, 2006), other studies found no such differences (Harrison et al., 2010; Svaldi et al., 2012). In addition, prior research has failed to demonstrate differences between $\mathrm{AN}$ and $\mathrm{BN}$ in terms of attenuating and regulating emotions (Harrison et al., 2010; Svaldi et al., 2010). In other studies that have examined differences between $\mathrm{AN}$ and $\mathrm{BN}$ subtypes, individuals with $\mathrm{AN}$ and $\mathrm{BN}$ endorsed greater emotional inhibition than control samples, while those with BN reported higher levels than those with AN (Forbush \& Watson, 2006). There is some support for the notion that individuals with AN and $\mathrm{BN}$ are similar to those with major depressive disorder, in that they exhibit such emotion regulation difficulties as emotional non-acceptance and impaired emotional clarity (Svaldi et al., 2012).

Although less is known about differences between subtypes of AN, some differences in emotion regulation have been found. In the study by Danner et al. (2014), women with AN binge-purge type were less likely to use cognitive reappraisal when experiencing more severe symptoms; however, women with AN restricting type tended to use cognitive reappraisal as their symptoms intensified, highlighting additional differences between these two AN subtypes. AN binge-purge type has also been associated with less inhibitory control (Rosval et al., 2006) and related to increased inattention, reward responsiveness, and impulsive behaviors, including selfinjury (Waxman, 2009). Individuals with AN binge-purge type seems to share features with those who have $\mathrm{BN}$, in that both typically have impulsive personalities, greater frequencies of 
emotional eating, and respond more impulsively to negative emotions (Claes, Vandereycken, \& Vertommen, 2005).

Since there is limited research regarding the relationships between the dimensions of emotion dysregulation and symptoms of BN, Lavender et al. (2014) sought to examine these associations. Overall, findings suggested that high levels of emotion dysregulation were related to disordered eating symptoms. Specifically, the strongest relationship with disordered eating symptoms was behavioral control in emotionally distressing experiences. However, contrary to prior findings (i.e., Racine \& Wildes, 2013), the dimension of lack of emotional awareness was not significantly related to symptoms, which may suggest that there are more averse implications for lack of emotional awareness in $\mathrm{AN}$ than in $\mathrm{BN}$. The authors also found that those individuals with fewer perceived problems in maintaining control of goal-oriented behavior amidst distress engaged in purging more frequently than those with more perceived problems. This finding suggests that, although purging is a maladaptive emotion regulation strategy, it may serve to manage negative emotions in a way that still allows for goal-focused behavior. Conversely, the finding may suggest that other variables that were not accounted for in this study impact this relationship.

\section{Mindfulness, Self-Compassion, and Emotion Regulation}

Self-compassion and mindfulness. It has been proposed that a reciprocal relationship exists between self-compassion and mindfulness, which links self-acceptance with the framework of mindfulness (Germer, 2009; Neff, 2003a; Neff, 2009c). Mindfulness in relation to self-compassion refers to being aware of uncomfortable or painful experiences in a way that neither ruminates over nor ignores unfavorable aspects of oneself or one's life. In order to extend self-compassion, there must be mindful awareness of personal suffering; likewise, one 
must also be able to demonstrate an attitude of non-judgment and acceptance, as is done in mindfulness practices, in order to develop self-compassion (Birnie et al., 2010). However, mindfulness in the context of self-compassion is narrower than the general construct of mindfulness because it refers to attention to negative thoughts and feelings, rather than attention to any experience (Neff \& Germer, 2013). More generally, mindfulness involves awareness and attention to any experience with acceptance and non-judgment. It also emphasizes attention to internal experiences, rather than to oneself as the experiencer. Baer et al. (2006) found moderately strong positive associations between self-compassion and the five factors of mindfulness. Specifically, the strongest positive correlations were found between selfcompassion and the facets of non-judgment and non-reactivity, followed by positive relationships to acting with awareness, observing inner experiences, and describing inner experiences.

Mindfulness and emotion regulation. Within the literature, there is limited information related to variables that are theoretically consistent with the emotion regulation model of eating disorders (Lavender et al., 2011). Mindfulness distinctly overlaps with domains of emotion regulation (Hays \& Feldman, 2004) and can be conceptualized as an adaptive emotion regulation process, marked by increased, non-judgmental awareness of present moment experiences (Chambers, Gullone, \& Allen, 2009). Therefore, it is likely to protect against emotion dysregulation, which is characteristic of eating disorders (Lavender et al., 2011), and may be a potential moderator between disordered eating and emotion regulation (Brown, Lejuez, Kahler, Strong, \& Zvolensky, 2005; Segal, Teasdale, \& Williams, 2004).

Self-compassion and emotion regulation. There is increasing evidence to support the role of self-compassion as an adaptive emotional regulation strategy (Gilbert \& Procter, 2006; 
McBeth \& Camley, 2012; Neff, 2003b) and it has been conceptualized as a helpful approach in self-critical individuals since one of its subcomponents is self-kindness (Gilbert \& Procter, 2006). It is theorized that the intensity of mood states may moderate the effectiveness of particular emotion regulation strategies (Aldao, 2013). Berking and Whitley (2014) postulated that, because negative affective states typically produce negative thoughts, cognitive reappraisal and acceptance may be more difficult strategies to employ as the intensity of an individual's suffering increases. Conversely, self-compassion may become increasingly easier to employ because the observation of suffering is necessary for the prompting of compassion (Hein \& Singer, 2008). 


\section{CHAPTER 2: RESEARCH DESIGN AND METHODOLOGY}

It is believed that mindfulness, self-compassion, and emotion regulation may be significant contributors to the trajectory of eating disorder symptoms (Germer, 2009; Lavender et al., 2011; McBeth \& Camley, 2012). This study aims to determine a model using mindfulness, self-compassion, and emotion regulation as the driving factors in the outcome of eating disorder symptoms. The research hypotheses included the following:

- It is hypothesized that the model, which describes the effects of mindfulness, selfcompassion, emotion regulation, and ED symptoms, will be consistent with observed correlations among these variables.

- It is hypothesized that if there is a high level of mindfulness, there will be an increased level of self-compassion, a decreased level of emotion regulation difficulties, and subsequently less disordered eating pathology.

- It is also hypothesized that if there is a high level of self-compassion, there will be an increased level of mindfulness, a decreased level of emotion regulation difficulties, and subsequently less eating disorder symptoms.

This chapter will describe the research design and methodology that will be employed to test these hypotheses.

\section{Research Design}

As mentioned, the aim of this study was to examine the relationship between mindfulness, self-compassion, and emotion regulation on eating disorder symptomatology. Path Analysis is an extension of multiple regression and aims to provide estimates of the magnitude and significance of hypothesized relationships between sets of variables. Multiple correlation and regression allow for examination of two or more predictors of a single criterion. In 
nonexperimental research, predictor variables are those variables believed to affect another variable or outcome and the criterion variable is the variable being predicted. In this study, the predictor variables are mindfulness, self-compassion, and emotion regulation and the criterion variable is eating disorder symptoms. This statistical modeling technique generates two types of estimates, including the total proportion of criterion variance explained by predictor variables and the relative importance of each predictor variable (Kline, 1998).

However, multiple regression does not allow for a variable to be both a predictor and a criterion variable. Path analysis goes beyond multiple regression, in that it can analyze more complex models that include examination of mediating variables. These variables exist in a chain of influence and explain the relationship between a predictor and a criterion (Streiner, 2005). In path analysis, the terms exogenous and endogenous are often used in place of predictor and criterion, respectively. The variance of exogenous variables is considered to be explained by variables outside of the model, where the variance of endogenous variables is assumed to be explained, in part, by factors in the model. In this study, the exogenous variables are mindfulness and self-compassion and the endogenous variable is eating disorder symptoms. Emotion regulation is considered to be both an exogenous and an endogenous variable. The variance of emotion regulation, in part, was explained by the variables of mindfulness and selfcompassion, whereas the variance of eating disorder symptoms, at least in part, was explained by emotion regulation, mindfulness, and self-compassion. Although this technique has often been termed causal modeling, a limitation is that it cannot confirm causality. Causality can only be proven with the use of experimental or longitudinal studies (Streiner, 2005). Nonetheless, this approach was used in order to examine the direct and indirect relationships among mindfulness, 
self-compassion, and emotion regulation on eating disorder symptoms, where emotion regulation was included as a mediating variable.

All measures in this study yield continuous variables; therefore, no cutoff scores were used. Higher scores on each of the measures reflected a greater association of the targeted variable assessed by the measure, while lower scores suggested a smaller association of the targeted variable assessed by the measure. Since this study drew on correlational data to generate a structural model, there were no conditions or manipulations.

Participants. Participants included undergraduate and graduate students at a large Eastern university in the United States. Inclusion criteria required that participants were at least 18 years of age. In order to increase generalizability of findings, participants could be enrolled either part-time or full-time, could be traditional or non-traditional students, and could be male or female. The study advertisement was solicited to individuals seeking services at the university's counseling center by means of a paper flyer, which was posted at the center. The paper flyer was also posted in a creative arts center on campus and sent electronically to an honors undergraduate course. In addition, the survey was solicited through online postings to the university's online news system. Snowball sampling was used to optimize the number of participants.

Regarding demographic information of students at this university, about $46 \%$ of students are female and 54\% are male (Americas Best Colleges, 2016). Of these students, approximately $83 \%$ are White, $4 \%$ are Black, $4 \%$ are international, $3 \%$ are Hispanic, $3 \%$ are Biracial, $2 \%$ are Asian, and less than $1 \%$ are American Indian/Alaskan Native or Native Hawaiian/Other Pacific Islander (Voluntary Systems of Accounting Program, n.d.). In regards to enrollment status, 92\% are full-time students and 8\% are part-time students (Voluntary Systems of Accounting Program, n.d.). The average age of students is 21 , with $7 \%$ of these students being 25 years of age or older 
(Voluntary Systems of Accounting Program, n.d.). In addition, about 3\% of students take part in varsity athletics (Americas Best Colleges, 2016). It is expected that the demographics of the sample approximate these demographics.

Descriptive Statistics. Descriptive statistics were calculated on the total number of participants, the range of scores, as well as the means, medians, modes, and standard deviations for all survey items and scales. All participant demographic information was also examined and reported. Sex was considered to be a covariate in the analyses, but other demographic variables were also examined. In order to analyze the descriptive statistics, SAS Statistical Software version 9.4 (SAS Institute Inc., 2013) was used.

Path Analysis. A Path Analysis (PA) was used to assess the structure of relationships between each of the variables in the model. It was used because only manifest variables were assessed and only one measure for each variable was used. PA is a multivariate statistical procedure that examines relationships between observed variables. It is an extension of multiple linear regression that focuses on correlational associations of data. As such, causality cannot be inferred. However, this analysis attempted to create a structural model to explain the relationship amongst the variables in the study. A path diagram was created with arrows representing the direct and indirect influences of each of the variables. As mentioned, mindfulness and selfcompassion were exogenous manifest variables, whereas eating disorder symptoms was an endogenous manifest variable. Emotion regulation served as both an exogenous variable and an endogenous variable. The hypothesized model, as well as the direct, indirect, and mediating effects on the outcome variables, was tested. In order to analyze the data using a Path Analysis approach, SAS Statistical Software version 9.4 (SAS Institute Inc., 2013) was used.

The hypothesized model is shown below in Figure 1. 


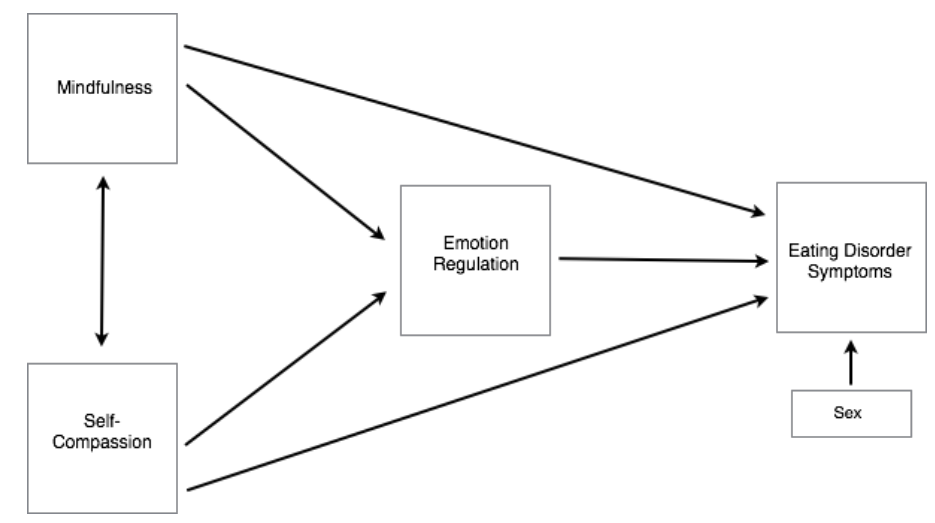

Figure 1. The proposed model of eating disorders for this study.

In the proposed integrated model, mindfulness was examined using the Five Facet Mindfulness Questionnaire (FFMQ; Baer et al., 2006), self-compassion was studied using the Self-Compassion Scale (SCS; Neff, 2003a), emotion regulation was assessed using the Difficulties in Emotion Regulation Scale (DERS; Gratz \& Roemer, 2004), and eating disorder symptomatology was studied using the Eating Attitudes Test-26 (EAT-26; Garner et al., 1982). Each of these measures will be described in greater detail in the measurements section.

It was hypothesized that there is a positive, significant direct path from mindfulness to emotion regulation and a negative, significant direct and indirect path to eating disorder symptomatology. Likewise, it was hypothesized that there is a positive, significant direct path from self-compassion to emotion regulation and a negative, significant direct and indirect path to eating disorder symptoms. Because higher levels of mindfulness and self-compassion are thought to be associated directionally with increased emotion regulation abilities and greater access to related strategies, the model only includes one-way relationships between these variables. It was also hypothesized that there is a negative, significant direct relationship from emotion regulation to eating disorder symptoms. Lastly, it was believed that mindfulness and self-compassion are highly and positively correlated. 
As mentioned, the 12-month prevalence of AN among young females is $0.4 \%$ and the prevalence of $\mathrm{BN}$ among young females is between $1 \%$ and $1.5 \%$ (APA, 2013). While less is known about the prevalence in males, both $\mathrm{AN}$ and $\mathrm{BN}$ are far more common in females than in males (APA, 2013). The 12-month prevalence of BED is approximately $1.6 \%$ among adult females and $0.8 \%$ among adult males (APA, 2013). Sex has also been identified as a fixed marker associated with AN, BN, and BED (DeBate et al., 2010). In addition, studies have found that young adult females have lower levels of self-compassion than their male counterparts (Neff et al., 2005; Neff \& Vonk, 2009; Raes, 2010). Therefore, sex was included as a covariate in this study. It functions as an exogenous variable and impacts sample size and power.

\section{Measures}

Mindfulness. The manifest exogenous variable, Mindfulness is measured by the Five Facet Mindfulness Questionnaire (see Appendix F). High scores on mindfulness are reflective of greater levels of mindfulness. Mindfulness was believed to be highly correlated with selfcompassion and it was hypothesized to have a positive relationship with emotion regulation. Conversely, mindfulness was thought to have a negative relationship with eating disorder symptomatology.

Five Facet Mindfulness Questionnaire (FFMQ; Baer et al., 2006). The FFMQ was developed from a factor analytic study of five mindfulness questionnaires. It assesses five facets of mindfulness, including (a) observing, (b) describing, (c) acting with awareness, (d) nonjudging of inner experience, and (e) non-reactivity to inner experience. The FFMQ is a 39-item instrument that uses a five-point Likert-type scale, with responses ranging from one (never or very rarely true) to five (very often or always true). It contains five subscales corresponding to each facet of mindfulness. The FFMQ has a total score range of 39 to 195, with possible score 
ranges of eight to 40 on the subscales of observing, describing, acting with awareness, and nonjudging of inner experience and a possible score range of seven to 35 on the non-reactivity to inner experience subscale. Higher scores are indicative of greater levels of mindfulness.

The FFMQ was determined to have good psychometric properties in its initial validation study (Baer et al., 2006). Baer et al. (2006) found adequate to good internal consistency, with Cronbach's alphas for the facets ranging from .75 to $.91(\alpha=.75$ for non-reactivity to inner experience; $\alpha=.83$ for observing; $\alpha=.87$ for acting with awareness; $\alpha=.91$ for describing; $\alpha$ $=.87$ for non-judging of inner experience). The authors also found modest and significant correlations between facets, ranging from .15 to .34 , except on the Observing facet, which was non-significant with non-judgment of inner experience. Other studies have also confirmed adequate internal consistency of the FFMQ, with Cronbach's alphas for the five subscales ranging from .67 to .93 (Park, Reilly-Spong, \& Gross, 2013; Williams, Dalgleish, Karl, \& Kuyken, 2014). There is evidence for construct validity for the total FFMQ and related subscales in its positive associations with emotional intelligence, openness, self-compassion, and well-being, as well as its negative associations with anxiety, depression, neuroticism, alexithymia, dissociation, thought suppression, and rumination (Baer et al., 2006; Barnes \& Lynn, 2010; Cash \& Whittingham, 2010; de Bruin, Topper, Muskens, Bogels, \& Kamphuis, 2012; Fisak \& von Lehe, 2012; Hollis-Walker \& Colosimo, 2011; Lavender et al., 2011). In regards to psychological symptoms, de Bruin et al. (2012) found adequate to excellent predictive validity for all facets, except for observing and describing, in a meditating sample $(=-.23$ for non-judging of inner experience; $\beta=-.78$ for non-reactivity to inner experience; $\beta=-.30$ acting with awareness). Subscale scores were added to create a single overall score. 
Self-Compassion. The manifest exogenous variable, Self-Compassion is measured by the Self-Compassion Scale (see Appendix G). High scores on self-compassion are indicative of greater levels of self-compassion. Self-compassion was hypothesized to be highly correlated with mindfulness and it was believed to have a positive relationship with emotion regulation skills. Conversely, self-compassion was thought to have a negative relationship with eating disorder symptomatology.

Self-Compassion Scale (SCS; Neff, 2003a). The SCS measures three facets of selfcompassion, including (a) self-kindness versus self-judgment, (b) common humanity versus isolation, and (c) mindfulness versus over-identification, with each facet containing two separate subscales. The SCS is a 26-item measure that uses a five-point Likert-type scale, with responses ranging from one (almost never) to five (almost always). It has a total score range of 26 to 130 , with possible score ranges of five to 25 on the subscales of self-kindness and self-judgment and possible score ranges of four to 20 on the subscales of common humanity, isolation, mindfulness, and over-identification. Higher scores are reflective of greater levels of self-compassion.

The SCS was determined to have good psychometric properties in its initial validation study (Neff, 2003a). Specifically, the two-factor model of the self-kindness versus self-judgment subscale demonstrated adequate fit for the data $(\mathrm{NNFI}=0.88 ; \mathrm{CFI}=0.91)$ and internal consistency was adequate for both factors ( $\alpha=.78$ for self-kindness; $\alpha=.77$ for self-judgment). For the model of common humanity and isolation subscale, a two-factor model demonstrated adequate fit $(\mathrm{NNFI}=0.99 ; \mathrm{CFI}=0.99)$ and internal consistency was adequate $(\alpha=.80$ for common humanity; $\alpha=.79$ for isolation). The two-factor model of the mindfulness versus overidentification subscale also demonstrated a good fit for the data $(\mathrm{NNFI}=0.94 ; \mathrm{CFI}=.96)$ and internal consistency was .75. In its initial validation, the SCS also demonstrated good construct 
validity and a nonsignificant correlation was found when comparing the SCS to the MarloweCrowne Social Desirability scale $(r=.05, p=0.34)$. In terms of discriminant validity, the SCS has demonstrated a negative relation with the Self-Criticism subscale of the DEQ $(r=.65$, $p<0.01)$, as well as a significant positive correlation with the Social Connectedness scale $(r=.41$, $p<0.01$ ) and all subscales of the Trait-Meta Mood Scale (Attention, $\mathrm{r}=.11, \mathrm{p}<.05$; Clarity, $\mathrm{r}=$ $.43, \mathrm{p}<.01$, and Repair, $r=.55, \mathrm{p}<.01)$. Additionally, Williams, Dalgleish, Karl, and Kuyken (2014) also found adequate internal consistency for the SCS, with Cronbach's alphas for the six subscales ranging from .71 to .86 in a convenience sample of adults, adults who practice meditation, and a clinical sample of adults with recurrent depression. Subscale scores were added to create a single overall score.

Emotion Regulation. The manifest endogenous variable, "Emotion Regulation" is measured by the Difficulties in Emotion Regulation Scale (see Appendix H). High scores on emotion regulation are reflective of greater difficulties with emotion regulation, whereas lower scores are indicative of greater emotion regulation abilities. Emotion regulation was hypothesized to have a positive relationship with mindfulness and self-compassion. Conversely, emotion regulation was thought to have a negative relationship with eating disorder symptomatology.

Difficulties in Emotion Regulation Scale (DERS; Gratz \& Roemer, 2004). The DERS measures six facets of emotion regulation difficulties, including non-acceptance of emotional responses, difficulties engaging in goal directed behavior, impulse control difficulties, lack of emotional awareness items, limited access to emotion regulation strategies, and lack of emotion clarity. The DERS is a 36-item measure that uses a five-point Likert-type scale, with responses ranging from one (almost never) to five (almost always). It has a total score range of 36 to 180, 
with possible score ranges of five to 25 on the difficulties engaging in goal directed behavior and lack of emotion clarity subscales, possible score ranges of six to 36 on the non-acceptance of emotional responses, impulse control difficulties, and lack of emotional awareness subscales, as well as possible score range of eight to 64 on the limited access to emotion regulation strategies subscale. Higher scores are indicative of greater emotion regulation difficulties.

The DERS was determined to have good psychometric properties in its initial validation (Gratz \& Roemer, 2004). Gratz and Roemer (2004) found good internal consistency of the facets (Cronbach's alphas ranging from .80 to .89). Cooper, O'Shea, Atkinson, and Wade (2014) also found good internal consistency for the measure (Cronbach's alphas ranging from .76 to .91), except for the Clarity subscale (Cronbach's alpha of .41). The authors also found adequate to excellent convergent validity with an eating disorder measure, with the total scores of the DERS significantly correlating with global EDE-Q scores $(r=.46)$ and the EDE Behaviors subscale $(r$ $=.38$ ). Bardeen, Fergus, and Orcutt et al (2012) found strong intercorrelations among facets, except for the Awareness factor, which demonstrated weaker latent factor intercorrelations with the other factors. Overall, good validity and reliability have been found in past research with ED samples (Harrison et al., 2010; Racine \& Wildes, 2013). Subscale scores were added to create a single overall score.

Eating Disorder Symptomatology. The manifest endogenous variable, "Eating Disorder Symptomatology" is measured by the Eating Disorder Test-26 (see Appendix I). High scores on eating disorder symptomatology are indicative of greater disordered eating symptoms and were hypothesized to be related to low levels of mindfulness, self-compassion, and emotion regulation abilities. Low scores were believed to be related to high levels of mindfulness, selfcompassion, and emotion regulation skills. 
Eating Attitudes Test-26 (EAT-26; Garner et al., 1982). The EAT-26 was developed from the original EAT-40 measure. It assesses disordered eating attitudes, beliefs, and behaviors. The EAT-26 is a 26-item instrument that uses a 6-point Likert-type scale, with responses ranging from zero (never, rarely, sometimes) to three (always). It has a total score range of 0 to 78 . Scores of 20 or more are reflective of eating disorder concerns. The EAT-26 also contains six behavioral questions related to disordered eating behaviors and history of prior treatment for an eating disorder, as well as questions related to age, gender, BMI, highest weight, lowest adult weight, and ideal weight.

Questions from "Part A" of the EAT-26 were omitted. These questions ask participants to provide their birthdate, gender, height and weight, as well as their current, highest, lowest, and ideal weight. These questions were omitted because all questions pertinent to this study were included in the demographic questionnaire. Questions from "Part C" of the EAT-26 were also omitted. These questions are related to compensatory behaviors. Since they are supplementary and do not factor into the total score, they were not included.

The EAT-26 is highly correlated with the original EAT measure $(r=0.98)$ and was determined to have good psychometric properties in its initial validation (Garner et al., 1982). It has demonstrated excellent internal consistency in samples of Black and White adult women, with Cronbach's alpha ranging from .85 to .88, respectively (Kelly et al., 2012). The EAT-26 has good concurrent validity with various eating disorder measures (Williamson, Anderson, Jackman, \& Jackson, 1995). It was also found to have good discriminant validity, such that it can differentiate between those with $\mathrm{AN}, \mathrm{BN}$, and BED from controls (Williamson, Prather, McKenzie, \& Blouin, 1990). Although it cannot discriminate between those with AN and BN, it can differentiate between those with AN or BN and those with BED (Williamson et al., 1990). 
Additionally, the EAT-26 was found to have a test-retest reliability estimate of .89 over a four- to five-week period (Allison \& Baskin, 2009).

Covariate. Sex was included as a covariate in this model. Because the prevalence of eating disorders is higher among females than males, sex was considered a covariate for eating disorder symptomatology. Additional demographic data, which were significantly correlated to the outcome variable, were examined post hoc to determine their influence on the structure and strength of the model.

Sample Size. The literature regarding adequate sample sizes for Path Analysis are inconsistent. Loehlin (2004) recommended that as a rule of thumb at least 100 participants be included when using a Path Analysis model. Stevens (2002) suggested that Path Analyses should use a sample size of at least 15 cases per measured variable. In this case, with four variables, one covariate, and two regression equations, 100 participants were needed for an adequate sample size.

Demographic Questionnaire. A self-report demographics questionnaire was also included in the measurements. It contained questions related to participants' age, sex, ethnicity, current level of education, involvement in campus organizations, self-reported height and weight (to calculate BMI), history of an eating disorder, history of treatment for an eating disorder, and history of mental health treatment (see Appendix E). As mentioned, sex was measured and included as a covariate in the study. Demographic variables that were significantly related to eating disorder symptoms were also included in post hoc analyses.

\section{Procedures}

This study used an online survey to obtain data. This web-based format was chosen to limit supply costs, reduce the time for protocol implementation, and ensure that data could be 
easily and accurately imported into the data analysis program (Dillman, 2000). Upon approval from the Institutional Review Board (IRB), the advertisement (see Appendix B), which contained a link to the survey, IRB approval information, and appropriate contact information, was provided to the university counseling center, an honors undergraduate course, and the university's online news system. The alternative advertisement (see Appendix C) was posted in a creative arts center on campus. Extended IRB approval information was also made available.

Upon clicking the Qualtrics link, interested participants were directed to the introductory page, which includes an informed consent (see Appendix D). Participants were informed that clicking "Yes" to "I willingly agree to be in the study" served as their consent to participate in the study. They were also informed that no identifying information would be obtained, in order to maintain confidentiality. Upon clicking "Yes" to "I willingly agree to be in the study," participants were directed to the first page of the study.

Participants were asked if they were enrolled at least part-time in an undergraduate or graduate students at the university. They were also asked if they were at least 18 years of age. If participants indicated that they were not currently enrolled at the university as an undergraduate or graduate student or that they were not at least 18 years of age, the survey was discarded. If participants indicated that they were currently enrolled at least part-time in an undergraduate or graduate program at the university and were at least 18 years of age, they were directed to the survey.

Participants were then asked to complete a demographics form and the assessment instruments (see Appendix E-I). Each measure was on a separate page and the order was randomly assigned. After each measure was completed, participants clicked the arrow at the bottom of the page until all measures were completed. 
None of the questions or statements was mandatory, except for the consent to participate. After all measures were completed, participants were directed to the final page of the survey, which thanked them for participating in the study. The final page also contained contact information of the principal investigator and a counseling referral list (see Appendix J). On this final page, participants had the opportunity to provide their email address to enter into the drawing of one of $10 \$ 20$ Visa gift cards. They were reminded that their contact information would not be connected to their survey responses and would remain confidential. This information was stored in a separate password protected file and was deleted following the drawing. The entire survey took approximately 15 minutes to complete. Data obtained through the online survey were collected and stored in the Qualtrics database and were subsequently analyzed using SAS. 


\section{CHAPTER 3: RESULTS}

\section{Demographics}

A total of 139 participants consented to take part in the study. By means of the Full Information Maximum Likelihood (FIML) procedure, incomplete responses were included in the analysis if at least one of the scales was completed. In this method, a likelihood function for each individual is estimated based on the present variables, in order to utilize all available information to estimate the model (Collins, Shafer, \& Kam, 2001). Thirty-nine participants were excluded because they did not complete any of the measures. Therefore, 100 participants were included in the data analysis, including 91 fully completed and nine partially completed surveys.

Of the included participants, the age range was between 18 and 52 years of age, with a mean age of 23 years $(\mathrm{SD}=5.42, n=98)$. The average age of students at this university is 21 , with $7 \%$ of these students being 25 years of age or older (Voluntary Systems of Accounting Program, n.d.). BMI ranged between 12.17 and 52.49, with a mean BMI of $24(\mathrm{SD}=5.83, n=$ 100). Participants included 12 males (12\%) and 49 females (49\%). Information about the sex of the remaining 39 participants (39\%) was unavailable. In comparison, about $46 \%$ of students at this university are female and 54\% are male (Americas Best Colleges, 2016).

Participants identified their ethnicity by selecting all ethnicities that applied to them. The most commonly reported ethnicity was White $(n=83 ; 83 \%)$, followed by Asian/Pacific Islander $(n=7,7 \%)$, Hispanic or Latino $(n=3,3 \%)$, and Black or African American $(n=2$, $2 \%)$, Other $(n=2,2 \%)$. Three participants identified as more than one ethnicity, and included the following: White and Native American or American Indian $(n=1,1 \%)$, Hispanic or Latino and Native American or American Indian $(n=1,1 \%)$, and Asian/Pacific Islander and Other $(n=$ 1, 1\%). Similarly, of the students at this university, approximately $83 \%$ are White, $4 \%$ are 
Black, 4\% are international, 3\% are Hispanic, 3\% are Biracial, 2\% are Asian, and less than 1\% are American Indian/Alaskan Native or Native Hawaiian/Other Pacific Islander (Voluntary Systems of Accounting Program, n.d.).

Participants were asked to indicate their level of education. The largest percentage reported being graduate students $(n=46,46 \%)$. Remaining participants identified their education level as freshman $(n=11,11 \%)$ sophomore $(n=12,12 \%)$ junior $(n=15,15 \%)$ senior $(n=12,12 \%)$, and $5^{\text {th }}$ year senior $(n=4,4 \%)$. Participants were also asked to report their involvement in campus organizations. The most commonly reported affiliations were with the Honors College ( $n=23,23 \%)$, academic and professional organizations $(n=11,11 \%)$, Greek Life $(n=10,10 \%)$, and athletics $(n=7,7 \%)$. The sample was comprised of a slightly higher percentage of student athletes, as about $3 \%$ of students at this university take part in varsity athletics (Americas Best Colleges, 2016).

Participants were asked if they had a history of an eating disorder and/or treatment for an eating disorder. Seven participants $(7 \%)$ indicated that they were previously diagnosed with an eating disorder and six participants $(6 \%)$ reported receiving past or current treatment for their disorder(s). Information about current mental health treatment was also obtained. Fifteen participants (15\%) endorsed that they currently receive mental health treatment for concerns other than an eating disorder. Of these, the majority $(n=7,7 \%)$ was treated by medication alone, followed by therapy $(n=4,4 \%)$ and a combination of medication and therapy $(n=4,4 \%)$. Additional information regarding participant demographics can be found in Table 1. 
Table 1

Demographic Information of Participants

\begin{tabular}{|c|c|c|}
\hline Demographics & $\begin{array}{l}\text { Number of } \\
\text { Participants }\end{array}$ & Percentage \\
\hline \multicolumn{3}{|l|}{ Campus Involvement } \\
\hline Honors College & 23 & $23 \%$ \\
\hline Academic/Professional Organization & 11 & $11 \%$ \\
\hline Greek Life & 10 & $10 \%$ \\
\hline Athletics & 7 & $7 \%$ \\
\hline Service Organization & 7 & $7 \%$ \\
\hline Creative Arts Organization & 2 & $2 \%$ \\
\hline Religious Organization & 2 & $2 \%$ \\
\hline Cultural Organization & 1 & $1 \%$ \\
\hline Sports Organization & 1 & $1 \%$ \\
\hline Athletic Support & 1 & $1 \%$ \\
\hline \multicolumn{3}{|l|}{ History of an Eating Disorder } \\
\hline Within last 6 months & 1 & $1 \%$ \\
\hline $1+$ year ago & 6 & $6 \%$ \\
\hline Total & 7 & $7 \%$ \\
\hline \multicolumn{3}{|l|}{ History of ED Treatment } \\
\hline Current & 1 & $1 \%$ \\
\hline Within last 6 months to 1 year & 1 & $1 \%$ \\
\hline $1+$ year ago & 4 & $4 \%$ \\
\hline Total & 6 & $6 \%$ \\
\hline \multicolumn{3}{|l|}{ Currently Receiving Mental Health Treatment } \\
\hline Medication Only & 7 & $7 \%$ \\
\hline Therapy Only & 4 & $4 \%$ \\
\hline Therapy and Medication & 4 & $4 \%$ \\
\hline Total & 15 & $15 \%$ \\
\hline
\end{tabular}

\section{Internal Consistency Reliability of Measures}

The internal consistency of the measures was obtained by calculating the Cronbach's alpha for each scale using this study's sample. Cronbach's alpha scores greater than .90 are considered to be "excellent" and scores greater than .80 are considered to be "good" (George \& Mallery, 2003). Scores for the scales ranged from "good" to excellent," with all but one being in the "excellent" range. Each of the scales' Cronbach's alpha scores are listed in Table 2. All 
scales were used as discussed in the previous section since none of their scores would have significantly changed with deletion of any items.

Table 2

Cronbach's Alpha Scores for Measures

\begin{tabular}{lcccc}
\hline Measure & $\begin{array}{c}\text { Number of } \\
\text { Items }\end{array}$ & $\begin{array}{c}\text { Number of } \\
\text { Participants }\end{array}$ & $\begin{array}{c}\text { Cronbach's } \\
\text { Alpha }\end{array}$ & Label \\
\hline FFMQ & 39 & 97 & .92 & Excellent \\
SCS & 26 & 100 & .96 & Excellent \\
DERS & 36 & 93 & .96 & Excellent \\
EAT-26 & 26 & 98 & .87 & Good \\
\hline
\end{tabular}

Note. FFMQ = Five Facet Mindfulness Questionnaire; SCS = Self-Compassion Scale; DERS = Difficulties in Emotion Regulation Scale; EAT-26 = Eating Attitudes Test-26.

\section{Statistical Assumptions}

Assumptions related to path analysis were checked before running any analyses that addressed the research questions. These included assumptions of univariate and multivariate normality, univariate outliers, linearity, homoscedasticity, multicollinearity, and correct model specification.

The assumption of univariate normality was assessed with reference to skewness and kurtosis. Concerns about extreme non-normality are suggested with absolute values of skewness greater than 3.0 and absolute values of kurtosis greater than 8.0 (Kline, 1998). The values for skewness and kurtosis statistics can be found in Table 3. In addition, QQ plots and histograms were also assessed. This assumption was met by all measures. In addition, no univariate outliers were found to exist within the data. In order to evaluate multivariate normality, QQ plots and histograms of the measures' independent to dependent variable residual relationships were assessed. All variables met this assumption. Scatter plots of the bivariate regression residuals 
were also evaluated. Linear relationships between independent and dependent variables were confirmed.

Table 3

Skewness and Kurtosis Statistics

\begin{tabular}{lcc}
\hline \multicolumn{1}{c}{ Measure } & Skewness & Kurtosis \\
\hline Mindfulness & -0.12 & 0.34 \\
Self-Compassion & -0.25 & -0.39 \\
Difficulties in Emotion & & \\
Regulation & 0.74 & -0.16 \\
Eating Disorder Symptoms & 1.61 & 2.68 \\
\hline
\end{tabular}

The assumption of homoscedasticity was determined by assessing the consistency of the residual spread. All data formed a consistent spread and, therefore, met this assumption.

Multicollinearity was evaluated using the tolerance and variance inflation factor related to each of the predictor variables in the model. Measures of tolerance below .2 are thought to indicate possible collinearity problems and variance inflation values of 5.3 have been suggested as a cutoff point for multicollinearity (Hair, Anderson, Tatham, \& Black, 1992). Measures of tolerance in this study ranged from .34 to $.42(\mathrm{FFMQ}=.38 ; \mathrm{SCS}=.42 ; \mathrm{EAT}-26=.34)$ and variance inflation scores ranged from 2.39 to $2.97(\mathrm{FFMQ}=2.64$; $\mathrm{SCS}=2.39$; EAT-26 $=2.97)$. Since no critical scores for tolerance or variance inflation were found, multicollinearity was not indicated by the data.

Pearson correlations were used as an initial step in using correct model specification. Correlations that were not significant $(p<.05)$ were excluded from the model. Significant correlations are listed in Table 4. The covariate of sex was not significantly correlated with the measure of eating disorder symptoms in males $[r(59)=-.22, p=.089]$ or females $[r(59)=.22, p$ $=.089]$ and was subsequently removed from the proposed model. The variable of sex was 
unintentionally omitted from the original online survey. IRB approval was obtained in order to follow-up with participants who provided their contact information for the drawing. Some information was recovered; however, because not all participants provided their contact information, there were limited reports of this demographic variable.

\section{Path Analysis}

Upon meeting the statistical assumptions, the path analysis was conducted. The proposed model (see Figure 1) was revised, in order to meet the correct model specification criteria. Sex was originally included as a covariate in the model. Since it was not significantly correlated to the measure of eating disorder symptoms, it was excluded from the model. Removal of sex as a covariate produced a just-identified model. A just-identified model has as many linearly independent equations as unknowns and does not allow for any tests for goodness of fit, whereas an over-identified model includes more equations than unknowns and results in one set of parameter estimates from the data (O'Rourke \& Hatcher, 2013). The modification function in Proc Calis was used to determine the recommended restrictions to be placed on the model, in order to produce an over-identified model. It was recommended that the direct path from mindfulness to eating disorder symptoms be removed. The revised model produced the desired over-identified model and can be found in Figure 2.

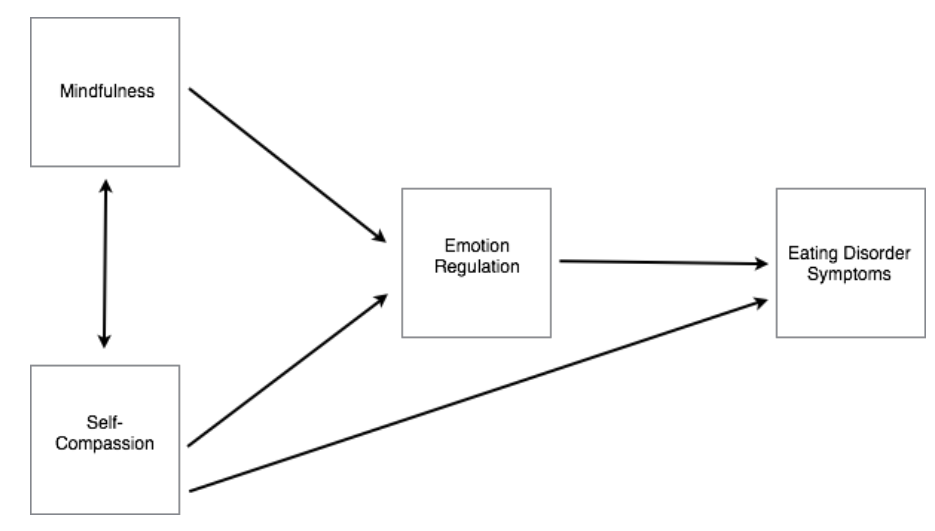

Figure 2. Revised hypothesized model. 
Table 4

Correlation Matrix for Variables Included in Tested Models

\begin{tabular}{|c|c|c|c|c|c|c|c|c|c|}
\hline Measure & FFMQ & SCS & DERS & EAT-26 & Religious & Service & Freshman & $\begin{array}{l}\text { History of } \\
\text { ED }\end{array}$ & $\begin{array}{c}\text { History } \\
\text { of ED } \\
T x\end{array}$ \\
\hline FFMQ & 1 & $.69^{* *}$ & $-.76^{* *}$ & $-.31^{*}$ & -.16 & $.39 *$ & -.19 & -.002 & -.02 \\
\hline SCS & $.69^{* *}$ & 1 & $-.74 * *$ & $-.37 *$ & -.13 & $.40^{*}$ & -.12 & -.08 & -.10 \\
\hline DERS & $-.76^{* *}$ & $-.74 * *$ & 1 & $.29^{*}$ & -.04 & $-.30^{*}$ & .11 & .10 & 0.06 \\
\hline EAT-26 & $-.31^{*}$ & $-.37 *$ & $.29^{*}$ & 1 & $.41^{*}$ & $-.28^{*}$ & $.20^{*}$ & $.41 * *$ & $.33 *$ \\
\hline Religious & -.16 & -.13 & -.04 & $.41 *$ & 1 & -.08 & $0.26^{*}$ & -.08 & 0.27 \\
\hline Service & $.39^{*}$ & $.40^{*}$ & $-.30^{*}$ & $-.28^{*}$ & -.08 & 1 & -.19 & -.14 & -.13 \\
\hline Freshman & -.19 & -.12 & .11 & $.20^{*}$ & $.26^{*}$ & -.19 & 1 & .08 & .05 \\
\hline Hx of ED & -.002 & -.08 & .10 & $.41 * *$ & -.08 & -.14 & .08 & 1 & $.76^{* *}$ \\
\hline $\begin{array}{l}\text { Hx of ED } \\
T x\end{array}$ & -.02 & -.10 & .06 & $.33 *$ & .27 & -.13 & .05 & $.76 * *$ & 1 \\
\hline
\end{tabular}

Note. ${ }^{*}$ denotes significance at the $p<.05$ level and $* *$ denotes significance at the $p<.0001$ level. FFMQ = Five Facet Mindfulness Questionnaire; SCS = Self-Compassion Scale; DERS = Difficulties in Emotion Regulation Scale; EAT-26 = Eating Attitudes Test-26; Hx of ED = history of an eating disorder; Hx of ED Tx = history of eating disorder treatment.

The revised hypothesized model was tested using the Proc Calis function in SAS 9.4.

Goodness of fit statistics were assessed and the model demonstrated adequate fit. Information on goodness of it can be found in Table 5. However, indices indicated that the model fit could be improved with certain modifications. Nonetheless, the initial model produced a non-significant $p$-value, $\chi^{2}(91)=0.13, p=.720$, for the chi-square test. This test measures overall model fit using reverse hypothesis testing. Therefore, the chi-square test suggested that the model fit the data. The Standardized Root Mean Square Residual (SRMR), an absolute measure of fit, was also considered. This fit index examines the standardized difference between the observed and predicted correlations. Values below .09 typically indicate adequate fit, while a value of zero suggests perfect fit (Hu \& Bentler, 1999). In the revised model, the SRMR was .006. 
Table 5

Fit Indices of the Revised Model

\begin{tabular}{lcc}
\hline \multicolumn{1}{c}{ Fit Index } & Desired Score & $\begin{array}{c}\text { Revised Model } \\
\text { (Best Fitting Model) }\end{array}$ \\
\hline Chi-Square & $p>0.05$ & 0.72 \\
SRMR & $<.09$ & .006 \\
GFI & $>.90$ & 1 \\
AGFI & $>.90$ & 0.99 \\
RMSEA Estimate & $<.08$ & 0 \\
AIC & smaller preferred & 3175.95 \\
Bentler CFI & $>0.90$ & 1 \\
Bentler Bonnet NNFI & $>0.90$ & 1.03 \\
\hline
\end{tabular}

Note. SRMR = Standard Root Mean Square Residual; GFI = Goodness of Fit; AGFI = Adjusted Goodness of Fit; RMSEA = Root Mean Square Error of Approximation; AIC = Akaike Information Criterion; Bentler CFI = Bentler Comparative Fit Index; Bentler Bonnet NNFI = Bentler Bonnet Non-normed Fit Index.

Overall model fit was also assessed using the Goodness of Fit (GFI), the Adjusted Goodness of Fit (AGFI), and the Root Mean Square Error of Approximation (RMSEA) statistics. For GFI and AGFI, values above 0.90 indicate good model fit (O’Rourke \& Hatcher, 2013). In this model the GFI $=1.00$ and AGFI $=.99$, which suggested that the model fit the data well. The RMSEA measures fit and adjusts for model parsimony. Values greater than .08 are considered to indicate poor model fit, values greater than .055 and less than .08 indicate adequate fit, and a value of 0 indicates perfect model fit (MacCallum, Browne, \& Sugawara, 1996). For the initial model, the RMSEA was equal to 0 , with a $90 \%$ confidence interval of 0 to .19 .

Additional measures of fit were evaluated, including the Akaike Information Criterion (AIC), the Bentler Comparative Fit Index (CFI), and the Bentler-Bonett Non-Normed Index (NNFI). The CFI and NNFI measures are based on the non-centrality measure and suggest that scores above .90 indicate good model fit (Hu \& Bentler, 1999). The initial model produced a CFI of 1 and a NNFI of 1.03. The NNFI considers model parsimony, which may account for the 
differences between these values. The AIC is a measure of parsimony and is only useful when comparing models. This index is non-normed and, therefore, no cut-off scores are use. Smaller values, relative to the AIC of other models, indicate a more parsimonious model (Akaike, 1974). The AIC for this model was 3175.95. The revised model with standardized beta coefficients can be found in Figure 3.

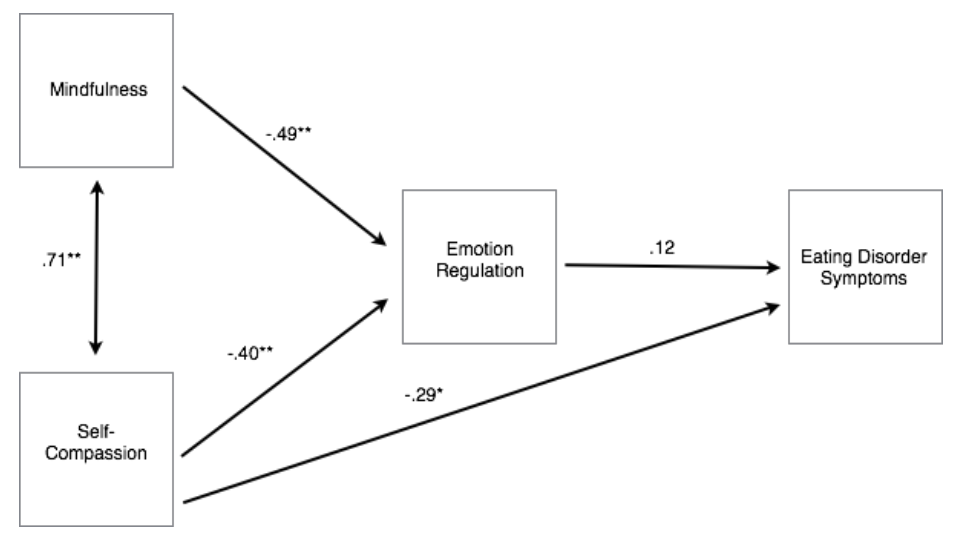

Figure 3. Revised hypothesized model with standardized beta coefficients.

Note. ${ }^{*}$ denotes significance at the $p<.05$ level and $* *$ denotes significance at the $p<.01$ level.

The revised hypothesized model demonstrated good model fit. The direct and then the indirect effects of the relationships between variables were evaluated. The direct effect involves the direct path from one variable to another, indirect effects include all indirect paths from one variable to another, and the total effects include all paths from one variable to another, mediated by at least one additional variable (Bollen, 1989). The total effects are determined by calculating the product of the direct and indirect effects between two variables. The direct, indirect, and total effects for the revised hypothesized model can be found in Table 6. Of note are the insignificant direct effect of emotion regulation on eating disorder symptoms and the significant total effects of mindfulness and self-compassion on eating disorder symptoms.

Table 6 
Direct, Indirect, and Total Effects of the Model

\begin{tabular}{|c|c|c|c|c|c|c|c|c|c|}
\hline \multirow[b]{2}{*}{ Measure } & \multicolumn{3}{|c|}{$\begin{array}{l}\text { Direct } \\
\text { Effects }\end{array}$} & \multicolumn{3}{|c|}{$\begin{array}{l}\text { Indirect } \\
\text { Effects }\end{array}$} & \multicolumn{3}{|c|}{$\begin{array}{c}\text { Total } \\
\text { Effects }\end{array}$} \\
\hline & DERS & FFMQ & SCS & DERS & FFMQ & SCS & DERS & FFMQ & SCS \\
\hline DERS & 0 & $-.49 * *$ & $-.40 * *$ & 0 & 0 & 0 & 0 & $-.49 * *$ & $0.40 * *$ \\
\hline EAT-26 & 0.12 & 0 & $-.29 *$ & 0 & -.06 & -.05 & 0.12 & -.06 & $-.34^{*}$ \\
\hline
\end{tabular}

Additional models were tested, in order to determine if there was a better fitting model. Again, the modification function in Proc Calis was used to determine the recommended restrictions to be placed on the model. Specifically, the path between emotion regulation and eating disorder symptoms was removed. However, removal of this path did not significantly change the model and, in fact, did not align with theoretical assumptions about the relationship between these variables. Next, both of the paths between mindfulness and eating disorder symptoms and between emotion regulation and eating disorder symptoms were removed. Again, removal of these paths did not significantly change the model and interfered with theoretical assumptions about the relationships between these variables. Current etiological models of eating disorders consider emotion dysregulation to be a transdiagnostic factor (Fairburn et al., 2003; Treasure et al., 2012), such that emotion regulation difficulties and the experiencing of negative emotions are thought to be significant contributors to the maintenance of these disorders (Harrison et al., 2010). Therefore, due to the well-documented relationship between these variables, this path was kept in the model.

Demographic variables that were correlated to the outcome variable were then included in the revised model to determine if they accounted for additional variance in the model. 
Information regarding correlations between variables can be found in Table 4. Specifically, involvement in a religious organization $[r(50)=.41, p=.0032]$, involvement in a service organization $[r(50)=-.28, p=.0501]$, status as an undergraduate freshman $[r(98)=.20, p=$ $.0511]$, history of an eating disorder $[r(98)=.41, p=<.0001]$, and history of eating disorder treatment $[r(98)=.33, p=.0007]$ were significantly correlated to the measure of eating disorder symptoms and were subsequently included in the model. By adding each of these as covariates, independently and collectively, the model was not significantly strengthened. Goodness of fit statistics for these models can be found in Table 7.

Table 7

Goodness of Fit Indices for Demographic Variables Included in the Model

\begin{tabular}{lccccc}
\hline \multicolumn{1}{c}{ Fit Index } & Religious & Service & Freshman & Hx of ED & Hx of ED Tx \\
\hline$\chi^{2}$ & .27 & .97 & .98 & .38 & .81 \\
df & 2 & 2 & 2 & 2 & 2 \\
SRMR & 0.04 & 0.004 & 0.003 & 0.02 & 0.009 \\
GFI & 0.96 & 1 & 1 & 0.99 & 1 \\
AGFI & 0.73 & 1 & 1 & 0.94 & 0.99 \\
RMSEA Estimate & 0.06 & 0 & 0 & 0 & 0 \\
AIC & 3152.70 & 3209.54 & 3229.46 & 3175.37 & 3167.85 \\
Bentler CFI & 1 & 1 & 1 & 1 & 1 \\
Bentler Bonnet & & & & & 1.04 \\
NNFI & 0.98 & 1.05 & 1.05 & 1 & \\
\hline
\end{tabular}

Note $\chi^{2}=$ Chi-Square; SRMR = Standard Root Mean Square Residual; GFI = Goodness of Fit; AGFI = Adjusted Goodness of Fit; RMSEA = Root Mean Square Error of Approximation; AIC $=$ Akaike Information Criterion; Bentler CFI = Bentler Comparative Fit Index; Bentler Bonnet NNFI $=$ Bentler Bonnet Non-normed Fit Index.

In total, ten models were analyzed. The best fitting model, based on both theoretical and statistical assumptions, was the revised hypothesized model shown in Figure 2. Goodness of fit statistics for this model can be found in Table 5. Evaluation of the specific paths and implications of these findings will be explored in the following chapter. 


\section{CHAPTER 4: DISCSUSSION}

Path Analysis (PA) was used to examine potential protective factors against the development and maintenance of eating disorder symptoms. The hypothesized model used emotion regulation as a partial mediator between mindfulness and self-compassion in relation to disordered eating symptoms. The resulting model provides support for the integrated theoretical frameworks for mindfulness, self-compassion, emotion-regulation, and eating disorder symptomatology, as outlined by Lavender et al. (2011), Germer (2009), and McBeth and Camley (2012).

The model suggests that higher levels of mindfulness and self-compassion are predictive of decreased emotion regulation difficulties, which is also related to the decreased occurrence of eating disorder symptoms. As such, emotion regulation was the primary mediating variable, in that it partially mediated the relationships between self-compassion and eating disorder symptoms and between mindfulness and eating disorder symptoms through self-compassion. While the relationship between self-compassion and eating disorders was partially mediated by emotion regulation, self-compassion was also directly related to eating disorder symptoms.

The model also provided support for the linkage between mindfulness and selfcompassion. It has been recommended that these constructs maintain a reciprocal relationship, such that self-acceptance is connected to the framework of mindfulness (Germer, 2009). These constructs were significantly and positively related and, in fact, maintained the strongest relationship in the model. This indicates that as levels of mindfulness increase, so do levels of self-compassion and vice versa.

One distinct difference between the findings of this study and the originally proposed model is the relationship between mindfulness and eating disorder symptoms. Prior research has 
shown a significant and negative direct relationship between mindfulness and disordered eating (Butryn et al., 2013). However, in this study, this relationship was partially mediated by emotion regulation abilities through self-compassion, such that increased levels of mindfulness was related to decreased difficulties in emotion regulation that, in turn, decreased eating disorder symptoms. This study used the combined influence of all five facets as a means of measuring mindfulness, which may indicate that only certain facets are directly related to disordered eating. For example, Lavendar et al. (2011) found a significant relationship between eating disorder symptoms and the facets of observing, acting with awareness, nonreactivity, and nonjudgment, but not describing. Nonetheless, the findings suggest that the ability to observe, attend to, and accept internal experiences, along with the ability to remain unattached to inner experiences during distress and maintain behavioral control, can be viewed as adaptive emotion regulation skills that aid in the decreased occurrence of disordered eating.

Another key difference is the proposed significance of the relationship between the variables of emotion regulation difficulties and eating disorder symptoms. There was a positive relationship between these constructs; however, this relationship did not reach statistical significance and, in fact, was the weakest relationship within the model. It could be that certain facets of emotion regulation are more predictive of eating disorder symptoms than others, which aligns with some prior research. For example, Racine \& Wildes (2013) found that the facets of difficulties with emotional understanding, lack of emotional awareness, and lack of emotional acceptance were all related to eating disorder symptoms. However, when emotion regulation difficulties were taken together, lack of emotional awareness was the only facet that predicted eating disorder symptoms. In addition, although those with eating disorders typically exhibit greater emotion regulation difficulties than healthy controls, such difficulties have been found to 
manifest differently depending on the type of disorder (Brockmeyer et al., 2014). Because a general definition of these constructs was used in the model, more specific information about the relationships between aspects of these variables is unclear. It is also possible that the relationship between emotion regulation difficulties and disordered eating becomes more distinguished over time. In this study, participants indicated current symptoms. However, if an individuals' previous experience of emotion dysregulation was adapted into eating disorder symptoms, then they may report lower levels of emotion regulation difficulties, while reporting higher levels of disordered eating.

In addition, the covariate of sex was removed from this model. Although less is known about the prevalence of eating disorders in males (APA, 2013), sex has been identified as a marker associated with AN, BN, and BED (DeBate et al., 2010). However, sex was not significantly related to disordered eating patterns in this study. Although this may reflect that sex differences in relation to these behaviors are more negligible than previously thought, it is most likely due to the limited self-reporting for this variable, as well as a small sample size.

Correlated variables of involvement in a religious organization, involvement in a service organization, status as an undergraduate freshman, history of an eating disorder, and history of eating disorder treatment were also tested, but not included in the final model. Analyses of goodness of fit indices showed that the model was not significantly strengthened with inclusion of these variables. An interesting finding in this study was the lack of significance between eating disorder symptoms and the variables of ethnicity and athletics. This differs from some prior studies, which demonstrated significant differences in symptoms between ethnicities (Baugh et al., 2010; DeLeel et al., 2009) and increased symptoms in student athletes (Chatterton \& Petrie, 2013). This suggests that engagement in disordered eating practices is better accounted 
for by the process of relating to, interpreting, and managing psychological experiences than individuals' relationship to these variables.

Overall, this study connects and builds on existing theories related to cognitive factors that are protective against eating disorders. It highlights the significant role of emotion regulation, a complex construct comprised of both cognitive and affective components, which is impacted by mindfulness and self-compassion. It also clarifies the role of mindfulness in relation to eating disorders. Clinicians may assume that interventions targeting mindfulness will decrease an individual's likelihood of developing or maintaining an eating disorder. However, it appears to be more beneficial to focus on interventions that utilize mindfulness practices as a means to strengthen emotion regulation skills. Additionally, the model supported the direct and indirect effects of self-compassion. Increased levels of self-compassion were directly related to decreased levels of disordered eating and indirectly related to these symptoms through emotion regulation. This finding suggests that treatment approaches would benefit from focusing on the enhancement of self-compassion.

Although the final model is considered to be a statistically good fit for the data, it is a relatively simplistic model that focuses exclusively on cognitive factors related to eating disorders. Future research could focus on expanding the model to include a more complex combination of variables (i.e., psychosocial, neurobiological). Nonetheless, the results lend support for the integration of existing theoretical frameworks of cognitive variables in relation to eating disorders.

\section{Clinical Implications}

One of the greatest clinical implications of this study is its partial support for the combined theoretical frameworks of Lavendar et al. (2011), Germer (2009), and McBeth and 
Camley (2012). The findings indicate that mindfulness and self-compassion can be viewed as adaptive emotion regulation skills. Self-compassion, both directly and indirectly through emotion regulation, was found to be a key variable in the prediction of eating disorder symptoms. This finding supports the notion that higher levels of self-compassion are related to increased abilities to deal with negative life experiences by having access to and using more adaptive skills to respond to unpleasant events (Neff \& Vonk, 2009).

Clinicians working with individuals with an eating disorder or those who are considered to be "at risk" should consider the significance of monitoring and facilitating the development of emotion regulation skills, through increasing mindfulness and self-compassion. Attention to these, particularly self-compassion, could aid in the reduction or prevention of disordered eating behaviors during stressful academic demands and life transitions. For example, Gilbert's (2010) compassion-focused therapy (CFT) is one approach that may assist in facilitating increased selfcompassion by helping those who are self-critical overcome their resistance to extending selfcompassion. Likewise, incorporation of Mindful Self-Compassion (MSC; Neff \& Germer, 2013) programs could provide individuals with a means to enhancing not only self-compassion, but mindfulness as well. Such an approach has demonstrated positive outcomes for both clinical and non-clinical samples and could improve individuals' emotion regulation abilities and subsequently decrease the occurrence of disordered eating. Overall, modalities focusing on selfcompassion may not only serve to increase mindfulness and improve emotion regulation abilities, but also have the potential to directly reduce disordered eating patterns (for more information on compassion-focused readings, interventions, and tools, see http://psychology.tools/compassion-focused-therapy.html). Future research could work to 
identify variables predictive of mindfulness and self-compassion, in order to better understand methods of promoting these within individuals.

Implications of these findings can also help to inform prevention and intervention efforts at the university level. For example, these findings can be used to facilitate the establishment and/or improvement of eating disorder awareness and prevention programs on campuses. Undergraduate and graduate students are likely to experience emotional stress related to this phase of life and are at an increased risk of developing psychological problems, including eating disorders (DeBate et al., 2010). Developing programs to inform students about risk factors and effective interventions that may help to prevent these disorders is critical. Likewise, mindfulness-based, and particularly, self-compassion focused treatments could be incorporated into existing individual and group therapy modalities for those who have, or are at-risk for, an eating disorder. Lastly, it would also be worthwhile to consider use of such prevention and intervention efforts in primary and secondary educational settings, as issues of body image and eating disturbances have been found in elementary-age students (Smolak, 2011). This would aid in early detection and also better prepare individuals for the stressful transition into higher education.

\section{Limitations}

The findings of the present analysis must be interpreted within the context of the study's limitations. There is limited external validity, considering that the data came from university students in Eastern United States. The sample was a sample of convenience and may not accurately represent undergraduate and graduate students in other universities, clinical populations, or individuals in the general population. It may also limit generalizability to more diverse, and less educated, populations. The sample included a large standard deviation for age, 
BMI, and education level. Sampling also drew from a clinical setting, as well as more general sources. Again, this may have impacted the representativeness of the target population. Likewise, there was limited self-reporting for the demographic variable of sex. Therefore, the sample may have underrepresented the experience of male undergraduate and graduate students. Since it was such a heterogeneous group, it makes it difficult to determine what additional factors may be impacting the outcome variables. Nonetheless, the demographics of this sample were similar to those of the university, which suggests that the findings can be generalized to the university population.

Another limitation of the study was its use of self-report measures. Although survey responses were anonymous, it is possible that social desirability impacted responses (van de Mortel, 2008). Personal questions about eating disorder diagnoses, treatment of an eating disorder or mental health concerns, along with those related to general health practices may have been sensitive to social desirability bias. Due to the length of survey, no measures were included to control for this. Introspective ability may have also played a role in survey responses. Even if participants did not make attempts to respond in a socially desirable way, their level of introspective ability may have impacted the accuracy of their responses. In addition, there may have been variability in participants' understanding or interpretation of the questions. The survey scales measured somewhat abstract constructs and, therefore, may have produced inconsistency in the pattern of understanding and responding to items.

There are also limitations related to the instrument used to measure disordered eating. The use of the Eating Attitudes Test-26 limited specific information about types of eating disorder symptoms. Although this measure can differentiate between the disorders of AN and $\mathrm{BN}$ and $\mathrm{BED}$, the study used an overall score and focused on a general picture of these 
symptoms. Therefore, there is no information regarding the distinct symptoms that the constructs predicted. In addition, the EAT-26 was likely impacted by the truncation of range effect. The sample was, in part, drawn from a clinical setting. This may have reduced variability among responses and negatively impacted the strength of the relationships between eating disorder symptoms and the included predictor variables.

Lastly, there are limits to using path analysis. This form of analysis is often considered to be a form of causal modeling, but causality cannot be inferred in this study. Considering the findings, it could be assumed that decreased levels of mindfulness, self-compassion, and emotion regulation cause disordered eating. However, it could also be that disordered eating decreases one's access to, and use of, adaptive emotion regulation skills, including mindfulness and selfcompassion. Therefore, some caution is necessary in the interpretation of these results. In addition, a single instrument was used to measure each construct. Although these instruments used multidimensional definitions of the constructs and were well validated prior to this study, use of a single instrument for each construct neglects the contribution of distinct aspects of variables and discounts measurement error in the data. Despite these limitations, the findings from this study offer valuable contributions to the literature.

\section{Strengths}

This study was the first known to connect various theoretical assumptions of protective cognitive variables and disordered eating and integrate them into one comprehensive model. The resulting model clarifies the relationships between factors predictive of eating disorder symptoms and supports current independent theories. The study also relied on multidimensional definitions of constructs, which provided a richer conceptual framework for the data. 
A major strength of the findings was the clarified role of mindfulness and selfcompassion. This study demonstrates support for the notion that these variables can be viewed as adaptive forms of emotion regulation. In fact, mindfulness was linked to disordered eating through its relationship with emotion regulation. This finding highlights the importance of mindfulness-based treatments that work to strengthen individuals' abilities to manage affective states by consciously attending to their present experiences in a non-judgmental way. Furthermore, self-compassion emerged as a key variable in the prediction of both emotion regulation and eating disorder symptoms. This outcome provides support for compassionfocused treatments that help individuals to manage their psychological experiences in a way that promotes self-kindness, mindfulness, and connection to a shared experience, subsequently decreasing reliance on unhealthy eating patterns.

Overall, this study illuminated the role of cognitive variables in relation to eating disorder symptoms. It explored an important area of this research and provided a starting point for future work. The findings also provided useful insights that may aid in the development of more productive psychotherapeutic interventions.

\section{Future Directions}

Due to the various limitations of this study, it is important for these to be addressed in prospective research. It is hoped that, by taking into account these shortcomings, the model and related theories can be further elucidated. Future studies should consider the impact of the samples, instruments, and research design being used.

First, future work should consider using a larger, more homogenous sample with a better representation of male participants. This study had limited records of participants' sex and such information would clarify this variable's influence in the model. Additionally, the sample used 
in this study was recruited from both clinical and general sources. Although generalizability may become more limited, a narrower population focus may decrease the variability of responses and better translate to a specific population. Next, a design that tests individual facets within each measure may provide additional information regarding those aspects of variables that are most influential in the model. For example, the use of a structural equation modeling approach would not only clarify the nature of the chosen variables, but would also account for measurement error. Lastly, it would be beneficial for future work to test the impact of mindfulness- and compassion-based interventions, in order to provide further support for this study's model.

\section{Conclusion}

This study offers insights about factors predictive of the development and maintenance of eating disorders. It contributes to the relatively small, but growing literature related to these variables' potentially protective impact on disordered eating. The findings suggest that there is a strong connection between mindfulness and self-compassion, which influences one's emotion regulation abilities and subsequent eating attitudes and behaviors. Since eating disorders are some of the most fatal psychological disorders, and are particularly prevalent during "emerging adulthood," it is hoped that continued research in this area would benefit those who suffer from their damaging consequences. 


\section{References}

Abrams, L. S., \& Stormer, C. C. (2002). Sociocultural variations in the body image perceptions of urban adolescent females. Journal of Youth and Adolescence, 31(6), 443-450.

Adams, C. E., \& Leary, M. R. (2007). Promoting self-compassionate attitudes toward eating among restrictive and guilty eaters. Journal of Social and Clinical Psychology, 26(10), 1120-1144.

Agras, W. S. (2010). The Oxford handbook of eating disorders (Ed.). New York: Oxford University Press.

Akaike, H. (1974). A new look at the statistical model identification. IEE Transactions on Automatic Control, 19(6), 716-723.

Alberts, H. J. E. M., Thewissen, R., \& Raes, L. (2012). Dealing with problematic eating behavior: The effects of a mindfulness-based intervention on eating behavior, food cravings, dichotomous thinking and body image concern. Appetite, 58, 847-851.

Aldao, A. (2013). The future of emotion regulation research: Capturing context. Perspectives on Psychological Science, 8, 155-172.

Aldao, A., \& Nolen-Hoeksema, S. (2010). Specificity of cognitive emotion regulation strategies: A transdiagnostic examination. Behaviour Research and Therapy, 48(10), 974-983.

Aldao, A., Nolen-Hoeksema, S., \& Schweizer, S. (2010). Emotion-regulation strategies across psychopathology: A meta-analytic review. Clinical Psychology Review, 30(2), 217-237.

Allison, D. B., \& Baskin, M. L. (2009). Handbook of assessment methods for eating behaviors and weight-related problems: Measures, Theory, and Research ( $2^{\text {nd }}$ ed.). Thousand Oaks, CA: SAGE Publications, Inc. 
Alpers, G. W., \& Tuschen-Caffier, B. (2001). Negative feelings and the desire to eat in bulimia nervosa. Eating Behaviors, 2, 339-352.

American Psychiatric Association. (2013). Diagnostic and statistical manual of mental disorders (5th ed.). Washington, DC: Author.

American Psychological Association, Task Force on the Sexualization of Girls. (2007). Report of the APA Task Force on the Sexualization of Girls. Washington, DC: American Psychological Association.

America’s Best Colleges (2016). West Virginia University. Retrieved from http://www.forbes.com/colleges/west-virginia-university/

Anderson, C., \& Petrie, T. A. (2012). Prevalence of Disordered Eating and Pathogenic Weight Control Behaviors among NCAA Division I Female Collegiate Gymnasts and Swimmers. Research Quarterly For Exercise And Sport, 83(1), 120-124.

Anestis, M. D., Selby, E. A., Fink, E., \& Joiner, T. E. (2007). The multifaceted role of distress tolerance in dysregulated eating behaviors. International Journal of Eating Disorders, 40, 718-726.

Anshel, M. H. (2004). Sources of disordered eating patterns between ballet dancers and nondancers. Journal of Sport Behavior, 27(2), 115-133.

Arnett, J. (2001). Conceptions of the transition to adulthood: Perspectives from adolescence through midlife. Journal of Adult Development, 8, 133-143.

Baer, R. A. (2010). Self-compassion as a mechanism of change in mindfulness- and acceptancebased treatments. In R. A. Baer (Ed.), Assessing mindfulness and acceptance processes in clients: Illuminating the theory and practice of change (pp. 135-153). Oakland, CA: New Harbinger Publications. 
Baer, R. A., Smith, G. T., \& Allen, K. B. (2004). Assessment of mindfulness by self-report: The Kentucky Inventory of Mindfulness Skills. Assessment, 11, 191-206.

Baer, R. A., Smith, G. T., Hopkins, J., Krietemeyer, J., \& Toney, L. (2006). Using self-report assessment methods to explore facets of mindfulness. Assessment, 13, 27-45.

Bardeen, J. R., Fergus, T. A., \& Orcutt, H. K. (2012). An examination of the latent structure of the Difficulties in Emotion Regulation Scale. Journal of Psychopathology and Behavioral Assessment, 34, 382-392.

Barnard, L. K., \& Curry, J. F. (2011). Self-compassion: Conceptualizations, correlates, and interventions. Review of General Psychology, 15(4), 289-303.

Barnes, S. M., \& Lynn, S. J. (2010). Mindfulness skills and depressive symptoms: A longitudinal study. Imagination, Cognition and Personality, 30(1), 77-91.

Baugh, E., Mullis, R., Mullis, A., Hicks, M., \& Peterson, G. (2010). Ethnic identity and body image among Black and White college females. Journal of American College Health, 59(2), 105-109.

Bell, S. \& Lee, C. (2006). Does timing and sequencing of transitions to adulthood make a difference? Stress, smoking, and physical activity among young Australian women International Journal of Behavioral Medicine, 13, 256-274.

Berking, M., \& Whitley, B. (2014). Affect regulation training (ART). Book in print. New York, NY: Springer.

Berry, K. A., Kowalski, K. C., Ferguson, L. J., \& McHugh, T. L. F. (2010). An empirical phenomenology of young adult women exercisers' body self-compassion. Qualitative Research in Sport, Exercise and Health, 2, 293-312. 
Birnie, K., Speca, M., \& Carlson, L. E. (2010). Exploring self-compassion and empathy in the context of Mindfulness-Based Stress Reduction (MBSR). Stress and Health, 26, 359-371.

Bishop, S., Lau, M., Shapiro, S., Carlson, L., Anderson, N., Carmody, J., et al. (2004).

Mindfulness: A proposed operational definition. Clinical Psychology: Science and Practice, 11(13), 230-241.

Bollen, K.A. (1989). Structural equations with latent variables. New York: John Wiley \& Sons.

Bornovalova, M. A., Gratz, K. L., Daughters, S. B., Nick, B., Delany-Brumsey, A., Lynch, T. R., \& Lejuez, C. W. (2008). A multimodal assessment of the relationship between emotion dysregulation and borderline personality disorder among inner-city substance users in residential treatment. Journal of Psychiatric Research, 42(9), 717-726.

Bridges, L. J., Denham, S. A., \& Ganiban, J. M. (2004). Definitional issues in emotion regulation research. Child Development, 75, 340-345.

Brittain, C. V. (1963). Adolescent choices and parent-peer cross pressures. American Sociological Review, 28(3), 385-391.

Brockmeyer, T., Bents, H., Holtforth, M. G., Pfeiffer, N., Herzog, W., \& Friederich, H. C. (2012a). Specific emotion regulation impairments in major depression and anorexia nervosa. Psychiatry Research, 200, 550-553.

Brockmeyer, T., Holtforth, M. G., Bents, H., Kämmerer, A., Herzog, W., \& Friederich, H. C. (2012b). Starvation and emotion regulation in anorexia nervosa. Comprehensive Psychiatry, 53, 496-501.

Brockmeyer, T., Skunde, M., Wu, M., Bresslein, E., Rudofsky, G., Herzog, W., \& Friederic, H. (2014). Difficulties in emotion regulation across the spectrum of eating disorders. Comprehensive Psychiatry, 55(3), 565-571. 
Brooks, S., Prince, A., Stahl, D., Campbell, I. C., \& Treasure, J. (2011). A systematic review and meta-analysis of cognitive bias to food stimuli in people with disordered eating behaviour. Clinical Psychology Review, 31(1), 37-51.

Brown, B. (1998). Soul without shame: A guide to liberating yourself from the judge within. Boston, MA: Shambhala Publications.

Brown, K. W., \& Ryan, R. M. (2003). The benefits of being present: Mindfulness and its role in psychological well-being. Journal of Personality and Social Psychology, 84, 822-848.

Brown, K. W., Ryan, R. M., \& Creswell, J. D. (2007). Mindfulness: Theoretical foundations and evidence for its salutary effects. Psychological Inquiry, 18(3), 211-237.

Brown, R. A., Lejuez, C. W., Kahler, C. W., Strong, D. R., \& Zvolensky, M. J. (2005). Distress tolerance and early smoking lapse. Clinical Psychology Review, 25(6), 713-733.

Bruch, H. (1987). The golden cage. Cambridge, MA: Harvard University Press.

Bulik, C. M. (2002). Eating disorders in adolescents and young adults. Child And Adolescent Psychiatric Clinics Of North America, 11(2), 201-218.

Butryn, M. L., Juarascio, A., Shaw, J., Kerrigan, S. G., Clark, V., O’Planick, A., \& Forman, E. M. (2013). Mindfulness and its relationship with eating disorder symptomatology in women receiving residential treatment. Eating Behaviors, 14, 13-16.

Carter, J. C., Kelly, A. C., \& Norwood, S. J. (2012). Interpersonal problems in anorexia nervosa: Social inhibition as defining and detrimental. Personality and Individual Differences, 53, 169-174.

Carver, C. S., \& Scheier, M. F. (1998). On the self-regulation of behavior. New York, NY: Cambridge University Press. 
Cash, T. F., \& Pruzinsky, T. (2004). Body image: A handbook of theory, research, and clinical practice. New York: Guilford Press.

Cash, M., \& Whittingham, K. (2010). What facets of mindfulness contribute to psychological well-being and depressive, anxious, and stress-related symptomatology? Mindfulness, $1(3), 177-182$.

Cavedini, P., Bassi, T., Ubbiali, A., Casolari, A., Giordani, S., Zorzi, C., et al. (2006).

Neuropsychological investigation of decision-making in anorexia nervosa. Psychiatry Research, 127, 259-66.

Chadwick, P., Hember, M., Symes, J., Peters, E., Kuipers, E., \& Dagnan, D. (2008). Responding mindfully to unpleasant thoughts and images: Reliability and validity of the Southampton Mindfulness Questionnaire (SMQ). British Journal of Clinical Psychology, 47, 451-455.

Chambers, R., Gullone, E., \& Allen, N. B. (2009). Mindful emotion regulation: An integrative review. Clinical Psychological Review, 29, 560-570.

Chatterton, J. M., \& Petrie, T. A. (2013). Prevalence of disordered eating and pathogenic weight control behaviors among male collegiate athletes. Eating Disorders, 21, 328-341.

Chiesa, A., \& Serretti, A. (2009). Mindfulness-based stress reduction for stress management in healthy people: A review and meta-analysis. The Journal of Alternative and Complimentary Medicine, 15(5), 593-600.

Clabaugh, A., \& Morling, B. (2004). Stereotype accuracy of ballet and modern dancers. Journal of Social Psychology, 144(1), 3-48.

Claes, L., Vandereycken, W., \& Vertommen, H. (2005). Impulsivity-related traits in eating disorder patients. Personality and Individual Differences, 39(4), 739-749. 
Clark, L., \& Tiggemann, M. (2008). Sociocultural and Individual Psychological Predictors of Body Image in Young Girls: A Prospective Study. Developmental Psychology, 44(4), 1124-1134.

Clyne, C., Latner, J. D., Gleaves, D. H., \& Blampied, N. M. (2010). Treatment of emotional dysregulation in full syndrome and subthreshold binge eating disorder. Eating Disorders, $18,408-424$.

Collins, L. M., Schafer, J. L., \& Kam, C. (2001). A comparison of inclusive and restrictive strategies in modern missing data procedures. Psychological Methods, 6(4), 330-351.

Compassion focused therapy (2016). Retrieved from http://psychology.tools/compassionfocused-therapy.html

Conner, M., Fitter, M., \& Fletcher, W. (1999). Stress and snacking: A diary study of daily hassles and between meal snacking. Psychology and Health, 14, 51-63.

Cook, D. R. (1994). Internalised shame scale professional manual. Wisconsin: Channel Press.

Cooley, E., \& Toray, T. (2001). Body image and personality predictors of eating disorder symptoms during the college years. International Journal of Eating Disorders, 30, 28-36.

Cooper, M. J. (2006). Beliefs and their relationship to eating attitudes and depressive symptoms in men. Eating Behaviors, 7, 423-426.

Cooper, J. L., O'Shea, A. E., Atkinson, M. J., \& Wade, T. D. (2014). Examination of the Difficulties in Emotion Regulation Scale and its relation to disordered eating in a young female sample. International Journal of Eating Disorders, 47(6), 630-639.

Cowdrey, F. A., \& Park, R. J. (2012). The role of experiential avoidance, rumination and mindfulness in eating disorders. Eating Behaviors, 13, 100-105. 
Crow, S.J., Peterson, C.B., Swanson, S.A., Raymond, N.C., Specker, S., Eckert, E.D., Mitchell, J.E. (2009) Increased mortality in bulimia nervosa and other eating disorders. American Journal of Psychiatry, 166, 1342-1346.

Crow, S., Zander, K., Crosby, R., \& Mitchell, J. (1996). Discriminant function analysis of depressive symptoms in binge eating disorder, bulimia nervosa, and major depression. International Journal of Eating Disorders, 19, 399-404.

Danner, U. N., Ouwehand, C., Haastert, N. L., Hornsveld, H., \& Ridder, D. T. D. (2012). Decision-making impairments in women with binge eating disorder in comparison with obese and normal weight women. European Eating Disorders Review, 20, 56-62.

Danner, U. N., Evers, C., Stok, F., Elburg, A. A., \& Ridder, D. D. (2012). A double burden: Emotional eating and lack of cognitive reappraisal in eating disordered women. European Eating Disorders Review, 20(6), 490-495.

Danner, U. N., Sternheim, L., \& Evers, C. (2014). The importance of distinguishing between the different eating disorders (sub)types when assessing emotion regulation strategies. Psychiatry Research, 215(3), 727-732.

Deaver, C. M., Miltenberger, R. G., Smyth, J., Meidinger, A., \& Crosby, R. (2003). An evaluation of affect and binge eating. Behavior Modification, 27, 578-599.

DeBate, R., Blunt, H., \& Becker, M. (2010). Eating disorders. In B. Levin, M. Becker (Eds.), $A$ public health perspective of women's mental health (pp. 121-141). New York: Springer Science + Business Media

de Bruin, E. I., Topper, M., Muskens, J. G. A. M., Bogels, S. M., \& Kamphuis, J. H. (2012). Psychometric properties of the Five Facets Mindfulness Questionnaire (FFMQ) in a meditating and non-meditating sample. Assessment, 19(2), 187-197. 
DeLeel, M. L., Hughes, T. L., Miller, J. A., Hipwell, A., \& Theodore, L. A. (2009). Prevalence of eating disturbance and body image dissatisfaction in young girls: An examination of the variance across racial and socioeconomic groups. Psychology in the Schools, 46(8), 767-775.

Dewberry, C., \& Ussher, J. M. (2001). Restraint and perception of body weight among British adults. The Journal of Social Psychology, 134, 609-619.

Dijkstra, P., \& Barelds, D. P. H. (2011). Examining a model of dispositional mindfulness, body comparison, and body satisfaction. Body Image, 8, 419-422.

Dillman, D. A. (2000). Mail and Internet surveys: The tailored design method. New York: John Wiley \& Sons, Inc.

Disordered eating in midlife and beyond. (2012). Harvard Women's Health Watch, 19(6), 1-3.

Engelberg, M. J., Steiger, H., Gauvin, L., \& Wonderlich, S. (2007). Binge antecedents in bulimic syndromes: An examination of dissociation and negative affect. International Journal of Eating Disorders, 40, 531-536.

Elfhag, K., \& Linne, Y. (2004). Gender differences in associations of eating pathology between mothers and their adolescent offspring. Obesity Research, 13(6), 1070-1076.

Espeset, E. S., Gulliksen, K. S., Nordbø, R. S., Skårderud, F., \& Holte, A. (2012). The link between negative emotions and eating disorder behaviour in patients with anorexia nervosa. European Eating Disorders Review, 20(6), 451-460.

Evers, C., Stok, M. F., \& de Ridder, D. T. D. (2010). Feeding your feelings: Emotion regulation strategies and emotional eating. Personality and Social Psychology Bulletin, 36, 792-804.

Fairburn, C. G. (Ed.). (2008). Cognitive behavior therapy and eating disorders. New York: The Guilford. 
Fairburn, C. G., \& Brownell, K. D. (Eds.). (2013). Eating disorders and obesity (2 ${ }^{\text {nd }}$ ed.). New York: The Guilford Press.

Fairburn, C. G., Cooper, Z., \& Shafran, R. (2003). Cognitive behavior therapy for eating disorders. A 'transdiagnostic' theory and treatment. Behavior Research and Therapy, 41, $509-528$.

Favaro, A., Monteleone, P., \& Santonastaso, P., \& Maj, M. (2008). Psychobiology of eating disorders. Annual Review of Eating Disorders (Part 2). Oxford, UK: Radcliffe.

Ferguson, C. J., Munoz, M. E., Contreras, S., \& Velasquez, K. (2011). Mirror, mirror on the wall: Peer competition, television influences, and body image dissatisfaction. Journal of Social and Clinical Psychology, 30(5), 458-483.

Ferreira, C., Pinto-Gouveia, J., \& Duarte, C. (2013). Self-compassion in the face of shame and body image dissatisfaction: Implications for eating disorders. Eating Behaviors, 14, 207 210.

Fisak, B., \& von Lehe, A. C. (2012). The relation between the Five Facets of Mindfulness and worry in a non-clinical sample. Mindfulness, 3(1), 15-21.

Fischer, S., Smith, G. T., \& Cyders, M. A. (2008). Another look at impulsivity: A meta-analytic review comparing specific dispositions to rash action in their relationship to bulimic symptoms. Clinical Psychology Review, 28, 1413-1425.

Fisher, S. (1990). The evolution of psychological concepts about the body. In T. F. Cash \& T. Pruzinsky (Eds.), Body images. Development, deviance and change (pp. 3-20). New York: The Guilford Press.

Forbush, K., \& Watson, D. (2006). Emotional inhibition and personality traits: A comparison of women with anorexia, bulimia, and normal controls. Annals of Clinical Psychiatry, 18, 
$115-121$

Forney, K. J., \& Ward, R. M. (2013). Examining the moderating role of social norms between body dissatisfaction and disordered eating in college students. Eating Behaviors, 14(1), 73-78.

Fox, H., Hong, K., \& Sinha, R. (2008). Difficulties in emotion regulation and impulse control in recently abstinent alcoholics compared with social drinkers. Addictive Behaviors, 33, 388-394.

Fox, J. R., \& Power, M. J. (2009). Eating disorders and multi-level models of emotion: An integrated model. Clinical Psychology \& Psychotherapy, 16, 240-267.

Fredrickson, B. L. (2001). The role of positive emotions in positive psychology. American Psychologist, 56, 218-226.

Friederich, H. C., Wu, M., Simon, J. J., \& Herzog, W. (2013). Neurocircuit function in eating disorders. International Journal of Eating Disorders, 46, 425-432.

Furman, W., \& Buhrmester, D. (1992). Age and sex differences in perceptions of networks of personal relationships. Child Development, 63(1), 102-115.

Garfinkel, P. E., \& Garner, D. M. (1982). Anorexia nervosa: A multidimensional approach. New York: Brunner/Mazel.

Garner, D. M., Olmsted, M. P., Bohr, Y., Garfinkel, P. E., Garner, D. M., Olmsted, M. P., \& Garfinkel, P. E. (1982). Eating Attitudes Test-26. Psychological Medicine, 12(4), 871878.

George, D., \& Mallery, P. (2003). SPSS for Windows step by step: A simple guide and reference. 11.0 update $\left(4^{\text {th }}\right.$ ed.). Boston: Allyn \& Bacon. 
Germer, C. (2009). The mindful path to self-compassion: Freeing yourself from destructive thoughts and emotions. New York, NY: Guilford Press.

Gilbert, P. (2005). Compassion and cruelty: A biopsychological approach. In P. Gilbert (Ed.), Compassion: Conceptualisations, research and use in psychotherapy (pp. 9-74). London: Routledge.

Gilbert, P. (2010). Compassion focused therapy: Distinctive features. New York, NY: Routledge/Taylor \& Francis Group.

Gilbert, P. (2009a). Introducing compassion-focused therapy. Advances in Psychiatric Treatment, 15(3), 199-208.

Gilbert, P. (2009b). The compassionate mind: A new approach to facing the challenges of life. London: Constable Robinson.

Gilbert, P. (2012). Fears of self-compassion in a clinical population. Manuscript under review. Gilbert, P., \& Irons, C. (2005). Focused therapies and compassionate mind training for shame and self-attacking. In P. Gilbert (Ed.), Compassion: Conceptualisations, research and use in psychotherapy. (pp. 263-325). New York, NY: Routledge.

Gilbert, P., McEwan, K., Matos, M., \& Rivis, A. (2011). Fears of compassion: Development of three self-report measures. Psychology and Psychotherapy, 84(3), 239-255.

Gilbert, P., \& Procter, S. (2006). Compassionate Mind Training for people with high shame and self-criticism: Overview and pilot study of a group therapy approach. Clinical Psychology \& Psychotherapy, 13, 353-379.

Gilboa-Schechtman, E., Avnon, L., Zubery, E., \& Jeczmien, P. (2006). Emotional processing in eating disorders: Specific impairment or general distress related deficiency? Depression and Anxiety, 23, 331-339. 
Godart, N., Perdereau, F., Rein, Z., Berthoz, S., Wallier, J., Jeammet, P. H., et al. (2007). Comorbidity studies of eating disorders and mood disorders. Critical review of the literature. Journal of Affective Disorders, 97, 37-49.

Goldstein, J. (2002). One Dharma: The emerging Western Buddhism. San Francisco: Harper Collins.

Goss, K., \& Allan, S. (2010). Compassion focused therapy for eating disorders. International Journal of Cognitive Therapy, 3(2), 141-158.

Goss, K. P., \& Gilbert, P. (2002). Eating disorders, shame and pride: A cognitive-behavioural functional analysis. In P. Gilbert, \& J. Miles (Eds.), Body shame: Conceptualization, research \& treatment (pp. 219-255). Hove, UK: Brunner-Routledge.

Grabe, S., Ward, L., \& Hyde, J. (2008). The role of media in body image concerns among women: A meta-analysis of experimental and correlational studies. Psychological Bulletin, 134(3), 460-476.

Gratz, K. L. (2007). Targeting emotion dysregulation in the treatment of self-injury. Journal of Clinical Psychology, 63, 1091-1103.

Gratz, K. L., \& Roemer, L. (2004). Multidimensional assessment of emotion regulation and dysregulation: Development, factor structure, and initial validation of the Difficulties in Emotion Regulation Scale. Journal of Psychopathology and Behavioral Assessment, 26, 41-54.

Gratz, K. L., \& Tull, M. T. (2010). Emotion regulation as a mechanism of change in acceptanceand mindfulness-based treatments. In R. A. Baer (Ed.), Assessing mindfulness and acceptance: Illuminating the processes of change (pp. 107-134). Oakland, CA: New Harbinger Publications. 
Grilo, C. M., \& Mitchell, J. E. (Eds.). (2010). The treatment of eating disorders. New York: The Guilford Press.

Groesz, L. M., Levine, M. P., \& Murnen, S. K. (2002). The effect of experimental presentation of thin media images on body satisfaction: A meta-analytic review. International Journal of Eating Disorders, 31(1), 1-16.

Gross, J. J. (1998). The emerging field of emotion regulation: An integrative review. Review of General Psychology, 2, 271-299.

Gross, J. J. (2002). Emotion regulation: affective, cognitive, and social consequences. Psychophysiology, 39, 281-291.

Gross, J. J., \& John, O. P. (2003). Individual differences in two emotion regulation processes: Implications for affect, relationships, and well-being. Journal of Personality and Social Psychology, 85, 348-362.

Haber, S. N., Kim, K., Mailly, P., \& Calzavara, R. (2006). Reward-related cortical inputs define a large striatal region in primates that interface with associative cortical connections, providing a substrate for incentive-based learning. Journal of Neuroscience, 26(32), 8368-8376.

Haedt-Matt, A. A., \& Keel, P. K. (2011). Revisiting the affect regulation model of binge eating: A meta-analysis of studies using ecological momentary assessment. Psychological Bulletin, 137, 660-681.

Hair, Jr., J. F., Anderson, R. E., Tatham, R. \& Black, W. C. (1992). Multivariate data analysis with readings $\left(3^{\text {rd }}\right.$ ed.). New York: Macmillan Publishing.

Halford, J., Cooper, G., \& Dovey, T. (2004). The pharmacology of human appetite expression. Current Drug Targets; 5, 221-240. 
Hall, C. W., Row, K. A., Wuensch, K. L., \& Godley, K. R. (2013). The role of self-compassion in physical and psychological well-being. The Journal of Psychology, 147(4), 311-323.

Hambrook, D., Oldershaw, A., Rimes, K., Schmidt, U., Tchanturia, K., Treasure, J., et al. (2011). Emotional expression, self-silencing, and distress tolerance in anorexia nervosa and chronic fatigue syndrome. British Journal of Clinical Psychology, 50(3), 310-325.

Hargreaves, D. A., \& Tiggemann, M. (2004). Idealized media images and adolescent body image: 'Comparing' boys and girls. Body Image, 1, 351-361.

Harrison, A., Sullivan, S., Tchanturia, K., \& Treasure, J. (2010). Emotional functioning in eating disorders: Attentional bias, emotion recognition and emotion regulation. Psychological Medicine, 40, 1887-1897.

Harvey, A., Watkins, E., Mansell, W., \& Shafran, R. (2004). Cognitive behavioural processes across psychological disorders: A transdiagnostic approach to research and treatment. Oxford: Oxford University Press.

Hayaki, J. (2009). Negative reinforcement eating expectancies, emotion dysregulation, and symptoms of bulimia nervosa. International Journal of Eating Disorders, 42, 552-556.

Hayes, A. M., \& Feldman, G. (2004). Clarifying the construct of mindfulness in the context of emotion regulation and the process of change in therapy. Clinical Psychology: Science and Practice, 11(3), 255-262.

Hayes, S. C., Strosahl, K., \& Wilson, K. G. (1999). Acceptance and commitment therapy: An experiential approach to behavior change. New York: Guilford.

Heatherton, T. F., \& Baumeister, R. F. (1991). Binge eating as escape from self-awareness. Psychological Bulletin, 110, 86-108.

Hein, G., \& Singer, T. (2008). I feel how you feel but not always: The empathic brain and its 
modulation. Current Opinion in Neurobiology, 18, 153-158.

Hilbert, A., \& Tuschen-Caffier, B. (2007). Maintenance of binge eating through negative mood: A naturalistic comparison of binge eating disorder and bulimia nervosa. International Journal of Eating Disorders, 40, 521-530.

Hoek, H. (2006). Incidence, prevalence and mortality of anorexia and other eating disorders. Current Opinion in Psychiatry, 19, 389-394.

Hoffman, S. G., Sawyer, A. T., Witt, A. A., \& Oh, D. (2010). The effect of mindfulness-based therapy on anxiety and depression: A meta-analytic review. Journal of Consulting and Clinical Psychology, 78(2), 169-183.

Holas, P., \& Jankowski, T. (2013). A cognitive perspective on mindfulness. International Journal of Psychology, 48(3), 232-243.

Hollis-Walker, L., \& Colosimo, K. (2011). Mindfulness, self- compassion, and happiness in nonmeditators: A theoretical and empirical examination. Personality and Individual Differences, 50(2), 222-227.

Hu, L. T., \& Bentler, P. M. (1999). Cutoff criteria for fit indices in covariance structure analysis: Conventional criteria versus new alternatives. Structural Equation Modeling, 6, 1-55.

Hudson, J. I., Hiripi, E., Pope, H. G. Jr., \& Kessler, R. C. (2007). The prevalence and correlates of eating disorders in the National Comorbidity Survey Replication. Biological Psychiatry, 61, 348-358.

Kabat-Zinn, J. (1982). An outpatient program in behavioral medicine for chronic pain patients based on the practice of mindfulness meditation: Theoretical considerations and preliminary results. General Hospital Psychiatry, 4, 33-47.

Kabat-Zinn, J. (1990). Full catastrophe living: Using the wisdom of your mind to face stress, 
pain and illness. New York, NY: Dell Publishing.

Kabat-Zinn, J. (2000). Indra's net at work: The mainstreaming of Dharma practice in society. In G. Watson \& S. Batchelor (Eds.), The psychology of awakening: Buddhism, science, and our day-to-day lives (pp. 225-249). North Beach, ME: Weiser.

Kabat-Zinn, J. (2003). Mindfulness-based interventions in context: Past, present, and future. Clinical Psychology Science and Practice, 10, 144-156.

Kaufman, G. (1989). The psychology of shame: Theory and treatment of shame-based syndromes. New York: Springer.

Kaye, W. (2008). Neurobiology of anorexia and bulimia nervosa. Physiology \& Behavior, 94, $121-135$.

Kaye, W. H., Bulik, C. M., Thornton, L., Barbarich, N., \& Masters, K. (2004). Comorbidity of anxiety disorders with anorexia and bulimia nervosa. The American Journal of Psychiatry, 161(12), 2215-2221.

Kaye, S. H., Frank, G. K., Bailer, U. F., \& Henry, S. E. (2005). Neurobiology of anorexia nervosa: Clinical implications of alterations of the function of serotonin and other neuronal systems. International Journal of Eating Disorders, 37, S15-S19.

Keel, P. K. (2005). Eating disorders. Upper Saddle River, NJ: Pearson Prentice-Hall.

Keith, L., Gillanders, D., \& Simpson, S. (2009). An exploration of the main sources of shame in an eating-disordered population. Clinical Psychology and Psychotherapy, 16, 317-327.

Kelly, A. C., Carter, J. C., \& Zuroff, D. C. (2013). Self-compassion and fear of self-compassion interact to predict response to eating disorders treatment: A preliminary investigation. Psychotherapy Research, 23(3), 252-264. 
Kelly, N. R., Cotter, E. W., Tanofsky-Kraff, M., \& Mazzeo, S. E. (2015). Racial variations in binge eating, body image concerns, and compulsive exercise among men. Psychology of Men \& Masculinity, 16(3), 326-336.

Kelly, N. R., Mitchell, K. S., Gow, R. W., Trace, S. E., Lydecker, J. A., Bair, C. E., \& Mazzeo, S. (2012). An evaluation of the reliability and construct validity of eating disorder measures in White and Black women. Psychological Assessment, 24(3), 608-617.

Kelly, N. R., Zuroff, D. C., \& Shapira, L. B. (2009). Soothing oneself and resisting self-attacks: The treatment of two intrapersonal deficits in depression vulnerability. Cognitive Therapy and Research, 33, 301-313.

Kemps, E., \& Wilsdon, A. (2010). Preliminary evidence for a role for impulsivity in cognitive disinhibition in bulimia nervosa. Journal of Clinical and Experimental Neuropsychology, $32,515-21$.

Keng, S. L., Smoski, M. J., \& Robins, C. J. (2011). Effects of mindfulness on psychological health: A review of empirical studies. Clinical Psychology Review, 31, 1041-1056.

Kline, R. B. (1998). Principles and practice of structural equation modeling. New York: The Guilford Press.

Krasnow, D. H. (2005). Sustaining the dance artist: Barriers to communication between educators, artists, and researchers. In Ausdance national, Dance rebooted: Initializing the grid (pp. 1-10). Toronto, Canada: York University.

Kristeller, J. L., \& Hallett, B. (1999). Effects of a meditation-based intervention in the treatment of binge eating. Journal of Health Psychology, 4, 357-363.

Krones, P. G., Stice, E., Batres, C., \& Orjada, K. (2005). In vivo social comparison to a thinideal peer promotes body dissatisfaction: A randomized experiment. International 
Journal of Eating Disorders, 38, 134-142.

Langer, E., Pirson, M., \& Delizonna, L. (2010). The mindlessness of social comparisons.

Psychology of Aesthetics, Creativity, and the Arts, 4, 68-74.

Latner, J. D., \& Clyne, C. (2008). The diagnostic validity of the criteria for binge eating disorder. International Journal of Eating Disorders, 41, 1-14.

Lavender, J. M., \& Anderson, D. A. (2009). Effect of perceived anonymity in assessments of eating disordered behaviors and attitudes. International Journal of Eating Disorders, 42, $546-551$.

Lavender, J. M., \& Anderson, D. A. (2010). Contribution of emotion regulation difficulties to disordered eating and body dissatisfaction in college men. International Journal of Eating Disorders, 43(4), 352-357.

Lavender, J. M., Gratz, K. L., \& Tull, M. T. (2011). Exploring the relationship between facets of mindfulness and eating pathology in women. Cognitive Behaviour Therapy, 40(3), 174182.

Lavender, J. M., Jardin, B. F., \& Anderson, D. A. (2009). Bulimic symptoms in undergraduate men and women: Contributions of mindfulness and thought suppression. Eating Behaviors, 10(4), 228-231.

Lavender, J. M., Wonderlich, S. A., Peterson, C. B., Crosby, R. D., Engel, S. G., Mitchell, J. E., \& Berg, K. C. (2014). Dimensions of Emotion Dysregulation in Bulimia Nervosa. European Eating Disorders Review, 22(3), 212-216.

Leary, M. R., Adams, C. E., \& Tate, E. B. (2006). Hypo-egoic self-regulation: Exercising selfcontrol by diminishing the influence of the self. Journal of Personality, 74, 1803-1831.

Linehan, M. M. (1993a). Cognitive-behavioral treatment of borderline personality disorder. 
New York: Guilford.

Linehan, M. M. (1993b). Skills training manual for treating borderline personality disorder. New York: Guilford.

Loelin, J.C. (2004). Latent Variable Models: An Introduction to Factor, Path, and Structural Equation Analysis, Fourth Edition. New Jersey: Lawrence Erlbaum Associates.

Lowens, I. (2010). Compassion focused therapy for people with bipolar disorder. International Journal of Cognitive Therapy, 3(2), 172-185.

Luce, K., Engler, P. A., \& Crowther, J. H. (2007). Eating disorders and alcohol use: Group differences in consumption rates and drinking motives. Eating Behaviors, 8, 177-184.

MacCallum, R. C., Browne, M. W., \& Sugawara, H. M. (1996). Power analysis and determination of sample size for covariance structure modeling. Psychological Methods, 2, $130-149$.

Magnus, C.M.R., Kowalski, K.C., \& McHugh, T.F. (2010). The role of self-compassion in women's self-determined motives to exercise and exercise-related outcomes. Self and Identity, 9, 363-382.

Mann, T., \& Ward, A. (2001). Forbidden fruit. Does thinking about a prohibited food lead to its consumption? International Journal of Eating Disorders, 29, 319-327.

Marcos, Y. Q., Sebastian. M. J. Q., Aubalat, L. P., Ausina, J. B., \& Treasure, J. (2013). Peer and family influence in eating disorders: A meta-analysis. European Psychiatry, 28, 199-206.

Marlatt, G. A., \& Gordon, J. R. (1985). Relapse prevention: Maintenance strategies in the treatment of addictive behaviors. New York: Guilford.

Marques, L., Algeria, M., Becker, A. E., Chen, C., Fang, A., Chosak, A., \& Belo Diniz, J. (2011). Comparative prevalence, correlates of impairment, and service utilization for 
eating disorders across U.S. ethnic groups: Implications for reducing ethnic disparities in health care access for eating disorders. International Journal of Eating Disorders, 44(5), 412-420.

Martell, C. R., Dimidjian, S., \& Herman-Dunn, R. (2010). Behavioral activation for depression: A clinician's guide. New York, NY: Guilford Press.

Masuda, A., Anderson, P. L., \& Sheehan, S. (2009). Mindfulness and mental health among African American college students. Complementary Health Practice Review, 14, 115127.

Masuda, A., Price, M., Anderson, P.L., \& Wendell, J. W. (2010). Disordered eating-related cognition and psychological flexibility as predictors of psychological health among college students. Behavior Modification, 34, 3-15.

Masuda, A., Price, M., \& Latzman, R. D. (2012). Mindfulness moderates the relationship between disordered eating cognitions and disordered eating behaviors in a non-clinical college sample. Journal of Psychopathology and Behavioral Assessment, 34, 107-115.

Masuda, A., \& Wendell, J. W. (2010). Mindfulness mediates the relation between disordered eating-related cognitions and psychological distress. Eating Behaviors, 11(4), 293-296.

McBeth, A., \& Camley, A. (2012). Exploring compassion: A meta-analysis of the association between self-compassion and psychopathology. Clinical Psychology Review, 32(6), 545552.

McCabe, M. P., \& Ricciardelli, L. A. (2005). A prospective study of pressures from parents, peers, and the media on extreme weight change behaviors among adolescent boys and girls. Behaviour Research \& Therapy, 43(5), 653-668. 
Mchiza, Z. J., Goedecke, J. H., \& Lambert, E. V. (2011). Intra-familial and ethnic effects on attitudinal and perceptual body image: A cohort of South African mother-daughter dyads. BMC Public Health, 11(1), 433-440.

Mellor, D., Fuller-Tyszkiewicz, M., McCabe, M. P., \& Ricciardelli, L. A. (2010). Body image and self-esteem across age and gender: A short-term longitudinal study. Sex Roles, 63, $672-681$

Mills, A., Gilbert, P., Bellew, R., McEwan, K., \& Gale, C. (2007). Paranoid beliefs and selfcriticism in students. Clinical Psychology \& Psychotherapy, 14, 358-364.

Mitchell, J. E., Hatsukami, D., Eckert, E. D., \& Pyle, R. L. (1985). Characteristics of 275 patients with bulimia. American Journal of Psychiatry, 142, 482-485.

Mizes, J. S., Christiano, B., Madison, J., Post, G., Seime, R., \& Varnado, P. (2000). Development of the Mizes anorectic cognitions questionnaire-revised: Psychometric properties and factor structure in a large sample of eating disorder patients. International Journal of Eating Disorder, 28, 415-421.

Monteleone, P., \& Maj, M. (2008). Genetic susceptibility to eating disorders: Associated polymorphisms and pharmacogenetic suggestions. Pharmacogenomics, 9, 487-520.

Morton, G., Cummings, D., Baskin, D., Barsh, G., \& Schwartz, M. (2006). Central nervous system control of food intake and body weight. Nature, 443(7109): 289-295.

Neff, K. (2003a). The development and validation of a scale to measure self-compassion. Self and Identity, 2, 223-250.

Neff, K. (2003b). Self-Compassion: An alternative conceptualization of a healthy attitude toward oneself. Self and Identity, 2, 85-101.

Neff, K. D. (2004). Self-compassion and psychological well-being. Constructivism in the Human 
Sciences, 9, 27-37.

Neff, K. D. (2009a). The role of self-compassion in development: A healthier way to relate to oneself. Human Development, 52, 211-214.

Neff, K. D. (2009b). Self-compassion versus global self-esteem: Two different ways of relating to oneself. Journal of Personality, 77, 23-50.

Neff, K. D. (2009c). Self-compassion. In M. R. Leary \& R. H. Hoyle (Eds.), Handbook of individual differences in social behavior (pp. 561-573). New York, NY: Guilford Press.

Neff, K., \& Germer, C. K. (2013). A pilot study and randomized controlled trial of the Mindful Self-Compassion program. Journal of Clinical Psychology, 69(1), 28-44.

Neff, K., Hsieh, Y., \& Dejitterat, K. (2005). Self-compassion, achievement goals, and coping with academic failure. Self and Identity, 4, 263-287.

Neff, K. D., Kirkpatrick, K. L., \& Rude, S. (2007). Self-compassion and adaptive psychological functioning. Journal of Research in Personality, 41(1), 139-154.

Neff, K., Rude, S., \& Kirkpatrick, K. (2007). An examination of self- compassion in relation to positive psychological functioning and personality traits. Journal of Research in Personality, 41, 908-916.

Neff, K., \& Vonk, R. (2009). Self-compassion versus global self-esteem: Two different ways of relating to oneself. Journal of Personality, 77, 23-50.

Nieuwenhuis, S., Ridderinkhof, K. R., Blom, J., Band, G. P., Kok, A. (2001). Error-related brain potentials are differentially related to awareness of response errors: Evidence from an antisaccade task. Psychophysiology, 38(5), 752-756

Nolen-Hoeksema, S., Wisco, B. E., \& Lyubomirsky, S. (2008). Rethinking rumination. Perspectives on Psychological Science, 3, 400-424. 
O’Rourke, N., \& Hatcher, L. (Eds.). (2013). A step-by-step approach to using SAS for factor analysis and structural equation modeling ( $2^{\text {nd }}$ ed.). Cary, NC: SAS Institute, Inc.

Park, R., Dunn, B., \& Barnard, P. (2011). Schematic models and modes of mind in anorexia nervosa I: A novel process account. International Journal of Cognitive Therapy, 4, 415437.

Park, R., Dunn, B., \& Barnard, P. (2012). Schematic models and modes of mind in anorexia nervosa II: Implications for treatment and course. International Journal of Cognitive Therapy, 5, 86-98.

Park, T., Reilly-Spong, M., \& Gross, C. (2013). Mindfulness: a systematic review of instruments to measure an emergent patient-reported outcome (PRO). Quality of Life Research: An International Journal of Quality of Life Aspects of Treatment, Care And Rehabilitation, 22(10), 2639-2659.

Parks, G. A., Anderson, B. K., \& Marlatt, G. A. (2001). Relapse prevention therapy. In N. Heather, T. J. Peters, \& T. Stockwell (Eds.), International handbook of alcohol dependence and problems (pp. 575- 592). New York: John Wiley.

Peterson, K. A., Paulson, S. E., \& Williams, K. K. (2007). Relations of eating disorder symptomatology with perceptions of pressure from mother, peers, and media in adolescent girls and boys. Sex Roles, 57(9/10), 629-639.

Petrie, T. A., \& Greenleaf, C. A. (2013). Eating disorders in sport. In S. Murphy (Ed.), Oxford handbook of sport and performance psychology (pp. 635-659). New York, NY: Oxford University Press.

Petrie, T. A., Greenleaf, C., Reel, J., \& Carter, J. (2008). Prevalence of eating disorders and disordered eating behavior in male collegiate athlete. Men and Masculinity, 9, 267-277. 
Pliner, P., Rizvi, S., \& Remick, A. (2009). Competition affects food choice in women. International Journal of Eating Disorders, 42(6), 557-564.

Power, M. J., \& Dalgleish, T. (2008). Cognition and emotion: From order to disorder (2nd edition). Hove, UK: Psychology Press, Taylor and Francis group.

Quick, V. M., \& Byrd-Bredbenner, C. (2013). Disturbed eating behaviours and associated psychographic characteristics of college students. Journal of Human Nutrition and Dietetics: The Official Journal of The British Dietetic Association, 26, 53-63.

Racine, S. E., \& Wildes, J. E. (2013). Emotion dysregulation and symptoms of anorexia nervosa: The unique roles of lack of emotional awareness and impulse control difficulties when upset. International Journal of Eating Disorders, 46(7), 713-720.

Raes, F. (2010). Rumination and worry as mediators of the relationship between self-compassion and depression and anxiety. Personality and Individual Differences, 48, 757-761.

Rawal, A., Park, R. J., \& Williams, J. M. G. (2010). Rumination, experiential avoidance, and dysfunctional thinking in eating disorders. Behaviour Research and Therapy, 48(9), 851859.

Rawal, A., Williams, J. M. G., \& Park, R. J. (2011). Effects of analytical and experiential selffocus on stress-induced cognitive reactivity in eating disorder psychopathology. Behaviour Research and Therapy, 49, 635-645.

Reindl, S. M. (2002). Sensing the self: Women's recovery from bulimia. London: Harvard University Press.

Richards, J. M., \& Gross, J. J. (2000). Emotion regulation and memory: The cognitive costs of keeping one's cool. Journal of Personality and Social Psychology, 79, 410-424.

Ringham, R., Klump, K., Kaye, W., Stone, D., Libman, S., Stowe, S., et al. (2006). Eating 
disorder symptomatology among ballet dancers. International Journal of Eating Disorders, 39(6), 503-508.

Rodin, J., Silberstein, L., \& Striegel-Moore, R. (1985). Women and weight: A normative discontent. In T. B. Sonderegger (Ed.), Psychology and gender (pp. 267-307). Lincoln: University of Nebraska Press.

Roemer, L., Lee, J. K., Salters-Pedneault, K., Erisman, S. M., Orsillo, S. M., \& Mennin, D. S. (2009). Mindfulness and emotion regulation difficulties in generalized anxiety disorder: Preliminary evidence for independent and overlapping contributions. Behavior Therapy, 40, $142-154$.

Rosval, L., Steiger, H., Bruce, K., Israël, M., Richardson, J., \& Aubut, M. (2006). Impulsivity in women with eating disorders: Problem of response inhibition, planning, or attention? International Journal of Eating Disorders, 39, 590-593.

Sacker, A. \& Cable, N. (2010). Transitions to adulthood and psychological distress in young adults born 12 years apart: Constraints on and resources for development. Psychological Medicin, 40, 301-313.

Safer, D. L., Telch, C. F., \& Chen, E. Y. (2009). Dialectical behavior therapy for binge eating and bulimia. New York, NY: Guilford Press.

SAS Institute Inc. (2013). Cary, NC: SAS Institute Inc.

Schluger, A. E. (2010). Disordered eating attitudes and behaviors in female college dance students: Comparison of modern dance and ballet majors. North American Journal of Psychology, 12(1), 117-128.

Schlundt, D. G., Virts, K. L., Sbrocco, T., \& Pope-Cordle, J. (1993). A sequential behavioural analysis of craving sweets in obese women. Addictive Behaviors, 18, 67-80. 
Schmidt, U., \& Treasure, J. (2006). Anorexia nervosa: Valued and visible. A cognitiveinterpersonal maintenance model and its implications for research and practice. British Journal of Clinical Psychology, 45, 343-366.

Schwartz, D. J., Phares, V., Tantleff-Dunn, S., \& Thompson, K. J. (1999). Body image, psychological functioning, and parental feedback regarding physical appearance. International Journal of Eating Disorders, 25(3), 339-343.

Schwartz, M. W., Woods, S. C., Porte Jr, D., Seeley, R. J., \& Baskin, D. G. (2000). Central nervous system control of food intake. Nature, 404(6778), 661-671.

Segal, Z. V., Teasdale, J. D., \& Williams, J. M. G. (2004). Mindfulness-based cognitive therapy: Theoretical rationale and empirical status. In S. C. Hayes, V. M. Follette, \& M. M. Linehan (Eds.), Mindfulness and acceptance: Expanding the cognitive behavioral tradition (pp. 45-65). New York: Guilford.

Segal, Z. V., Williams, J. M. G., \& Teasdale, J. D. (2002). Mindfulness-based cognitive therapy for depression. New York: Guilford Press.

Shapiro, S. L., Astin, J. A., Bishop, S. R., \& Cardova, M. (2005). Mindfulness Based Stress Reduction for health care professionals: Results from a randomized trial. International Journal of Stress Management, 12, 164-176.

Shapiro, S. L., Brown, K. W., \& Biegel, G. M. (2007). Teaching self-care to caregivers: Effects of mindfulness-based stress reduction on the mental health of therapists in training. Training and Education in Professional Psychology, 1, 105-115.

Shapiro, S. L., Carlson, L. E., Astin, J. A., \& Freedman, B. (2006). Mechanisms of mindfulness. Journal of Clinical Psychology, 62, 373-386. 
Shomaker, L. B. \& Furman, W. (2007). Same-sex peers' influence on young women's body image: An experimental manipulation. Journal of Social and Clinical Psychology, 26(8), 871-895.

Sides-Moore, L. \& Tochkov, K. (2011). The thinner the better? Competitiveness, depression and body image among college student women. College Student Journal, 45(2), 439-448.

Siegel, D. J. (2010). The mindful therapist: A clinician's guide to mindsight and neural integration. New York: W.W. Norton.

Sira, N. \& White, C. P. (2010). Individual and familial correlates of body satisfaction in male and female college students. Journal of American College Health, 58(6), 507-514.

Skarderud, F. (2003). Shame in cyberspace: Relationships without faces: the e-media and eating disorders. European Eating Disorders Review, 11, 155-169.

Slade, P. D. (1994). What is body image? Behavior Research and Therapy, 32, 297-502.

Smith, A. R., Li, N., \& Joiner, T. E. (2011). The pursuit of success: Can status aspirations negatively affect body satisfaction? Journal of Social and Clinical Psychology, 30(5), $531-547$.

Smolak, L., Murnen, S., \& Ruble, A. (2000). Female athletes and eating problems: a metaanalysis. International Journal of Eating Disorders, 27(4), 371-380.

Smyth, J. M., Wonderlich, S. A., Heron, K. E., Sliwinski, M. J., Crosby, R. D., Mitchell, J. E., \& Engel, S.G. (2007). Daily and momentary mood and stress are associated with binge eating and vomiting in bulimia nervosa patients in the natural environment. Journal of Consulting and Clinical Psychology, 75, 629-638.

Soh, N. L., Touyz, S. W., \& Surgenor, L. J. (2006). Eating and body image disturbances across cultures: A review. European Eating Disorders Review, 14(1), 54-65. 
Spangler, D. L. (2002). Testing the cognitive model of eating disorders. The role of dysfunctional beliefs about appearance. Behavior Therapy, 33, 87-105.

Stevens, J. P. (2002). Applied multivariate statistics for social science (4th Ed.). Hillsdale, New Jersey.

Stoving, R. K., Hangaard, J., Hansen-Nord, M., \& Hagen, C. (1999). A review of endocrine changes in anorexia nervosa. Journal of Psychiatric Research, 33, 139-152.

Streiner, D. L. (2005). Finding our way: An introduction to path analysis. Canadian Journal of Psychiatry, 50(2), 115-122.

Striegel-Moore, R. H., \& Cachelin, F. M. (1999). Body image concerns and disordered eating in adolescent girls: Risk and protective factors. In N. G. Johnson \& M. C. Roberts (Eds.), Beyond appearance: A new look at adolescent girls (pp. 85-108). Washington, DC: American Psychological Association

Svaldi, J., Caffier, D., \& Tuschen-Caffier, B. (2010). Emotion suppression but not reappraisal increases desire to binge in women with binge eating disorder. Psychotherapy and Psychosomatics, 79, 188-190.

Svaldi, J., Griepenstroh, J., Tuschen-Caffier, B., \& Ehring, T. (2012). Emotion regulation deficits in eating disorders: A marker of eating pathology or general psychopathology? Psychiatry Research, 197, 103-111.

Swan, S., \& Andrews, B. (2003). The relationship between shame, eating disorders and disclosure in treatment. British Journal of Clinical Psychology, 42, 367-378.

Swanson, S. A., Crow, S. J., Le Grange, D., Swendsen, J., \& Merikangas, K. R. (2011). Prevalence and correlates of eating disorders in adolescents. Archives of General Psychiatry, 68, 714-723. 
Tangney, J., \& Dearing, R.L. (2002). Shame and guilt. New York: Guilford Press.

Thomas, J. J., Keel, P. K., \& Heatherton, T. F. (2005). Disordered eating attitudes and behaviors in ballet students: Examination of environmental and individual risk factors. International Journal of Eating Disorders, 38(3), 263-268.

Thompson, J. K., Heinberg, L. J., Altabe, M., \& Tantleff Dunn, S. (1999). Exacting beauty. Theory, assessment, and treatment of body image disturbance. Washington, DC: American Psychological Association.

Thompson, B. L., \& Waltz, J. (2008). Self-compassion and PTSD symptom severity. Journal of Traumatic Stress, 21, 556-558.

Treasure, J., Corfield, F., \& Cardi, V. (2012). A three-phase model of the social emotional functioning in eating disorders. European Eating Disorders Review, 20, 431-438.

Tugade, M. M., \& Fredrickson, B. L. (2004). Resilient individuals use positive emotions to bounce back from negative emotional experiences. Journal of Personality and Social Psychology, 86, 320-333.

Tylka, T. L. (2011). Positive psychology perspectives on body image. In T. F. Cash \& L. Smolak (Eds.), Body image: A handbook of science, practice, and prevention (pp. 56-64).

Twenge, J., Gentile, B., DeWall, C., Ma, D., Lacefiled, K. \& Schurtz, D. (2010). Birth cohort increases in psychopathology among young Americans, 1938-2007: A cross-temporal meta-analysis of the MMPI. Clinical Psychology Review, 30, 145-154.

van de Mortel, T. (2008). Faking it: Social desirability response bias in self-report research. Australian Journal of Advanced Nursing, 25(4), 40-48.

Van Strien, T., Frijters, J. E. R., Bergers, G. P. A., \& Defares, P. B. (1986). The Dutch Eating Behaviour Questionnaire (DEBQ) for assessment of restrained, emotional and external 
eating behaviour. International Journal of Eating Disorders, 5, 747-755.

Voluntary Systems of Accounting Program (n.d.). College Portraits. Retrieved from http://www.collegeportraits.org/WV/WVU/characteristics

Wade, T. D., Bergin, J. L., Tiggemann, M., Bulik, C. M., \& Fairburn, C. G. (2006). Prevalence and long-term course of lifetime eating disorder in adult Australian twin cohort. Australian and New Zealand Journal of Psychiatry, 40, 121-128.

Walach, H., Buchheld, N., Buttenmuller, V., Kleinknecht, N., \& Schmidt, S. (2006). Measuring mindfulness: The Freiburg Mindfulness Inventory (FMI). Personality and Individual Differences, 40, 1543-1555.

Walcott, D. D., Pratt, H. D., \& Patel, D. R. (2003). Adolescents and eating disorders: Gender, racial, ethnic, sociocultural, and socioeconomic issues. Journal of Adolescent Research, 18(3), 223-243.

Wasylkiw, L., MacKinnon, A. L., \& MacLellan, A. M. (2012). Exploring the link between selfcompassion and body image in university women. Body Image, 9, 236-245.

Waxman, S. E. (2009). A systematic review of impulsivity in eating disorders. European Eating Disorders Review, 17, 408-425.

Webb, J. B., \& Forman, M. J. (2013). Evaluating the indirect effect of self-compassion on binge eating severity through cognitive-affective self-regulatory pathways. Eating Behaviors, 14, 224-228.

Weingarten, H., \& Elston, D. (1991). Food cravings in a college population. Appetite, 17, 167175.

West Virginia University (WVU) Introduction and Academics (2016). Students. Retrieved from http://www.stateuniversity.com/universities/WV/West_Virginia_University.html 
Whelton, W., \& Greenberg, L. (2005). Emotion in self-criticism. Personality and Individual Differences, 38, 1583-1595.

Whiteside, U., Chen, E., Neighbors, C., Hunter, D., Lo, T., \& Larimer, M. (2007). Difficulties regulating emotions: Do binge eaters have fewer strategies to modulate and tolerate negative affect? Eating Behaviors, 8, 162-169.

Wildes, J. E., Ringham, R. M., \& Marcus, M. D. (2010). Emotion avoidance in patients with anorexia nervosa: Initial test of a functional model. International Journal of Eating Disorders, 43(5), 398-404.

Williams, M. J., Dalgleish, Karl, A., \& Kuyken, W. (2014). Examining the factor structures of the Five Facet Mindfulness Questionnaire and the Self-Compassion Scale. Psychological Assessment, 26(2), 407-418.

Williams, J. G., Stark, S. K., \& Foster, E. E. (2008). Start today or the very last day? The relationships among self-compassion, motivation, and procrastination. American Journal of Psychological Research, 4, 37-44.

Williamson, D. A., Anderson, D. A., Jackman, L. P., \& Jackson, S. R. (1995). Assessment of eating disordered thoughts, feelings, and behaviors. In D. B. Allison (Ed.), Handbook of assessment methods for eating behaviors and weight-related problems (pp. 347-386). Newbury Park, CA: Sage.

Williamson, D. A., Prather, R. C., McKenzie, S. J., \& Blouin, D. C. (1990). Behavioral assessment procedures can differentiate bulimia nervosa, compulsive overeater, obese, and normal subjects. Behavioral Assessment, 12, 239-252.

Wiser, S., \& Telch, C. F. (1999). Dialectical behavior therapy for binge-eating disorder. Journal of Clinical Psychology, 55, 755-768. 
Woolhouse, H., Knowles, A., \& Crafti, N. (2012). Adding mindfulness to CBT programs for binge eating: A mixed-methods evaluation. Eating Disorders, 20, 321-339.

Yin, H., \& Knowlton, B. (2006). The role of the basal ganglia in habit formation. Nature Reviews Neuroscience, 7(6), 464-476.

Ying, Y. W. (2009). Contribution of self-compassion to competence and mental health in social work students. Journal of Social Work Education, 45, 309-323.

Zeeck, A., Stelzer, N., Linster, H. W., Joos, A., \& Hartmann, A. (2011). Emotion and eating in binge eating disorder and obesity. European Eating Disorder Review, 19, 426-437. 
Appendix A

\section{Integrated Model of Eating Disorder Symptomatology}

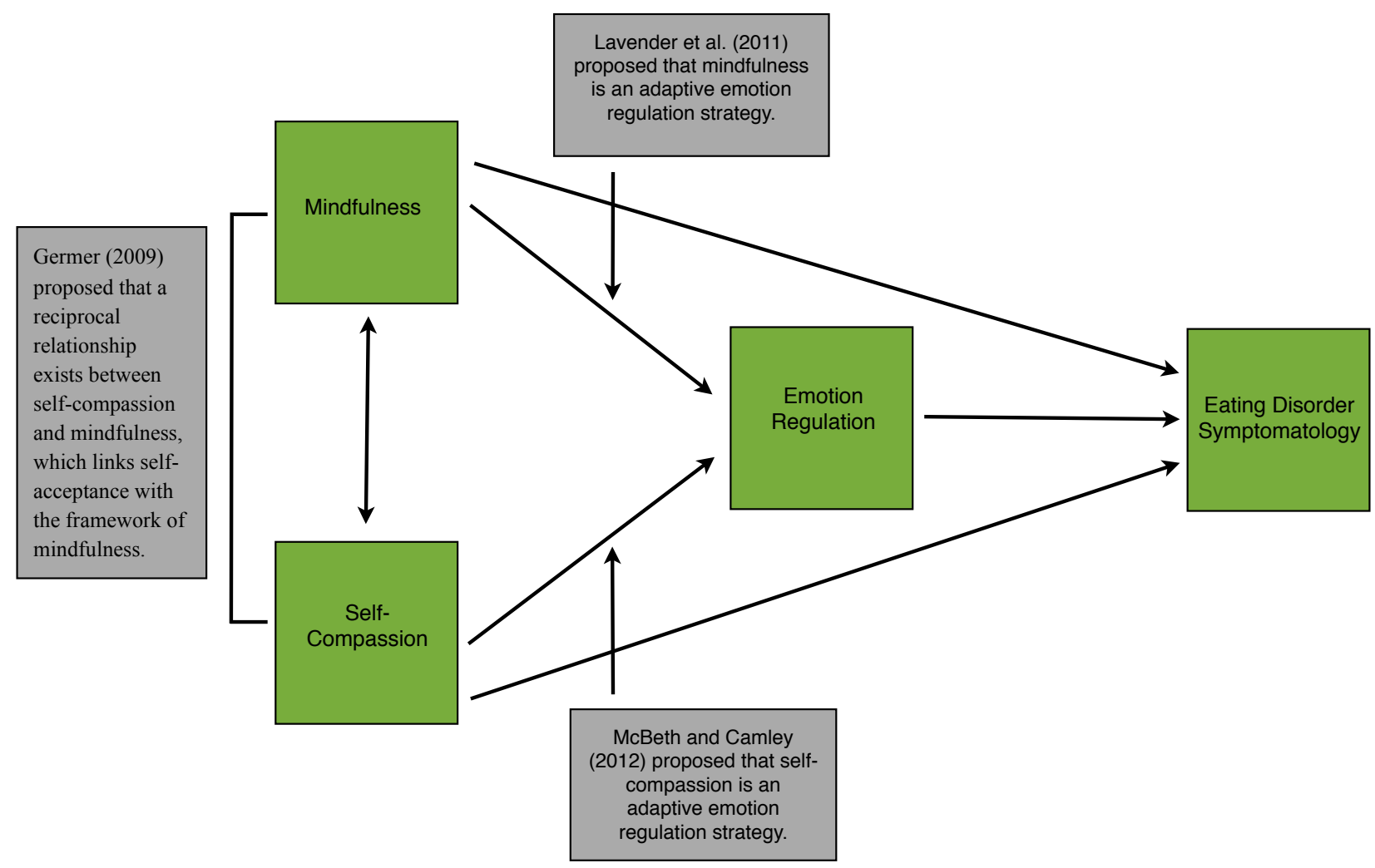


Appendix B

\section{Survey Advertisement}

\section{Health Research Study}

Purpose of the Study

To explore the role of potential protective factors on eating disorder symptoms

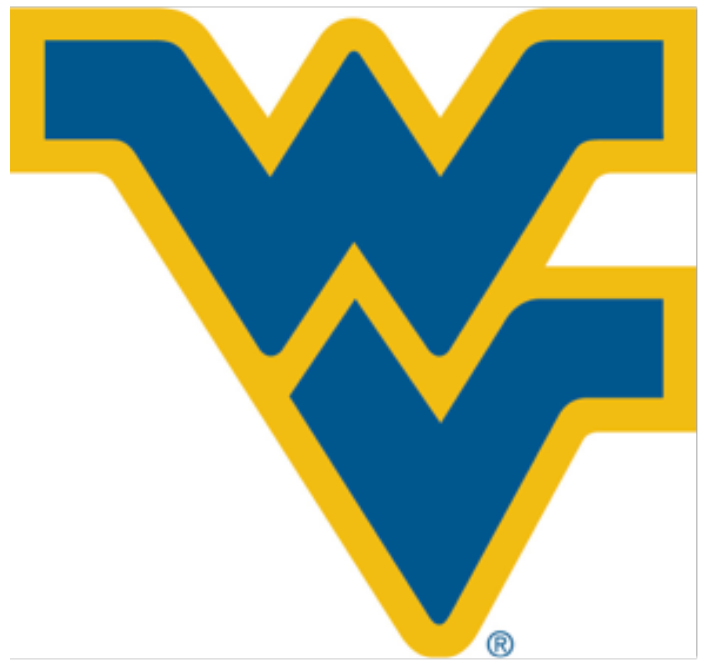

Who Can Be in This Study?

Participants must be 18 years or older and enrolled at least part-time in an undergraduate or graduate

program at WVU

Incentive

Drawing for 1 of $10 \$ 20$ Visa gift cards

Survey Link

https://qtrial2olscol.col.qualtrics.com/SE/?

SID $\approx S V$ eRODP.JVaT9MCTH

Expected time to complete survey is 15 minutes

Contact

Monica Leppma, Ph.D., Frincipal Investigator

Monica.Leppmaømail.uvu.edu (304) $295-0540$

Lisa Meyer, M.A., Co-Investigator

paylomix.wvu.edu

IRB Frotocol \# 1412529029 


\title{
Appendix C
}

\section{Alternative Survey Advertisement}

\section{Health Research Study}

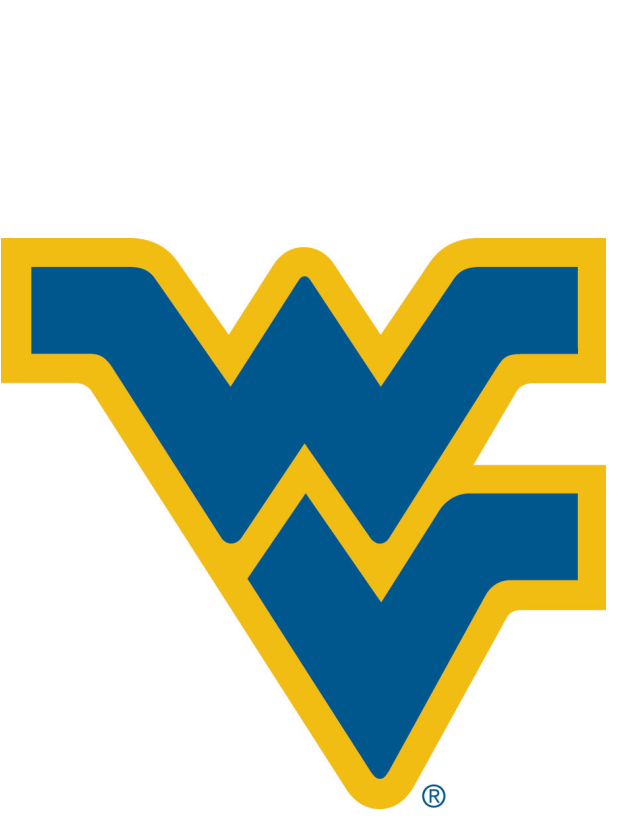

\author{
Purpose of the Study \\ To explore the role of potential protective \\ factors on eating disorder symptoms
}

Who Can Be in This Study? Participants must be 18 years or older and enrolled at least part-time in an undergraduate program at WVU

Incentive

Drawing for 1 of $10 \$ 20$ Visa gift cards

Survey Link
$\frac{\text { https://qtrial2O15col.col.qualtrics.com/SE/? }}{\text { SID=SV eRoDpJIVaT9MCTH }}$
Expected time to complete survey is 15 minutes

Contact

Monica Leppma, Ph.D., Príncípal Investigator Monica.Leppma@mail.wvu.edu (304) 293-0540

Lisa Meyer, M.A., Co-Investigator lpaylo@mix.wvu.edu

IRB Approval \# 1412529029
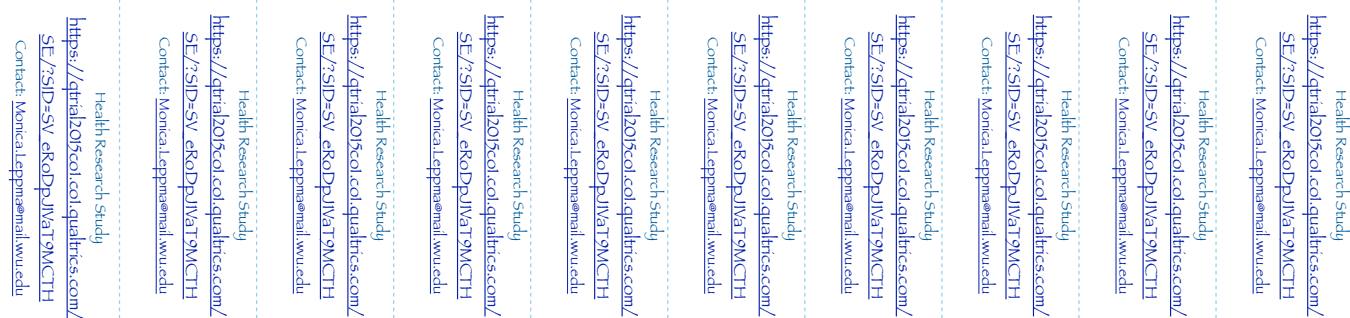


\section{Appendix D}

\section{Informed Consent}

\section{Only Minimal Risk \\ Consent Information Form (without HIPAA)}

Study Title

Principal Investigator

Co-Investigator(s)

Department

Protocol Number

\section{Health Research Dissertation Study}

Monica Leppma, Ph.D.

Lisa Meyer, M.A.

Counseling, Rehabilitation Counseling, and Counseling Psychology

1412529029

\section{Contact Persons}

In the event you experience any side effects or injury related to this research, you should contact Dr. Monica Leppma at (304) 293-0540. If you have any questions, concerns, or complaints about this research, you can contact Dr. Monica Leppma (Monica.Leppma@mail.wvu.edu) or Lisa Meyer at (lpaylo@mix.wvu.edu).

For information regarding your rights as a research subject, to discuss problems, concerns, or suggestions related to the research, to obtain information or offer input about the research, contact the Office of Research Compliance at (304) 293-7073.

In addition if you would like to discuss problems, concerns, have suggestions related to research, or would like to offer input about the research, contact the Office of Research Integrity and Compliance at 304-293-7073.

\section{Introduction}

You have been asked to participate in this research study, which is being conducted by Monica Leppma, Ph.D. and Lisa Meyer, M.A. in the Department of Counseling, Rehabilitation Counseling, and Counseling Psychology at West Virginia University.

\section{Purpose(s) of the Study}

The purpose of this study is to explore the role of potential protective factors on eating disorder symptoms. It is not intended to diagnose any condition or eating disorder. You are encouraged to speak with your doctor if you are concerned about your eating habits.

\section{Description of Procedures}

This study involves completing this consent form and a paper and pencil questionnaire and will take approximately 15 minutes for you to complete. You will be asked to fill out a questionnaire regarding your engagement in practices thought to be related to health and eating habits, as well as some demographic information. You do not have to answer all the questions. You will have the opportunity to see the questionnaire before signing this consent form. 


\section{Discomforts}

There are no known or expected risks from participating in this study, except for the mild discomfort associated with answering the questions. You may find some of the questions to be sensitive or personal and may become emotionally upset by answering those questions related to prior eating disorder diagnosis and treatment, as well as prior or current mental health treatment. Any participants that would like access to mental health resources are encouraged to utilize the provided counseling referral list.

\section{Alternatives}

You do not have to participate in this study.

\section{Benefits}

You may not receive any direct benefit from this study. The knowledge gained from this study may eventually benefit others.

\section{Financial Considerations}

There are no costs associated with participating in this research study.

Participants will have the option to enter a drawing for one of $10 \$ 20$ Visa gift cards after completing the study. Interested participants will be asked to provide their email addresses if they wish to be entered into the drawing. This information will remain confidential and will not be connected to individual survey responses.

\section{Confidentiality}

There will be no way to link your identity with your survey responses, as this data is being collected in the aggregate. Any information (email address) provided for the optional drawing will be stored separately from your survey responses.

Your survey responses will be kept locked up and will be destroyed as soon as possible after the research is finished. Because you are not required to provide your name or signature, any publications that result from this research will not include any identifying information.

\section{Voluntary Participation}

Participation in this study is voluntary. You are free to withdraw your consent to participate in this study at any time.

Refusal to participate or withdrawal will not affect your class standing, grades, or your future care at West Virginia University and will involve no penalty to you.

You have been given the opportunity to ask questions about the research, and you have received answers concerning areas you did not understand. 


\section{Appendix E}

\section{Demographic Questionnaire}

1. What is your age?

2. Sex:

$\square$ Male

$\square$ Female

$\square$ Other

Please specify:

3. Ethnicity (indicate all that apply):

$\square$ White

$\square$ Hispanic or Latino

$\square$ Black or African American

$\square$ Native American or American Indian

$\square$ Asian/Pacific Islander

$\square$ Other

4. Current Level of Education:

$\square$ Undergraduate - Freshman

$\square$ Undergraduate - Sophomore

$\square$ Undergraduate - Junior

$\square$ Undergraduate - Senior

$\square$ Undergraduate $-5^{\text {th }}$ Year Senior

$\square$ Graduate

5. Campus organizations (indicate all that apply):

$\square$ Athletics

$\square$ Greek Life

$\square$ Honors College

$\square$ Other

Please specify:

6. Height: feet inches

7. Weight: pounds

8. Have you ever been diagnosed with an eating disorder?

$\square$ No

$\square$ Yes

Please specify when:

$\square$ Received a diagnosis for an eating disorder within the last six months 
$\square$ Received a diagnosis for an eating disorder six months to one year ago

$\square$ Received a diagnosis for an eating disorder more than one year ago

9. Have you ever received treatment for an eating disorder?

$\square$ No

$\square$ Yes

Please specify when:

$\square$ Currently in treatment for an eating disorder

$\square$ Received treatment for an eating disorder within the last six months

$\square$ Received treatment for an eating disorder six months to one year ago

$\square$ Received treatment for an eating disorder more than one year ago

10. Are you currently receiving mental health treatment?

$\square$ No

$\square$ Yes

Please specify type of service(s):

$\square$ Therapy

$\square$ Medication management

$\square$ Therapy and medication management 


\section{Appendix F}

\section{Five Facet Mindfulness Questionnaire}

\section{Reference:}

Baer, R. A., Smith, G. T., Hopkins, J., Krietemeyer, J., \& Toney, L. (2006). Using self-report assessment methods to explore facets of mindfulness. Assessment, 13, 27-45.

Please rate each of the following statements using the scale provided. Write the number in the blank that best describes your own opinion of what is generally true for you.
1
2
3
4
never or very
rarely true
sometimes true often true
5 rarely true
very often or
always true

1. When I'm walking, I deliberately notice the sensations of my body moving.

2. I'm good at finding words to describe my feelings.

3. I criticize myself for having irrational or inappropriate emotions.

4. I perceive my feelings and emotions without having to react to them.

5. When I do things, my mind wanders off and I'm easily distracted.

6. When I take a shower or bath, I stay alert to the sensations of water on my body.

7. I can easily put my beliefs, opinions, and expectations into words.

8. I don't pay attention to what I'm doing because I'm daydreaming, worrying, or otherwise distracted.

9. I watch my feelings without getting lost in them.

10. I tell myself I shouldn't be feeling the way I'm feeling.

11. I notice how foods and drinks affect my thoughts, bodily sensations, and emotions.

12. It's hard for me to find the words to describe what I'm thinking.

13. I am easily distracted.

14. I believe some of my thoughts are abnormal or bad and I shouldn't think that way.

15. I pay attention to sensations, such as the wind in my hair or sun on my face.

16. I have trouble thinking of the right words to express how I feel about things.

17. I make judgments about whether my thoughts are good or bad.

18. I find it difficult to stay focused on what's happening in the present.

19. When I have distressing thoughts or images, I "step back" and am aware of the thought or image without getting taken over by it.

20. I pay attention to sounds, such as clocks ticking, birds chirping, or cars passing.

21. In difficult situations, I can pause without immediately reacting.

22. When I have a sensation in my body, it's difficult for me to describe it because I can't find the right words.

23. It seems I am "running on automatic" without much awareness of what I'm doing. 
24. When I have distressing thoughts or images, I feel calm soon after.

25. I tell myself that I shouldn't be thinking the way I'm thinking.

26. I notice the smells and aromas of things.

27. Even when I'm feeling terribly upset, I can find a way to put it into words.

28. I rush through activities without being really attentive to them.

29. When I have distressing thoughts or images I am able just to notice them without reacting.

30. I think some of my emotions are bad or inappropriate and I shouldn't feel them.

31. I notice visual elements in art or nature, such as colors, shapes, textures, or patterns of light and shadow.

32. My natural tendency is to put my experiences into words.

33. When I have distressing thoughts or images, I just notice them and let them go.

34. I do jobs or tasks automatically without being aware of what I'm doing.

35. When I have distressing thoughts or images, I judge myself as good or bad, depending what the thought/image is about.

36. I pay attention to how my emotions affect my thoughts and behavior.

37. I can usually describe how I feel at the moment in considerable detail.

38. I find myself doing things without paying attention.

39. I disapprove of myself when I have irrational ideas.

\section{Scoring:}

Observe items: 1, 6, 11, 15, 20, 26, 31, 36

Describe items: 2, 7, 12R, 16R, 22R, 27, 32, 37

Act with Awareness items: 5R, 8R, 13R, 18R, 23R, 28R, 34R, 38R

Non-judge items: 3R, 10R, 14R, 17R, 25R, 30R, 35R, 39R

Non-react items: 4, 9, 19, 21, 24, 29, 33

$\mathrm{R}=$ Reverse scoring

Subscale scores are computed by calculating the mean of subscale item responses.

To compute a total mindfulness score, reverse score the negative items (i.e., $1=5,2=4,3=3.4$ $=2,5=1$ ) then compute a total mean.

Higher scores indicate greater levels of mindfulness. 
Appendix G

\section{Self-Compassion Scale}

\section{Reference:}

Neff, K. D. (2003a). Development and validation of a scale to measure self-compassion. Self and Identity, 2, 223-250.

\section{HOW I TYPICALLY ACT TOWARDS MYSELF IN DIFFICULT TIMES}

Please read each statement carefully before answering. To the left of each item, indicate how often you behave in the stated manner, using the following scale:

$\begin{array}{llll}1 & 2 & 3 & 4\end{array}$

Almost never

1. I'm disapproving and judgmental about my own flaws and inadequacies.

2. When I'm feeling down I tend to obsess and fixate on everything that's wrong.

3. When things are going badly for me, I see the difficulties as part of life that everyone goes through.

4. When I think about my inadequacies, it tends to make me feel more separate and cut off from the rest of the world.

5. I try to be loving towards myself when I'm feeling emotional pain.

6. When I fail at something important to me I become consumed by feelings of inadequacy.

7. When I'm down and out, I remind myself that there are lots of other people in the world feeling like I am.

8. When times are really difficult, I tend to be tough on myself.

9. When something upsets me I try to keep my emotions in balance.

10. When I feel inadequate in some way, I try to remind myself that feelings of inadequacy are shared by most people.

11. I'm intolerant and impatient towards those aspects of my personality I don't like.

12. When I'm going through a very hard time, I give myself the caring and tenderness I need.

13. When I'm feeling down, I tend to feel like most other people are probably happier than I am.

14. When something painful happens I try to take a balanced view of the situation.

15. I try to see my failings as part of the human condition.

16. When I see aspects of myself that I don't like, I get down on myself.

17. When I fail at something important to me I try to keep things in perspective.

18. When I'm really struggling, I tend to feel like other people must be having an easier time of it.

19. I'm kind to myself when I'm experiencing suffering. 
20. When something upsets me I get carried away with my feelings.

21. I can be a bit cold-hearted towards myself when I'm experiencing suffering.

22. When I'm feeling down I try to approach my feelings with curiosity and openness.

23. I'm tolerant of my own flaws and inadequacies.

24. When something painful happens I tend to blow the incident out of proportion.

25. When I fail at something that's important to me, I tend to feel alone in my failure.

26. I try to be understanding and patient towards those aspects of my personality I don't like.

\section{Scoring:}

Self-Kindness Items: 5, 12, 19, 23, 26

Self-Judgment Items: 1, 8, 11, 16, 21

Common Humanity Items: 3, 7, 10, 15

Isolation Items: 4, 13, 18, 25

Mindfulness Items: $9,14,17,22$

Over-Identified Items: 2, 6, 20, 24

Subscale scores are computed by calculating the mean of subscale item responses.

To compute a total self-compassion score, reverse score the negative subscale items - selfjudgment, isolation, and over-identification (i.e., $1=5,2=4,3=3.4=2,5=1$ ) - then compute a total mean.

Higher scores indicate greater levels of self-compassion. 
Appendix H

\section{Difficulties in Emotion Regulation Scale}

\section{Reference:}

Gratz, K. L. \& Roemer, E. (2004). Multidimensional assessment of emotion regulation and dysregulation: Development, factor structure, and initial validation of the Difficulties in Emotion Regulation Scale. Journal of Psychopathology and Behavioral Assessment, 26(1), 41-54.

12

Almost never Sometimes
3

$\begin{array}{cc}\text { About half } & \text { Most of the } \\ \text { the time } & \text { time }\end{array}$

5

Almost always

1. I am clear about my feelings.

2. I pay attention to how I feel.

3. I experience my emotions as overwhelming and out of control.

4. I have no idea how I am feeling.

5. I have difficulty making sense out of my feelings.

6. I am attentive to my feelings.

7. I know exactly how I am feeling.

8. I care about what I am feeling.

9. I am confused about how I feel.

10. When I'm upset, I acknowledge my emotions.

11. When I'm upset, I become angry with myself for feeling that way.

12. When I'm upset, I become embarrassed for feeling that way.

13. When I'm upset, I have difficulty getting work done.

14. When I'm upset, I become out of control.

15. When I'm upset, I believe that I will remain that way for a long time.

16. When I'm upset, I believe that I'll end up feeling very depressed.

17. When I'm upset, I believe that my feelings are valid and important.

18. When I'm upset, I have difficulty focusing on other things.

19. When I'm upset, I feel out of control.

20. When I'm upset, I can still get things done.

21. When I'm upset, I feel ashamed with myself for feeling that way.

22. When I'm upset, I know that I can find a way to eventually feel better.

23. When I'm upset, I feel like I am weak.

24. When I'm upset, I feel like I can remain in control of my behaviors.

25. When I'm upset, I feel guilty for feeling that way.

26. When I'm upset, I have difficulty concentrating.

27. When I'm upset, I have difficulty controlling my behaviors.

28. When I'm upset, I believe there is nothing I can do to make myself feel better.

29. When I'm upset, I become irritated with myself for feeling that way. 
30. When I'm upset, I start to feel very bad about myself.

31. When I'm upset, I believe that wallowing in it is all I can do.

32. When I'm upset, I lose control over my behaviors.

33. When I'm upset, I have difficulty thinking about anything else.

34. When I'm upset, I take time to figure out what I'm really feeling.

35. When I'm upset, it takes me a long time to feel better.

36. When I'm upset, my emotions feel overwhelming.

\section{Scoring:}

Non-acceptance of emotional responses items: 11, 12, 21, 23, 25, 29

Difficulties engaging in goal directed behavior: $13,18,20 \mathrm{R}, 26,33$

Impulse control difficulties: 3, 14, 19, 24R, 27, 32

Lack of emotional awareness items: 2R, 6R, 8R, 10R, 17R, 34R

Limited access to emotion regulation strategies items: 15, 16, 22R, 28, 30, 31, 35, 36

Lack of emotional clarity items: 1R, 4, 5, 7R, 9

$\mathrm{R}=$ Reverse scoring

Subscale scores are computed by calculating the mean of subscale item responses.

To compute a total self-compassion score, reverse score the negative items (i.e., $1=5,2=4,3=$ $3.4=2,5=1$ ) then compute a total mean.

Higher scores suggest greater problems with emotion regulation.

All items will be reverse coding so that higher scores suggest greater emotion regulation abilities and lower scores reflect greater emotion regulation difficulties. 
Appendix I

\section{Eating Attitudes Test - 26}

\section{Reference:}

The EAT-26 has been reproduced with permission.

Garner, D. M., Olmsted, M. P., Bohr, Y., Garfinkel, P. E., Garner, D. M., Olmsted, M. P., \& Garfinkel, P. E. (1982). Eating Attitudes Test-26. Psychological Medicine, 12(4), 871-878.

\begin{tabular}{|c|c|c|c|c|c|c|}
\hline $\begin{array}{l}\text { Part B: Check a response } \\
\text { for each of the following } \\
\text { statements: }\end{array}$ & Always & Usually & Often & $\begin{array}{l}\text { Sometim } \\
\text { es }\end{array}$ & Rarely & Never \\
\hline \multicolumn{7}{|l|}{$\begin{array}{l}\text { 1. I am terrified at being } \\
\text { overweight. }\end{array}$} \\
\hline \multicolumn{7}{|l|}{$\begin{array}{l}\text { 2. I avoid eating when I } \\
\text { am hungry. }\end{array}$} \\
\hline \multicolumn{7}{|l|}{$\begin{array}{l}\text { 3. I find myself } \\
\text { preoccupied with food. }\end{array}$} \\
\hline \multicolumn{7}{|l|}{$\begin{array}{l}\text { 4. I have gone on eating } \\
\text { binges where I feel that I } \\
\text { may not be able to stop. }\end{array}$} \\
\hline \multicolumn{7}{|l|}{$\begin{array}{l}\text { 5. I cut my food into } \\
\text { small pieces. }\end{array}$} \\
\hline \multicolumn{7}{|l|}{$\begin{array}{l}\text { 6. I am aware of the } \\
\text { calorie content of foods } \\
\text { that I eat. }\end{array}$} \\
\hline \multicolumn{7}{|l|}{$\begin{array}{l}\text { 7. I particularly avoid } \\
\text { food with a high } \\
\text { carbohydrate content } \\
\text { (i.e., bread, rice, potatoes, } \\
\text { etc.) }\end{array}$} \\
\hline \multicolumn{7}{|l|}{$\begin{array}{l}\text { 8. I feel that others would } \\
\text { prefer if I ate more. }\end{array}$} \\
\hline \multicolumn{7}{|l|}{$\begin{array}{l}\text { 9. I vomit after I have } \\
\text { eaten. }\end{array}$} \\
\hline \multicolumn{7}{|l|}{$\begin{array}{l}\text { 10. I feel extremely guilty } \\
\text { after eating. }\end{array}$} \\
\hline \multicolumn{7}{|l|}{$\begin{array}{l}\text { 11. I am occupied with a } \\
\text { desire to be thinner. }\end{array}$} \\
\hline $\begin{array}{l}\text { 12. I think about burning } \\
\text { up calories when I } \\
\text { exercise. }\end{array}$ & & & & & & \\
\hline
\end{tabular}




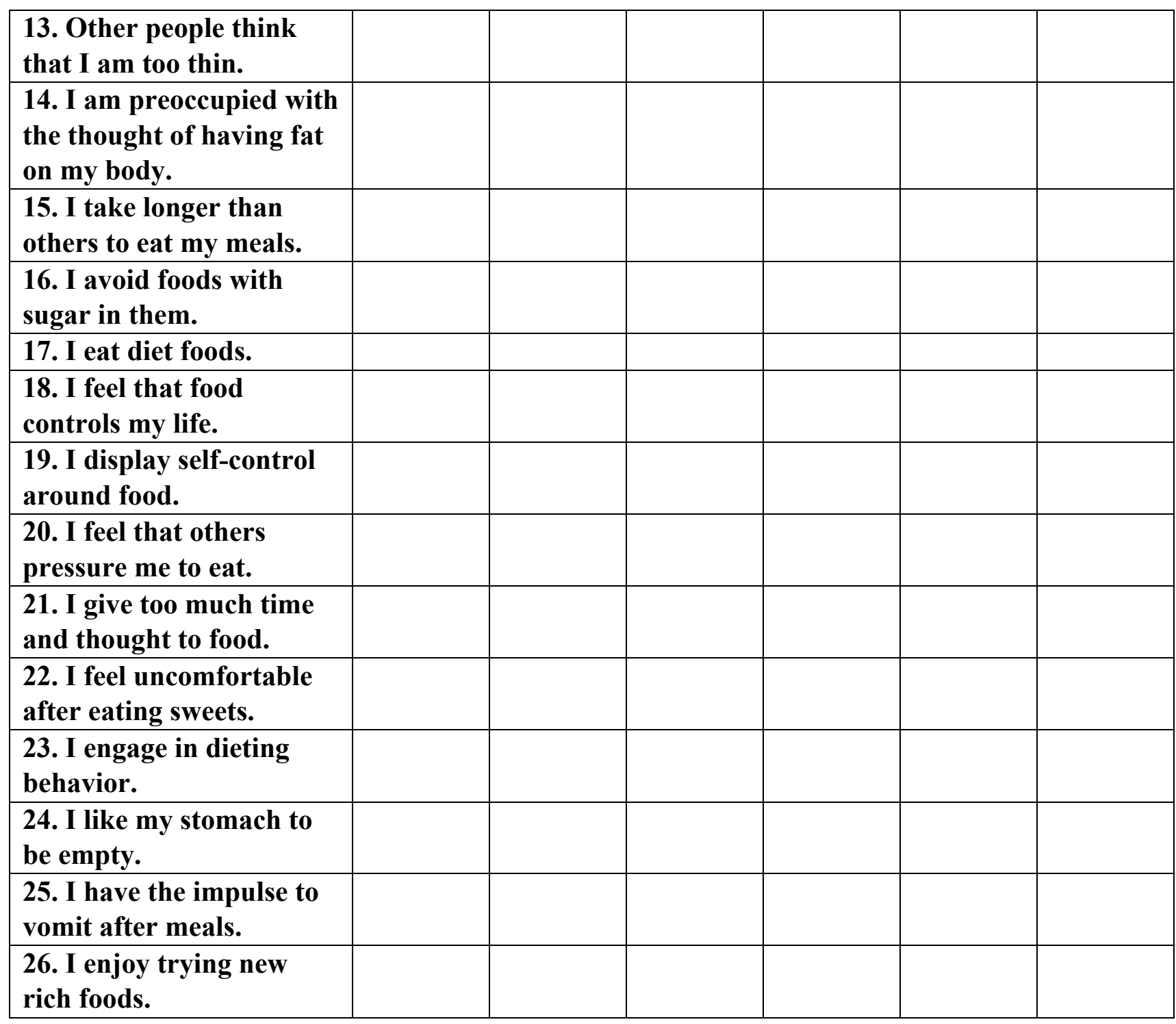

\section{Scoring:}

Test Items and Total Test Score:

Items 1-25: Always=3; Usually $=2$; Often $=1$; Other answers $=0$

Item 26: Reverse scored (Never $=3$, etc.)

Total test score: Add item scores for a "total test score"

Is the total 20 or more? $\square$ No $\square$ Yes, make a referral

Note: A score at or above 20 on the EAT-26 indicates a high level of concern about dieting, body weight or problematic eating behaviors. 
Appendix $\mathbf{J}$

Counseling Referral List

COUNSELING REFERRAL LIST

Below is a list of local mental health agencies.

This list is not extensive. Inclusion on the list does not imply endorsement of these agencies or services. Payment for services rendered at these agencies is the sole responsibility of the participant and not the researchers of the current study.

Carruth Center for Psychological and Psychiatric Services (CCPPS)

WELLWVU

West Virginia University

(304) 293-WELL (9355)

(304) 293-4431 (After-Hours Crisis Line)

United Summit Center

Serving Braxton, Doddridge, Gilmer, Harrison, \& Lewis Counties

1-800-SUMMIT-0

1-800-786-6480

Valley HealthCare System

Serving Fairmont, Grafton, Kingwood \& Morgantown

1-800-232-0020

Fairmont General Hospital

24-hour Crisis Line

304-367-7281

Wesley Spectrum Services (Outpatient) Women's and Men's Group

Hotline (24/7)

724-222-7500

Chestnut Ridge Counseling 
24/7 Crisis Line

724-437-1003

National Suicide Prevention Lifeline

1-800-273-TALK or 1-800-SUICIDE (784-2433) 